\title{
Calcination/Dissolution Chemistry Development Fiscal Year 1995
}

\author{
C. H. Delegard
}

Date Published

September 1995

Prepared for the U.S. Department of Energy Assistant Secretary for Environmental Management

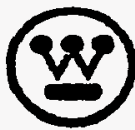

Approved for public release; distribution is unlimited 


\section{RELEASE AUTHORIZATION}

\section{Document Number: WHC-EP-0882}

Document Title: Calcination/Dissolution Chemistry Development:

FY 1995

Release Date: $\quad 9 / 29 / 95$

This document was reviewed following the procedures described in WHC-CM-3-4 and is:

APPROVED FOR PUBLIC RELEASE

WHC Information Release Administration Specialist:

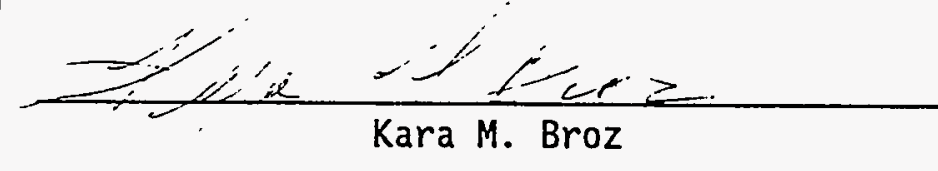

September 29, 1995 


\section{DISCLAMMER}

This report was prepared as an account of work sponsored by an agency of the United States Government. Neither the United States Government nor any agency thereof, nor any of their employees, makes any warranty, express or implied, or assumes any legal liability or responsibility for the accuracy, completeness, or usefulness of any information, apparatus, product, or process disclosed, or represents that its use would not infringe privately owned rights. Reference herein to any specific commercial product, process, or service by trade name, trademark, manufacturer, or otherwise does not necessarily constitute or imply its endorsement, recommendation, or favoring by the United States Government or any agency thereof. The views and opinions of authors expressed herein do not necessarily state or reflect those of the United States Government or any agency thereof. 
-

$-\cdots$ 


\section{DISCLAIMER}

Portions of this document may be illegible in electronic image products. Images are produced from the best available original document. 


\section{CALCINATION/DISSOLUTION CHEMISTRY DEVELOPMENT FISCAL YEAR 1995}

\section{EXECUTIVE SUMMARY}

An investigation into the chemistry of alkaline Hanford Site tank waste (TTP RL4-3-20-04) was conducted in Fiscal Year (FY) 1995 at the Westinghouse Hanford Company under the support of the Efficient Separations and Processing Crosscutting Program (EM-53). The investigation had two main subtasks: liaison with the Institute of Physical Chemistry of the Russian Academy of Science and further laboratory testing of the chemistry of calcination/dissolution (C/D or thermal reconstitution) of Hanford Site tank waste.

Progress, which was achieved in the calcination/dissolution subtask in FY 1995, is summarized in this report as follows.

1. Tests were run comparing the performances of $C / D$ and enhanced sludge washing using genuine wastes from tanks 104-S (a REDOX Process sludge containing large quantities of solid phase aluminum hydroxide), 101-SY (a complexant concentrate with high chromium concentration), and 102-SY (a high-transuranics [TRU], highchromium, Plutonium Finishing Plant waste). The tests showed that markedly improved dissolutions of aluminum from tank 104-S and tank 102-SY wastes were achieved by C/D. Comparative tests for chromium-rich wastes from tanks 101-SY and 102-SY showed greater than 99 percent chromium dissolutions were obtained by C/D but only 5 percent and 21 percent dissolutions, respectively, by enhanced sludge 
washing. Tests planned for waste from tank 110-U (a mixed aluminum cladding, REDOX process and bismuth phosphate process waste) were not performed because of budget reallocations to the Institute of Physical Chemistry. However, chemical and radionuclide analyses of tank 110-U waste were performed.

2. A mild peroxide oxidative treatment to dissolve chromium hydroxide under enhanced sludge washing conditions was tested with material simulating the composition of tank 101-SY waste and with genuine wastes from tanks 101-SY and 102-SY. The alkaline peroxide treatment dissolved approximately 65 percent of the chromium from the simulant waste. Negligible enhancement in chromium dissolution over the reference-enhanced sludge washing flowsheet was found for the peroxide treatment in tests with the tank wastes.

3. Tests to determine the speciation of plutonium and neptunium solubilized by C/D showed dissolved $\mathrm{Pu}(\mathrm{V})$ and $\mathrm{Np}(\mathrm{V})$ hydroxide complexes are produced. $\mathrm{A} N \mathrm{~Np}(\mathrm{~V})$ peroxide complex also was identified.

4. Reduction/coprecipitation methods to remove plutonium and neptunium solubilized by C/D were tested and shown to be rapid and efficient.

5. Recently published data on plutonium (IV) carbonate complexation in moderately alkaline $(\mathrm{pH} 12$ to 13 ) solution led to a reexamination of previous investigations of $\mathrm{Pu}$ complexation by carbonate in highly alkaline ( 3 to 5 molar $\mathrm{NaOH}$ ) solutions. The 
comparisons showed $\mathrm{Pu}(\mathrm{IV})$ carbonate complexes may also exist in the highly alkalinesolution. Visible/near infrared spectra of the suspected Pu(IV) carbonate complex were obtained.

6. Technical chemistry support was provided to calciner kinetics tests at the University of Idaho.

7. A technical report on progress in studies of the chemistry of $C / D$ was prepared and issued. A midyear report covering both the liaison and C/D studies also was written and issued. Contributions were made to a technical presentation given at the 19th Annual Actinide Separations Conference on the solubility of plutonium compounds in alkaline solution. A paper on $C / D$ chemistry has been submitted and accepted for presentation at the "Tank Waste Chemistry" symposium to be held during the 211th national meeting of the American Chemical Society in March 1996. 
WHC-EP-0882

This page intentionally left blank. 
WHC-EP-0882

\section{CONTENTS}

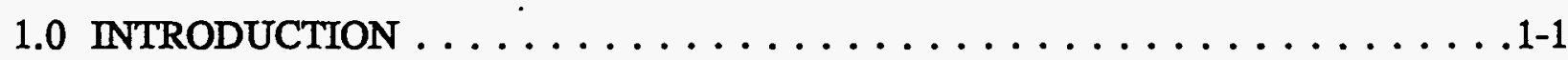

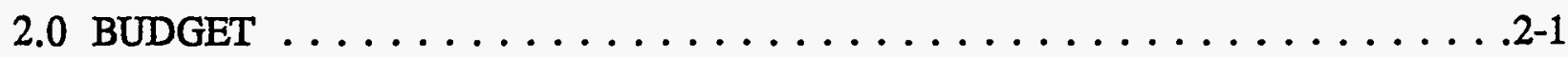

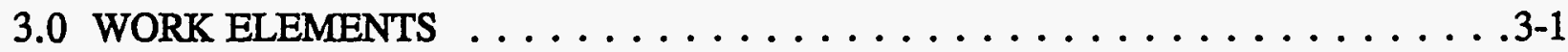

4.0 CALCINATION/DISSOLUTION AND WASTE CHEMISTRY STUDIES $\ldots . .4$ 4-1 4.1 CALCINATION/DISSOLUTION AND ENHANCED

SLUDGE WASHING COMPARISON TESTING $\ldots \ldots \ldots \ldots \ldots \ldots$ 4-2

4.1.1 Enhanced Sludge Washing Reference Flowsheet Chemistry . . . . . . 4-3

4.1.2 Enhanced Sludge Washing with Peroxide Addition . . . . . . . . 4-4

4.1.3 Experimental Materials and Methods . . . . . . . . . . 4-5

4.1.4 Results of Calcination/Dissolution and Enhanced

Sludge Washing Testing for Tank 104-S Waste . . . . . . . . 4-9

4.1.5 Results of Alkaline Peroxide Leaching of

Simulated Tank 101-SY Waste . . . . . . . . . . . 4-13

4.1.6 Results of C/D, ESW, and ESW/Peroxide

Testing for Tank 101-SY Waste . . . . . . . . . . . . . 4-14

4.1.7 Results of C/D, ESW, and ESW/Peroxide

Testing for Tank 102-SY Waste . . . . . . . . . . 4-16

4.2 PLUTONIUM REMOVAL FROM C/D PRODUCT SOLUTIONS . . . . 4-19

4.2.1 Coprecipitation Tests with Tank 102-SY Waste C/D Solution . . 4-20

4.2.2 Coprecipitation Tests with Neptuniumand Plutonium-Spiked Simulant . . . . . . . . . 4-22

4.3 DETERMINATION OF PLUTONIUM AND NEPTUNIUM

SOLUTION SPECIES . . . . . . . . . . . . . . 4-23

4.4 CARBONATE COMPLEXES OF PLUTONIUM IN

ALKALINE SOLUTION . . . . . . . . . . . . . 4-25

4.5 WORK WITH THE UNIVERSTTY OF IDAHO

PLASMA LABORATORY $\ldots \ldots \ldots \ldots \ldots \ldots \ldots \ldots \ldots$ 4-31

4.6 TECHNICAL PAPERS $\ldots \ldots \ldots \ldots \ldots \ldots \ldots \ldots \ldots$. . . . . . . . . . .

5.0 ACKNOWLEDGEMENTS $\ldots \ldots \ldots \ldots \ldots \ldots \ldots \ldots \ldots \ldots \ldots \ldots \ldots \ldots$

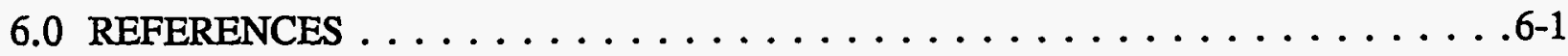


WHC-EP-0882

\section{APPENDICES}

A RESULTS OF ESW AND C/D TESTS OF WASTES FROM TANK 104-S . . . . A A-1

B RESULTS OF ESW/PEROXIDE TESTS OF SIMULANT TANK $101-$ SY WASTE $\ldots \ldots \ldots \ldots \ldots \ldots \ldots$. . . . . . $\ldots$ B

C RESULTS OF ESW AND C/D TESTS OF WASTES FROM TANK 101-SY . . . C C-1

D RESULTS OF ESW AND C/D TESTS OF WASTES FROM TANK 102-SY . . . D-1

E RESULTS OF TESTS TO REMOVE PLUTONIUM FROM C/D SOLUTIONS . . E E-1 


\section{LIST OF FIGURES}

4-1 Dissolution of Bulk Waste Constituents in ESW and C/D Processing of Tank 104-S Waste. . . . . . . . . . . . . . 4-9

4-2 Dissolution of Radioactive Components in ESW and C/D Processing of Tank 104-S Waste. . . . . . . . . . . . 4-12

4-3 Chromium Oxidative Dissolution from Simulated Waste of Tank 101-SY by Alkaline Peroxide Treatment. . . . . . . . . . . . 4-13

4-4 Dissolution of Bulk Waste Constituents in ESW and C/D Processing of Tank 101-SY Waste. . . . . . . . . . . . 4-14

4-5 Dissolution of Radioactive Components in ESW and C/D Processing of Tank 101-SY Waste. . . . . . . . . . . 4-15

4-6 Dissolution of Bulk Waste Constituents in ESW and C/D Processing of Tank 102-SY Waste. . . . . . . . . . . . 4-17

4-7 Dissolution of Radioactive Components in ESW and C/D Processing of Tank 102-SY Waste. . . . . . . . . . 4-18

4-8 Concentration of Bulk Waste Constituents in Tank 102-SY C/D

Solution Before and After Treatment with Peroxide and Hydroxylamine. . . . . 4 4-21

4-9 Concentrations of Radionuclides in Tank 102-SY C/D Solution Before and After Treatments with Peroxide and Hydroxylamine. . . . . . . . . 4-21

4-10 Concentrations of Bulk Constituents and Radionuclides in Simulant C/D Solution Before and After Treatment with Hydroxylamine. . . . 4 4-23

4-11 Effect of Carbonate on Plutonium Compound Solubility. . . . . . . . . . 4-28 


\section{WHC-EP-0882}

\section{LIST OF TABLES}

4-1 Materials Used in ESW, ESW/Peroxide, and C/D Tests . . . . . . . . . 4-8

4-2 Compositions of Hanford Site Tank Wastes Used in C/D and ESW Tests . . . . 4-10

4-3 Compositions of Waste Simulants Used in Speciation Tests . . . . . . . . . . 4-24

4-4 Experimental and Derived Data for Plutonium Compound Solubility in the $\mathrm{NaOH} / \mathrm{Na}_{2} \mathrm{CO}_{3}$ Aqueous System $\ldots \ldots \ldots \ldots \ldots \ldots . \ldots . \ldots . \ldots .29$

4-5 Spectral Features for $\mathrm{Pu}$ in $\mathrm{NaOH} / \mathrm{Na}_{2} \mathrm{CO}_{3}$ Solutions $\ldots \ldots \ldots \ldots . \ldots .40$ 
WHC-EP-0882

\section{LIST OF TERMS}

\begin{tabular}{ll} 
C/D & \multicolumn{1}{c}{ calcination/dissolution } \\
DOE & U.S. Department of Energy \\
ESW & Enhanced Sludge Washing \\
FY & fiscal year \\
HLW & high-level waste \\
IPC & "Institute of Physical Chemistry" \\
IPC/RAS & Institute of Physical Chemistry of the Russian Academy of \\
& Science \\
LLW & low-level waste \\
TC & technetium \\
TRU & Transuranic \\
TTP & technical task plan \\
WHC & Westinghouse Hanford Company
\end{tabular}


WHC-EP-0882

This page intentionally left blank. 


\subsection{INTRODUCTION}

The task "IPC Liaison and Chemistry of Thermal Reconstitution" is a $\$ 300,000$ program that was conducted in Fiscal Year (FY) 1995 with U.S. Department of Energy (DOE) Office of Research and Development (EM-53) Efficient Separations and Processing Crosscutting Program supported under technical task plan (TTP) RL4-3-20-04. The principal investigator was Cal Delegard of the Westinghouse Hanford Company (WHC). The task encompassed the following two subtasks related to the chemistry of alkaline Hanford Site tank waste:

1. Technical Liaison with the Institute of Physical Chemistry of the Russian Academy of Science (IPC/RAS) and its research into the chemistry of transuranic elements (TRU) and technetium (Tc) in alkaline media.

2. Laboratory investigation of the chemistry of calcination/dissolution (C/D) (or thermal reconstitution) as an alternative to the present reference Hanford Site tank waste pretreatment flowsheet, Enhanced Sludge Washing (ESW).

This report fulfills the milestone for the C/D subtask to "Provide End-of-Year Report on C/D Laboratory Test Results" due 30 September 1995. A companion report, fulfilling the milestone to provide an end-of-year report on the IPC/RAS liaison, also has been prepared (Delegard 1995c). 
WHC-EP-0882

This page intentionally left blank. 


\subsection{BUDGET}

Reallocation of funds to provide more support to the IPC/RAS (specifically, Professor A. K. Pikaev, principal investigator, and his investigations into the role of radiolysis on TRU and Tc chemistry in alkaline media) took place in April 1995. The reallocation decreased the total fiscal year funding from $\$ 300,000$ to $\$ 260,000$. The original budget allocated $\$ 100,000$ to the technical liaison and $\$ 200,000$ to the C/D subtask. To free funds for the work of Professor Pikaev, tests comparing C/D with ESW were decreased to study three rather than four genuine waste types.

In July 1995, funds spent on chemical and radionuclide concentration analyses (about $\$ 128,000$ ) were restored to the IPC Liaison and Chemistry of Thermal Reconstitution Task by the Tank Waste Characterization Project. The project restored funds as a means of supporting process chemistry development tasks, such as C/D, being undertaken within WHC and to make efficient use of analytical laboratory resources which were under-used in the latter half of the fiscal year. The funding restoration partially balanced the increased analytical chargeout rates (equivalent to $\$ 63,000$ ) which had been imposed since November 1994 and also permitted an additional work scope (on the Cesium Removal Pilot Plant) to be assumed. 
WHC-EP-0882

This page intentionally left blank. 


\subsection{WORK ELEMENTS}

Three work elements for the C/D chemistry task were identified and described in the TTP. Additional work elements, not anticipated at the time of drafting the TTP, emerged during the fiscal year and were incorporated into the task.

The original three work elements in the C/D chemistry subtask included the following:

1. Conduct C/D and ESW experiments using genuine Hanford Site tank wastes and compare the bulk chemical and radionuclide material balances.

2. Investigate candidate process steps for removing plutonium solubilized by $C / D$ treatment of genuine wastes.

3. Support engineering laboratory tests of calcination conducted at the University of Idaho under Tank Waste Remediation System (EM-30) funding.

The additional work elements initiated under the C/D chemistry subtask included the following:

1. Investigate the use of peroxide as a waste pretreatment agent to dissolve chromium hydroxide by oxidation to chromate.

2. Determine plutonium and neptunium solution species produced in $C / D$ processing of simulant wastes.

3. Investigate carbonate complexation of plutonium in highly alkaline solution.

4. Prepare technical reports on $C / D$ processing of Hanford Site tank wastes. 


\section{WHC-EP-0882}

This page intentionally left blank. 


\subsection{CALCINATION/DISSOLUTION AND WASTE CHEMISTRY STUDIES}

Studies of the technology (chemistry and engineering) of C/D have been conducted at WHC at various levels of both EM-30 and EM-50 support since FY 1992. As a result of the FY 1994 Tri-Party Agreement decision to focus on ESW as the reference pretreatment flowsheet, investigation of other pretreatment alternatives was markedly reduced. Limited support of C/D was provided by EM-30 through Tank Waste Remediation System in FY. 1995.

The Tank Waste Remediation System support of C/D ultimately was limited in FY 1995 to a continuation of engineering laboratory-scale calcination tests begun in FY 1994 using a 50 kilowatt nontransferred plasma torch at the University of Idaho. A small level of support for chemistry studies of C/D also was granted by the Tank Waste Remediation System primarily to aid University of Idaho tests.

In contrast, EM-50 saw merit in the continuing pursuit of alternative pretreatment technologies in case the reference ESW technology proved inadequate to provide efficient separations of low-level and high-level wastes (LLW and HLW, respectively). On this basis, EM-50, under the present TTP, granted $\$ 200,000$ to the continued studies of C/D chemistry.

The focus of the chemistry work was to compare C/D with ESW in laboratory-scale studies using genuine waste. Determining material balances (solution and residual solid phases) in these tests would enable evaluation of the relative performances of the reference ESW and competing C/D technologies. Solubilization of key bulk constituents (primarily aluminum, chromium, and phosphate) and radioactive but chemically trace constituents of Hanford Site tank wastes were the focus of these comparisons.

Tests conducted in FY 1993 and 1994 with genuine tank wastes showed plutonium was dissolved by $C / D$ processing. The dissolution caused the undesired partitioning of a portion of the plutonium, an HLW component, to the LLW fraction. It was postulated that plutonium dissolved by oxidation to more soluble (V) or (VI) oxidation states from the sparingly soluble $\mathrm{Pu}^{\text {Ih }} \mathrm{O}_{2} \cdot \mathrm{xH}_{2} \mathrm{O}$ solid phase likely to be present in the waste. In the earlier work, the plutonium behavior was compared with the demonstrated behavior of manganese, a bulk constituent in the waste, because manganese dioxide $\mathrm{MnO}_{2}$, undergoes a similar oxidative dissolution in $\mathrm{C} / \mathrm{D}$ processing to form manganate, $\mathrm{MnO}_{4}^{2-}$,

$$
\mathrm{MnO}_{2}+[\mathrm{O}]+2 \mathrm{OH}^{-} \rightarrow \mathrm{MnO}_{4}^{2-}+\mathrm{H}_{2} \mathrm{O} \text {. }
$$

These observations suggested chemical reduction and coprecipitation (which reverses the oxidative dissolution reactions of plutonium and manganese) to remove solubilized plutonium from solution. The coprecipitation was expected to be particularly effective because of the high sorptive capacity of the bulk product manganese dioxide. To explore this possibility, a work element to determine the feasibility of the reduction/coprecipitation approach was included in the TTP. 
A final TTP work element was included to support the laboratory-scale plasma calciner tests conducted by Professor Patrick Taylor of the Department of Metallurgical and Mining Engineering, College of Mines, at the University of Idaho. The work performed by Professor Taylor and colleagues was supported by the Tank Waste Remediation System, EM-30.

During the year, additional related work elements were identified and adopted for study. Work elements included the following: alkaline peroxide oxidative dissolution of chromium(III) hydroxide under ESW conditions, speciation of neptunium and plutonium solubilized by $\mathrm{C} / \mathrm{D}$ processing, a study of carbonate complexation of plutonium in alkaline solution, and.preparation of technical reports and presentations.

\subsection{CALCINATION/DISSOLUTION AND ENHANCED SLUDDGE WASHING COMPARISON TESTING}

The steps originally envisioned for pretreatment of Hanford Site tank waste were simple water washing followed by solid-liquid separation to segregate the high-level insoluble residue from the low-level solution fraction (produced after removal of dissolved ${ }^{137} \mathrm{Cs}$ ). The possible corollary removal of dissolved ${ }^{90} \mathrm{Sr}$ and ${ }^{99} \mathrm{Tc}$ was also considered. The high-level fraction (and separated ${ }^{137} \mathrm{Cs}$, ${ }^{90} \mathrm{Sr}$, and ${ }^{99} \mathrm{Tc}$ ) would be vitrified for storage in the $\mathrm{HLW}$ repository while the stripped LLW fraction would be immobilized for onsite storage as grout. Glass was chosen as the LLW form later.

Chemical and engineering studies showed that certain bulk components in the insoluble waste residue (primarily aluminum, chromium, and phosphate) contribute significantly to the volume of vitrified $\mathrm{HLW}$ identified for expensive packaging and deep geological repository storage. With this in mind, ESW was proposed as an improved pretreatment that would be more successful than simple water washing in dissolving the aluminum, chromium, and phosphate sludge components. ESW involves leaching washed sludges with a sodium hydroxide $(\mathrm{NaOH})$ solution. Alkaline hydrolysis and metathesis reactions dissolve the aluminum-, chromium-, and phosphate-bearing solid phases in the $\mathrm{NaOH}$ solution leach step.

To be considered a viable alternative to the reference ESW flowsheet, the C/D pretreatment process must demonstrate advantages in performance and/or cost over ESW. In comparative water wash and C/D tests conducted with genuine wastes in FY 1993 and 1994, dissolutions of aluminum, chromium, and phosphate were higher by $\mathrm{C} / \mathrm{D}$ than by water washing and often approached 100 percent dissolution (Delegard et al. 1994a, and Delegard 1995b). With the introduction of ESW as the reference pretreatment approach, similar tests, using genuine tank wastes, were required to compare the performances of C/D and ESW. These tests were performed in FY 1995. 
An alternative oxidative dissolution technique for chromium-bearing sludge, based on aqueous alkaline peroxide leaching, was discovered when the C/D and ESW pretreatment processes were compared. Tests also were performed to determine the efficacy of peroxide in the (oxidative) dissolution of chromium from sludge. The results C/D and ESW testing (with and without peroxide leaching) are described.

\subsubsection{Enhanced Sludge Washing Reference Flowsheet Chemistry}

The ESW pretreatment is a sequence of washes, alkaline leaches, and rinses intended to do the following:

1. dissolve water-soluble sodium salts (for example, $\mathrm{NaNO}_{3}, \mathrm{NaNO}_{2}, \mathrm{Na}_{2} \mathrm{CO}_{3}$, $\left.\mathrm{Na}_{3} \mathrm{PO}_{4}\right)$

2. dissolve, in sodium hydroxide solution, amphoteric aluminum and chromium hydroxides as their soluble hydroxide-complexed anions:

$$
\begin{gathered}
\mathrm{Al}(\mathrm{OH})_{3}(\mathrm{~s})+\mathrm{OH}^{-} \rightarrow \mathrm{Al}(\mathrm{OH})_{4}^{-} \\
\text {[bayerite or gibbsite solid phase] } \\
\mathrm{AlOOH}(\mathrm{s})+\mathrm{OH}^{-}+\mathrm{H}_{2} \mathrm{O} \rightarrow \mathrm{Al}(\mathrm{OH})_{4}^{-} \\
\text {[böhmite solid phase] } \\
\mathrm{Cr}(\mathrm{OH})_{3}(\mathrm{am})+\mathrm{OH}^{-} \rightarrow \mathrm{Cr}(\mathrm{OH})_{4}^{-} \\
\text {[amorphous chromium hydroxide solid phase] }
\end{gathered}
$$

3. dissolve phosphates by hydroxide metathesis:

$$
(\mathrm{Fe}, \mathrm{Bi}) \mathrm{PO}_{4}(\mathrm{~s})+3 \mathrm{OH}^{-} \rightarrow(\mathrm{Fe}, \mathrm{Bi})(\mathrm{OH})_{3}(\mathrm{~s})+\mathrm{PO}_{4}^{3-} .
$$

ESW leach conditions are similar to, but milder than, the conditions the aluminum industry uses to dissolve aluminum values from bauxitic ores containing the same gibbsite, bayerite, and böhmite aluminum-bearing solid. phases as found in tank sludges (Hudson 1987). Gibbsite and böhmite phases are especially prominent in REDOX process sludge.

The dissolution of $\mathrm{Cr}(\mathrm{OH})_{3}$ by alkaline treatment is analogous to that exhibited by $\mathrm{Al}(\mathrm{OH})_{3}$; that is, both are based the amphoterism of the respective trivalent metal ions. Quantification of the $\mathrm{Cr}(\mathrm{III})$ hydrolysis reaction is underway at the Pacific Northwest Laboratory (Felmy et al. 1994). According to this reference, approximately $0.0006 \mathrm{M}$ chromium should dissolve under ESW alkaline leaching conditions (that is, $3 \mathrm{M} \mathrm{NaOH}$ ). 


\subsubsection{Enhanced Sludge Washing with Peroxide Addition}

An alternative method for dissolving $\mathrm{Cr}(\mathrm{OH})_{3}(\mathrm{am})$ is through aqueous oxidation reactions to form soluble chromate $\left(\mathrm{CrO}_{4}^{2-}\right)$. The relevant oxidation potential is comparatively low $(-0.09 \mathrm{~V}$; [Bratsch 1989]). The chemical literature shows that many oxidants, for example, hypochlorite, hypobromite, peroxide, and pressurized oxygen are effective in oxidizing $\mathrm{Cr}(\mathrm{OH})_{3}$ (am) alkaline solution (Kirk-Othmer 1981 and Wulfsberg 1991). In fact, peroxide in $\mathrm{NaOH}$ solution is used in sample preparations for spectrophotometric analyses of chromium. The alkaline peroxide treatment dissolves chromium(III) compounds and forms the highly-absorbing chromate chromophore (Oelschläger 1955, Sandell 1959, and Kirk-Othmer 1993).

Recent work at the Pacific Northwest Laboratory has shown that permanganate $\left(\mathrm{MnO}_{4}^{-}\right)$can be used to oxidize $\mathrm{Cr}(\mathrm{OH})_{3}(\mathrm{am})$ to chromate. Oxidation of $\mathrm{Cr}(\mathrm{OH})_{3}(\mathrm{am})$ by pressurized air (oxygen) in simulated wastes has been observed by the Pacific Northwest Laboratory in developing wet-air oxidation of organic compounds contained in Hanford Site tank wastes. Oxidative dissolution of $\mathrm{Cr}(\mathrm{OH})_{3}(\mathrm{am})$ present in tank 101-SY waste by ozone has been demonstrated at WHC (Delegard et al. 1993).

Of these oxidants, peroxide, introduced as $30 \mathrm{wt} \% \mathrm{H}_{2} \mathrm{O}_{2}$ aqueous solution, is perhaps the most interesting for possible pretreatment operations. It does not contribute to the halide loading of the waste (as would hypochlorite and hypobromite), it does not contribute to the sludge volume (as would permanganate), and it does not require the pressurized equipment of wet air oxidation or the specialized equipment for ozonation.

The balanced reaction for the oxidation of $\mathrm{Cr}(\mathrm{OH})_{3}$ with peroxide

$$
2 \mathrm{Cr}(\mathrm{OH})_{3}+3 \mathrm{H}_{2} \mathrm{O}_{2}+4 \mathrm{OH}^{-} \rightarrow 2 \mathrm{CrO}_{4}^{2-}+8 \mathrm{H}_{2} \mathrm{O}
$$

indicates the 3:2 mole ratio of peroxide: $\mathrm{Cr}$ (III) required to achieve dissolution. In practice, excess peroxide probably would be required because of loss caused by disproportionation of peroxide (catalyzed by other waste components) to form oxygen gas and water. The balanced reaction shows that hydroxide would be consumed in the dissolution of $\mathrm{Cr}(\mathrm{OH})_{3}$. No hydroxide would be lost by the disproportionation of excess hydrogen peroxide. The consumption of hydroxide could affect aluminum solution concentration for wastes at or near the solubility limit for gibbsite $\left[\mathrm{Al}(\mathrm{OH})_{3}\right]$ by the reaction

$$
\mathrm{Al}(\mathrm{OH})_{4}^{-} \rightarrow \mathrm{Al}(\mathrm{OH})_{3}+\mathrm{OH}^{-} .
$$

Side reactions of peroxide with other waste components also are possible. For example, peroxide complexes of the actinides in their (V) and (V) oxidation states in alkaline media exist and have been described in the technical literature [Chernyaev 1966 for U(VI) and Musikas 1976 for $\mathrm{Np}(\mathrm{V})$ and $\mathrm{Pu}(\mathrm{V})$ ]. Salts of the peroxide complexes are generally more soluble in alkaline solution than their starting actinide compounds and potentially could increase the solution concentrations of these actinide elements. 
The $\mathrm{Pu}(\mathrm{V})$ peroxide complex has been shown to be relatively unstable and to decompose quickly at room temperature to precipitate $\mathrm{PuO}_{2}$ (Musikas 1976). The $\mathrm{Np}(\mathrm{V})$ peroxide complex, at approximately $0.26 \mathrm{~g} \mathrm{~Np} / \mathrm{L}$ solution concentration, was observed by spectrophotometry in some tests involving $\mathrm{C} / \mathrm{D}$ conditions. The $\mathrm{Np}(\mathrm{V})$ peroxide complex also was found to decompose with time but required a few weeks at room temperature to occur. Knowledge of the thermal stability of the U(VI) peroxide complex in alkaline solution is not available.

If a stable U(VI) complex forms, its existence may offer an attractive way to dissolve uranium from the sludge. This would allow separation of uranium from the waste or inclusion of uranium in the soluble LLW fraction for immobilization. In either case, removing uranium from the sludge would reduce the HLW glass volume.

\subsubsection{Experimental Materials and Methods}

Materials and experimental methods used in the comparative tests of C/D and ESW are described.

4.1.3.1 Calcination/Dissolution Tests. The $C / D$ experimental technique has been developed in tests performed over the past two years (Delegard et al. 1994a and Delegard 1995b). Weighed aliquots of genuine waste sludge materials are dried in an alumina crucible at approximately $120^{\circ} \mathrm{C}$ for several hours to remove solution water, heated at $300{ }^{\circ} \mathrm{C}$ for 20 minutes to remove bound (hydrate) water, and finally transferred directly to an $850^{\circ} \mathrm{C}$ furnace for 20 minutes calcination. This stepwise drying eliminates rapid boil-up and dispersal of the radioactive materials thereby improving operational safety and achieving a material balance.

The calcine is cooled and dissolved, in three contacts, with " $\mathrm{Q}$ " (purified) water. The initial water contact is conducted directly in the crucible. The solution and insoluble materials from the first water contact are transferred to a centrifuge cone. The product slurry is centrifuged, the supernatant solution decanted, and the solution weight and volume determined. Two subsequent $Q$ water wash contacts (with centrifugation and decantation) are made on the residual solids, the two separate solution fractions are composited, and their volumes are determined and weighed. The residue is dried at $100{ }^{\circ} \mathrm{C}$ and weighed. The solutions and residues are analyzed for chemical and radionuclide concentrations in the Analytical Laboratories of $222-\mathrm{S}$ at WHC, and a material balance is calculated.

For many sludges, which are deficient in salts (nitrate, nitrite, hydroxide) to supply the fluxing sodium hydroxide required for $C / D$ reactions, an additional source of flux is required. If $\mathrm{C} / \mathrm{D}$ were applied to the Hanford Site tank waste sludges, the source of the fluxing agent would be the abundant tank salt cake wastes. Hanford Site salt cake wastes are predominantly $\mathrm{NaNO}_{3}$. Prior C/D laboratory tests used waste from tank 101-SY or reagent sodium nitrate $\left(\mathrm{NaNO}_{3}\right)$ to supply the flux. 
Samples of genuine salt cake are not currently available in the laboratory; therefore, reagent $\mathrm{NaNO}_{3}$ now is used in C/D tests where additional fluxing agent is required. The amounts of $\mathrm{NaNO}_{3}$ added are calculated to be sufficient to exceed the $\mathrm{NaOH}$ requirements of the genuine waste aliquot at least two-fold on the basis of fusion reactions to form soluble sodium salts. The reaction of aluminum hydroxide with sodium hydroxide to form the water-soluble sodium aluminate salt is one such fusion reaction:

$$
2 \mathrm{NaOH}+2 \mathrm{Al}(\mathrm{OH})_{3} \rightarrow 2 \mathrm{NaAlO}_{2}+3 \mathrm{H}_{2} \mathrm{O}(\mathrm{g}) .
$$

4.1.3.2 Enhanced Sludge Washing Tests. The ESW test procedure was adopted from a laboratory protocol provided by Dr. Gregg Lumetta of PNL. The steps used in the ESW tests are described by the following general laboratory instructions.

1. Weigh a 5 gram genuine waste aliquot accurately into a tare-weighed, capped 50-mL polypropylene centrifuge cone.

2. Add $15 \mathrm{~mL}$ of $0.01 \mathrm{M} \mathrm{NaOH} / 0.01 \mathrm{M} \mathrm{NaNO}_{2}$ wash solution to the waste aliquot.

3. Heat the cone and contents to $100{ }^{\circ} \mathrm{C}$ for two hours.

4. Remove the cone/contents from the oven, cool, centrifuge, and decant the liquid into a tare-weighed container. Reweigh to determine solution weight.

5. Repeat steps 2 to 4 for two more wash contacts (that is, three total). Composite the three washes for analysis.

6. Contact the residue with $15 \mathrm{~mL} 3 \mathrm{M} \mathrm{NaOH}$ leach solution. Heat at $100{ }^{\circ} \mathrm{C}$ for five hours.

7. Remove the cone/contents from the oven, cool, centrifuge, and decant the liquid into a tare-weighed container. Reweigh to determine solution weight.

8. Repeat steps 6 and 7 for another contact. Composite the two collected leach solutions for analysis.

9. Rinse the residual solids with $15 \mathrm{~mL}$ water (no heating or extended contact time required). Centrifuge, decant, and repeat the rinse. Composite the two rinses for analysis in a tare-weighed container and reweigh.

10. Dry the residual solids at $100^{\circ} \mathrm{C}$ and record the final weight.

The solutions and residues produced by the ESW tests are analyzed for chemical and radionuclide concentrations in the Analytical Laboratories of 222-S at WHC and material balances are calculated. 
4.1.3.3 Enhanced Sludge Washing Tests with Peroxide. Tests of ESW with peroxide were performed using a procedure similar to the standard ESW procedure described in Section 4.1.3.2. To perform the ESW tests with peroxide, the steps 6 through 8 below were used in place of steps 6 through 8 above.

6. Contact the residue with $15 \mathrm{Ml} 3 \mathrm{M} \mathrm{NaOH}$ leach solution and $200 \mu \mathrm{L} 30$ percent $\mathrm{H}_{2} \mathrm{O}_{2}$ solution. Agitate to mix the solids and leach solution; continue agitation for a minimum two days contact at room temperature.

7. Centrifuge and decant the liquid into a tare-weighed container. Reweigh to determine solution weight.

8. Repeat steps 6 and 7 for another contact. Collect the two separate leach solutions for individual analyses.

4.1.3.4 Alkaline Peroxide Leaching of Simulated Tank 101-SY Waste. Scouting tests of the alkaline peroxide leach process were run to determine the efficacy of this technique to dissolve $\mathrm{Cr}(\mathrm{OH})_{3}$ from simulated tank 101-SY waste. The tests began with room temperature water washing of simulated tank 101-SY waste. The remaining residue contained the bulk of the chromium. Alkaline peroxide leaching of the residue then was tested using $3 \mathrm{M} \mathrm{NaOH}$ and varying quantities of added 30 percent $\mathrm{H}_{2} \mathrm{O}_{2}$ leachant at room temperature. Leachant was added at the ratio $3 \mathrm{~mL}$ of $\mathrm{NaOH}$ solution per gram of original tank 101-SY simulant. Two leach contacts were made.

The leach solutions and residues were agitated and solution samples were taken periodically. The sample aliquots were diluted in $0.5 \mathrm{M} \mathrm{NaOH}$, and the absorbance caused by the dissolved chromate was determined spectrophotometrically at the $372 \mathrm{~nm}$ absorbance maximum. Calibration tests were run with sodium chromate $\left(\mathrm{Na}_{2} \mathrm{CrO}_{4}\right)$ standard solutions prepared from reagent chemical in $0.5 \mathrm{M} \mathrm{NaOH}$ solution. Excellent adherence to the Beer-Lambert law was observed for the concentration range of interest.

4.1.3.5 Materials. Sludges used in the C/D and ESW tests were taken from tank 104-S, a REDOX process waste with high amounts of aluminum hydroxide phases; tank 101-SY, a complexed-concentrate waste containing a relatively high concentration of chromium in the sludge phase; and from tank 102-SY, a chromium-rich waste with high TRU concentrations from the Plutonium Finishing Plant. A sludge from tank 110-U containing mixed REDOX, aluminum cladding, and bismuth phosphate process wastes was to be tested, but the reallocation of $\$ 40,000$ to support Professor Pikaev at the IPC/RAS did not permit completion of this work. However, chemical and radionuclide analyses for tank 110-U waste were performed and are reported.

The amount of waste materials and added chemicals for tests with wastes from tanks 104-S, 101-SY, and 102-SY are summarized in Table 4-1. $\mathrm{NaNO}_{2}$ and $\mathrm{NaOH}$ were used in the ESW leachants. For the ESW tests with peroxide, 30 percent $\mathrm{H}_{2} \mathrm{O}_{2}$ was added. For the C/D tests with tank 104-S waste, $\mathrm{NaNO}_{3}$ was added as a salt cake simulant. The relative amount 
of sodium added in the tests also is compared. As shown in Table 4-1, the tank 104-S ESW test used more than twice as much sodium, per unit waste, than the C/D test. For the tanks 101-SY and 102-SY C/D tests, no added $\mathrm{NaNO}_{3}$ was used, whereas the prescribed amounts of $\mathrm{NaNO}_{2}$ and $\mathrm{NaOH}$ were used for the ESW tests (with and without added peroxide).

It is important to recognize that the sodium required for ESW originates from additions of freshly purchased $\mathrm{NaNO}_{2}$ and $\mathrm{NaOH}$. The added sodium in these salts ultimately becomes contaminated waste and contributes directly to the vitrified LLW waste bulk (LLW glass bulk is sodium limited). In contrast, the C/D sodium requirements are met using salt cake already present in the waste tanks thereby adding nothing to the LLW waste bulk.

Table 4-1. Materials Used in ESW, ESW/Peroxide, and C/D Tests.

\begin{tabular}{|c|c|c|c|c|}
\hline \multirow{2}{*}{ 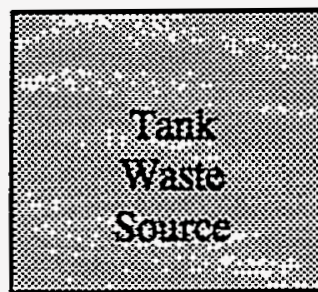 } & \multicolumn{4}{|c|}{ 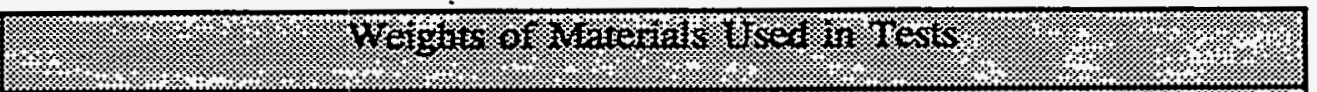 } \\
\hline & 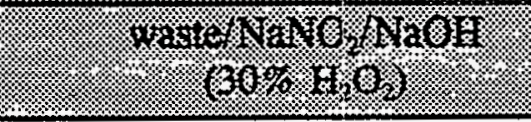 & (6.2. & : vat: & g. Not? \\
\hline $104-\mathrm{S}$ & $4.999 \mathrm{~g} / 0.031 \mathrm{~g} / 3.618 \mathrm{~g}$ & 0.42 & $10.011 \mathrm{~g} / 7.150 \mathrm{~g}$ & 0.19 \\
\hline 101-SY & $5.083 \mathrm{~g} / 0.031 \mathrm{~g} / 3.618 \mathrm{~g}$ & 0.41 & $5.98 \mathrm{~g} / 0 \mathrm{~g}^{1}$ & 0 \\
\hline 102-SY & $5.290 \mathrm{~g} / 0.031 \mathrm{~g} / 3.618 \mathrm{~g}$ & 0.40 & $18.086 \mathrm{~g} / 0 \mathrm{~g}^{2}$ & 0 \\
\hline $\begin{array}{l}101-\mathrm{SY} \\
\left(\mathrm{H}_{2} \mathrm{O}_{2}\right)\end{array}$ & $\begin{array}{c}4.805 \mathrm{~g} / 0.031 \mathrm{~g} / 3.618 \mathrm{~g} \\
(0.132 \mathrm{~g})\end{array}$ & 0.38 & & \\
\hline $\begin{array}{l}102-\mathrm{SY} \\
\left(\mathrm{H}_{2} \mathrm{O}_{2}\right)\end{array}$ & $\begin{array}{c}4.842 \mathrm{~g} / 0.031 \mathrm{~g} / 3.618 \mathrm{~g} \\
(0.132 \mathrm{~g})\end{array}$ & 0.39 & & \\
\hline
\end{tabular}

Notes:

'Delegard et al. 1994a.

${ }^{2}$ Delegard $1995 \mathrm{~b}$. 
The waste compositions used in the ESW and C/D comparison tests (from tanks 104-S, 101-SY, 102-SY) and 110-U are shown in Table 4-2. The simulant nonradioactive tank 101-SY waste composition is also shown in Table 4-2. This simulant was used in scouting tests of alkaline peroxide leach treatment to dissolve chromium hydroxide. The preparation of the simulant, which has been used in previous laboratory tests of C/D and ozone waste pretreatment, is described (Delegard et al. 1993).

\subsubsection{Results of Calcination/Dissolution and Enhanced Sludge Washing Testing for Tank 104-S Waste}

ESW and C/D test results for tank 104-S waste can be compared based on the quantities of bulk chemical components and trace radionuclides dissolved by the two processing alternatives. Data tables related to experiments with tank 104-S waste are provided in Appendix A.

The dissolutions of bulk chemical constituents by the two processes are compared in Figure 4-1. The amounts dissolved are displayed next to the amounts present in the initial waste mixtures (that is, mixtures which include the $\mathrm{NaNO}_{2} / \mathrm{NaOH}$ processing chemicals used in ESW and the $\mathrm{NaNO}_{3}$ salt cake simulant used in the C/D of the tank 104-S waste).

Figure 4-1. Dissolution of Bulk Waste Constituents in ESW and C/D Processing of Tank 104-S Waste.

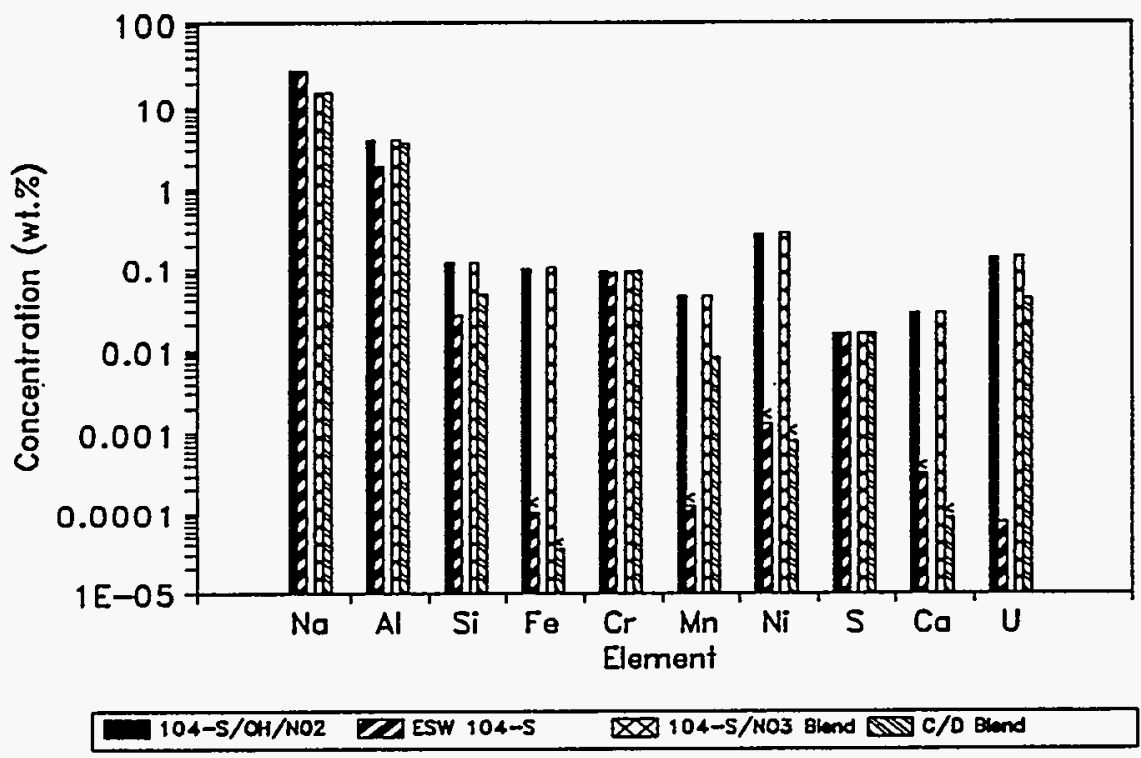




\section{WHC-EP-0882}

Table 4-2. Compositions of Hanford Site Tank Wastes Used in C/D and ESW Tests.

\begin{tabular}{|c|c|c|c|c|c|}
\hline \multirow{2}{*}{ (7) } & \multicolumn{5}{|c|}{ (1) } \\
\hline & 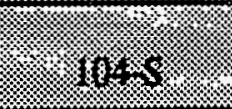 & 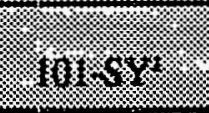 & 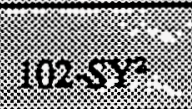 & 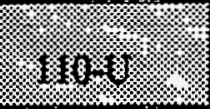 & 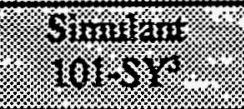 \\
\hline $\mathrm{Al}$ & 6.78 & 3.8 & 3.04 & 3.77 & 3.2 \\
\hline $\mathrm{Bi}$ & - & - & - & 0.94 & - \\
\hline$\overline{\mathrm{Ca}}$ & 0.049 & 0.027 & 0.15 & 0.068 & 0.023 \\
\hline $\mathrm{Cr}$ & 0.157 & 0.48 & 1.15 & 0.060 & 0.41 \\
\hline $\mathrm{Fe}$ & 0.177 & 0.028 & 0.82 & 0.97 & 0.028 \\
\hline $\mathbf{K}$ & - & 0.38 & $\overline{0.18}$ & 0.035 & 0.326 \\
\hline Mn & 0.080 & $0.0068^{\circ}$ & 0.26 & 0.42 & - \\
\hline$\widehat{\mathrm{Na}}$ & 7.00 & 24.4 & $\overline{8.13}$ & 7.89 & 20.7 \\
\hline $\mathrm{Ni}$ & 0.49 & $\overline{0.018}$ & $\overline{0.22}$ & 0.0009 & 0.015 \\
\hline$\overline{\mathrm{Si}}$ & $\overline{0.21}$ & $0.046^{\circ}$ & 0.13 & 0.50 & - \\
\hline $\mathrm{U}$ & 0.25 & 0.0074 & 0.14 & 0.67 & - \\
\hline $\mathrm{Cl}^{-}$ & 0.20 & 0.93 & 0.18 & 0.092 & 0.79 \\
\hline $\mathrm{F}$ & $<0.0007$ & 0.04 & 0.056 & 0.37 & 0.03 \\
\hline $\mathrm{NO}_{2}^{-}$ & 1.90 & 12.4 & 2.44 & 1.45 & 10.5 \\
\hline $\mathrm{NO}_{3}^{-}$ & 14.2 & 13.8 & 5.71 & 4.89 & 11.7 \\
\hline $\mathrm{PO}_{4}^{3-}$ & $<0.007$ & 0.76 & 1.26 & 4.20 & 0.64 \\
\hline $\mathrm{SO}_{4}^{2-}$ & 0.091 & 0.47 & 4.17 & 0.12 & 0.40 \\
\hline $\mathrm{CO}_{3}^{2-}$ & 1.39 & 3.72 & 1.96 & 0.78 & 3.15 \\
\hline $\mathrm{OH}^{-}$ & 0.94 & 2.92 & 0.96 & - & 2.47 \\
\hline TOC & 0.76 & 1.81 & 0.54 & 0.46 & 1.53 \\
\hline $\mathrm{H}_{2} \mathrm{O}$ & 60.5 & $23.8^{\circ}$ & 62.5 & 77.0 & 35.5 \\
\hline Nuretrage & & $9.1 \%$ & 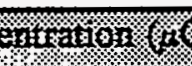 & ? & \\
\hline${ }^{90} \mathrm{Sr}$ & 154 & 25 & 85.8 & 0.113 & - \\
\hline${ }^{99} \mathrm{Tc}$ & 0.012 & 0.24 & 0.10 & 0.0055 & - \\
\hline${ }^{137} \mathrm{Cs}$ & 38.5 & 396 & 51.9 & 20.7 & - \\
\hline${ }^{277} \mathrm{~Np}$ & $<0.013$ & 0.000032 & 0.00086 & 0.00265 & - \\
\hline${ }^{299,200 \mathrm{Pu}}$ & 0.199 & 0.0076 & 4.38 & 0.292 & - \\
\hline $241 \mathrm{Am}$ & 0.061 & 0.12 & 14.9 & 0.1225 & - \\
\hline
\end{tabular}

Notes:

1 Based on Herting et al. 1992 and corrected for water content; "value from current analysis.

2 From Delegard 1995b.

${ }^{3}$ From Delegard et al. 1993. 
ESW and C/D dissolved approximately 99 percent of the sodium. This behavior would be expected except for wastes which contain significant concentrations of both aluminum and silicon. In such cases, sodium aluminosilicates $\left(\mathrm{NaAlSiO}_{4}\right)$, for example, sodalite and cancrinite of low solubility, form in alkaline solution, and sodium is precipitated. Because the tank 104-S waste contains high concentrations of aluminum but relatively minor concentrations of silicon, little $\mathrm{NaAlSiO}_{4}$ should form.

Aluminum dissolutions were markedly different for the ESW and C/D processes. C/D dissolved approximately 91 percent of the aluminum in tank 104-S waste; ESW dissolved 47 percent. X-ray diffractometry of tank 104-S starting material revealed the presence of the difficultly-soluble phase böhmite (AlOOH) but not the less refractory gibbsite $\left[\mathrm{Al}(\mathrm{OH})_{3}\right]$.

When böhmite is encountered in aluminum-bearing ore, the aluminum industry uses severe digestive conditions (200 to $230^{\circ} \mathrm{C}$ ) to achieve greater and faster aluminum dissolution. These temperatures are 90 to $100^{\circ} \mathrm{C}$ higher than those used to dissolve gibbsitic ores (Hudson 1987) and 100 to $120^{\circ} \mathrm{C}$ higher than those used in the present ESW tests.

Concentrations of aluminum and hydroxide in ESW caustic leach solutions, $0.228 \mathrm{M}$ and $2.57 \mathrm{M}$, respectively, are near the solubility limit for gibbsite in $\mathrm{NaOH}$ solution at room temperature (solubility curves derived by Barney [1976] from technical literature data). These results may indicate that increased aluminum phase dissolution requires further leach contacts. If so, an additional $1 \frac{1 / 2}{2}$ volumes of leach solution would be required to completely dissolve aluminum under ESW conditions. Nevertheless, for tank 104-S waste, aluminum dissolution by C/D processing was superior to that of ESW.

Both approaches dissolved almost all the chromium (approximately 97 percent dissolved by ESW and $>99.9$ percent dissolved by $\mathrm{C} / \mathrm{D}$ ). Inspection of the ESW data revealed that chromium dissolution was complete in the initial dilute $\mathrm{NaNO}_{2} / \mathrm{NaOH}$ wash steps. Analyses of the original tank 104-S waste also showed the contained chromium to be water soluble, and it reported to solution as chromate $\left(\mathrm{CrO}_{4}^{2-}\right)$. Because the chromium in this tank 104-S waste sample was present only as $\mathrm{CrO}_{4}^{2-}$, the $\mathrm{Cr}(\mathrm{OH})_{3}$ alkaline hydrolysis reaction could not be demonstrated for ESW.

All the sulfur (sulfate) was dissolved by ESW and C/D. Because tank 104-S waste contained phosphorus concentrations below analytical detection limits, phosphate dissolution behavior could not be determined. Dissolutions of silicon and manganese were higher for $C / D$ than for ESW. Approximately 40 percent of the silicon dissolved by C/D as compared to 22 percent by ESW. Manganese dissolution was approximately 18 percent by $\mathrm{C} / \mathrm{D}$ and less than 0.3 percent by ESW. Dissolutions of iron, nickel, and calcium were negligible by $C / D$ and ESW.

The dissolutions of radioactive components achieved by ESW and C/D processing of tank 104-S sludge are shown in Figure 4-2. As expected for wastes containing no complexing agents (for example, EDTA), neither process dissolved significant amounts of ${ }^{241} \mathrm{Am}$ (less than 1 percent dissolved in both cases) or ${ }^{90} \mathrm{Sr}$ (less than 0.3 percent dissolved). 
In contrast and as expected, both processes dissolved most of the ${ }^{137} \mathrm{Cs}$ (approximately 96 percent by ESW and 98 percent by C/D). Technetium- 99 dissolution was approximately 64 percent for ESW and approximately 20 percent by C/D. The behavior of ${ }^{99} \mathrm{Tc}$ is not expected (most ${ }^{99} \mathrm{Tc}$ should be easily dissolved as the pertechnetate ion, $\mathrm{TcO}_{4}^{-}$) and may be related to the low concentrations in tank 104-S waste thus making accurate analyses difficult. Tests with wastes having higher concentrations of ${ }^{99} \mathrm{Tc}$ (for example, tanks 101-SY and $102-\mathrm{SY}$ ) are described in the following sections.

Figure 4-2. Dissolution of Radioactive Components in ESW and C/D Processing of Tank 104-S Waste.

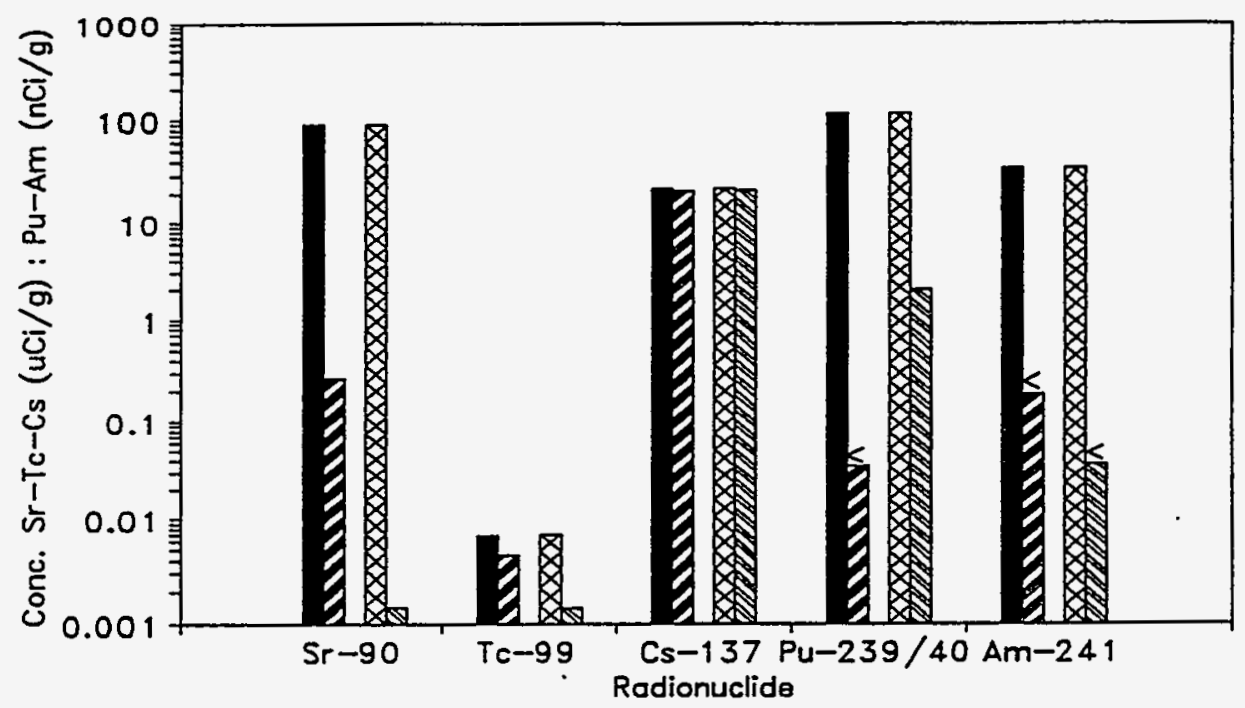

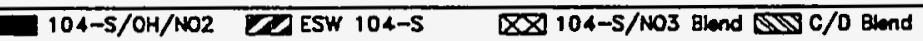


Because the concentrations of ${ }^{237} \mathrm{~Np}$ in tank 104-S waste were below the analytical detection limits, the behavior of this important TRU isotope could not be determined. In contrast, the concentrations of uranium present in the waste were relatively high (approximately 0.6 weight percent on a dry weight basis). The ESW process dissolved approximately 0.05 percent of the uranium (see Figure 4-1); the C/D process, almost 30 percent.

The ${ }^{239,240} \mathrm{Pu}$ dissolved in ESW processing was less than 0.02 percent. In contrast, the ${ }^{239,240} \mathrm{Pu}$ dissolved by $\mathrm{C} / \mathrm{D}$ was approximately 2 percent. Enhanced dissolution of plutonium by C/D processing has been noted in earlier studies (Delegard et al. 1994a and Delegard 1995b) and was postulated to be caused by oxidative dissolution in analogy with the behavior of manganese. Further experiments to confirm this hypothesis and to determine methods to remove the solubilized plutonium were conducted and are described in a later section.

\subsubsection{Results of Alkaline Peroxide Leaching of Simulated Tank 101-SY Waste}

Results of the scouting test of alkaline peroxide dissolution of chromium from simulated tank 101-SY waste are shown in Figure 4-3 (experimental data are given in Appendix B). Most of the reaction occurred in the first day of contact. As expected, the peroxide was not completely efficient in oxidizing $\mathrm{Cr}(\mathrm{OH})_{3}$ to chromate. An amount of peroxide just

- Figure 4-3. Chromium Oxidative Dissolution from Simulated Waste of Tank 101-SY by Alkaline Peroxide Treatment.

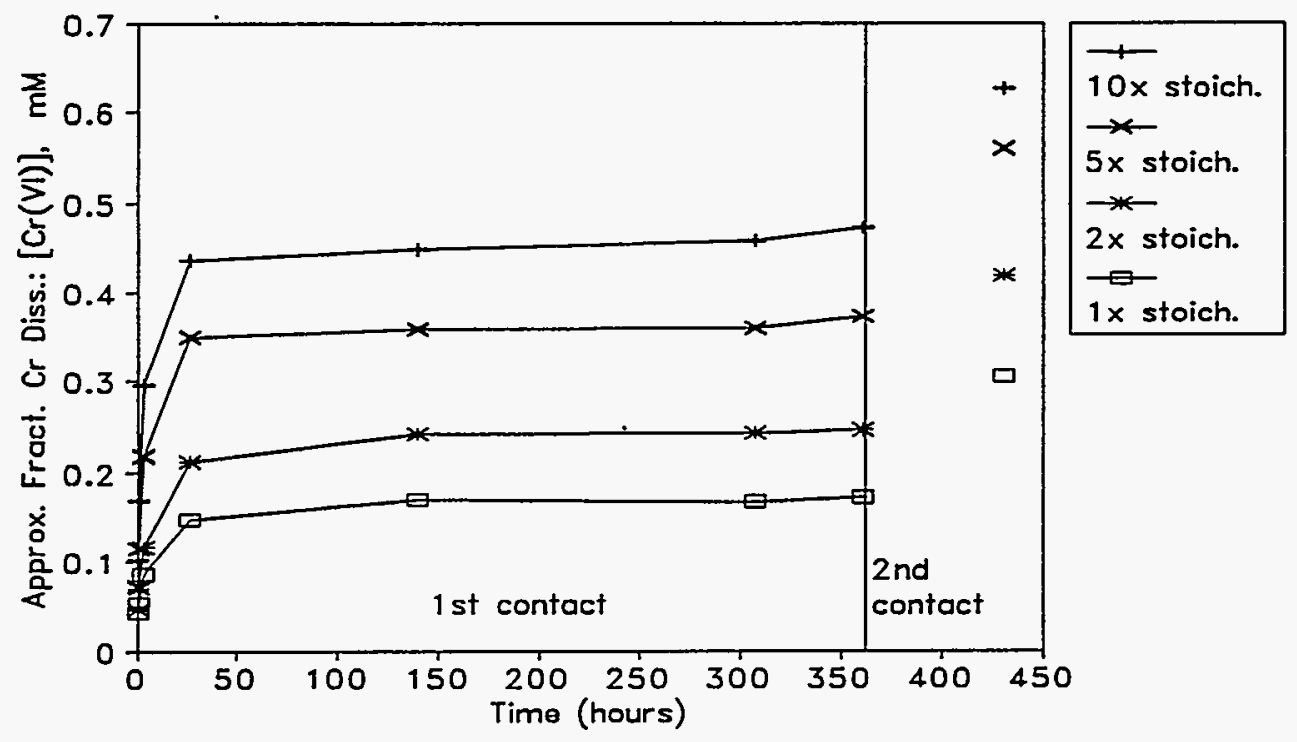


sufficient, stoichiometrically, to oxidize all the chromium hydroxide to chromate resulted in approximately 15 percent dissolution. Increasing the amount of peroxide to 10 times stoichiometry increased chromate yield approximately three times.

Each of the four experimental tests underwent a second contact of $3 \mathrm{M} \mathrm{NaOH}$ with peroxide. The peroxide again was added at 1-, 2-, 5-, and 10-times stoichiometry. At the end of the second (three day) contact, the total amount of chromium dissolved ranged from 30 percent (at stoichiometry) to 65 percent (at 10 times stoichiometry). Based on these results, ESW tests with peroxide were conducted at room temperature with two leach contacts at 20 times stoichiometry in peroxide and with contact times of at least two days.

\subsubsection{Results of C/D, ESW, and ESW/Peroxide Testing for Tank 101-SY Waste}

Test results for C/D and ESW treatment were compared based on the fractions of bulk chemical components and trace radionuclides dissolved. Separate comparisons of ESW and ESW/peroxide were made to determine the effects of peroxide treatment. Experimental data are given in Appendix C.

4.1.6.1 Comparison of C/D and ESW for Tank 101-SY Waste. The dissolution of bulk chemical constituents by $\mathrm{C} / \mathrm{D}$ and $\mathrm{ESW}$ processing are compared in Figure 4-4. The amounts dissolved are shown next to the amounts present in the initial waste mixtures (including processing chemicals used for ESW).

Figure 4-4. Dissolution of Bulk Waste Constituents in ESW and C/D Processing of Tank 101-SY Waste.

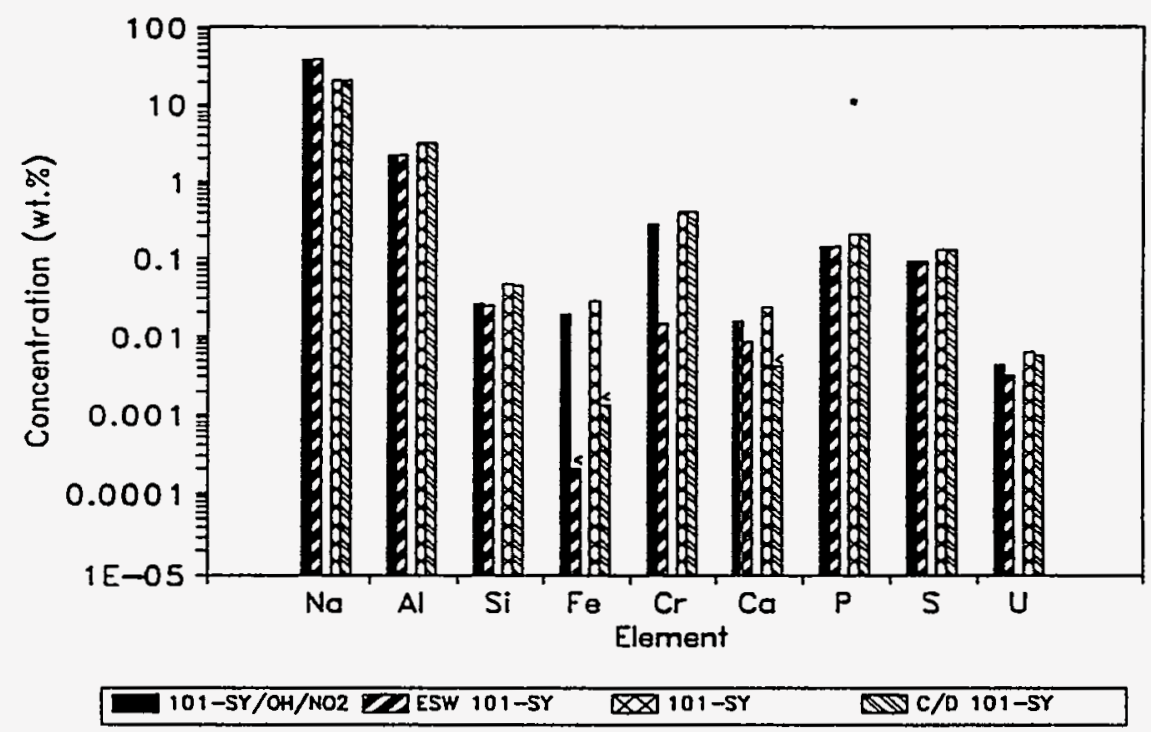


As expected for tank 101-SY waste composition, both treatments dissolved all the sodium. Aluminum also was largely dissolved by $C / D$ ( 99.8 percent) and ESW ( 98.8 percent). This was expected because most aluminum is in the solution phase in tank 101-SY waste. Phosphate and sulfate also were completely dissolved.

Chromium dissolution behaviors were different for C/D and ESW. While chromium dissolution was complete for $C / D$ (reporting to solution as chromate), approximately 5.2 percent of the chromium dissolved by ESW. Most of that chromium was dissolved in the $3 \mathrm{M} \mathrm{NaOH}$ leach step. The solution concentrations relevant for the ESW alkaline hydrolysis reactions are as follows: $\left[\mathrm{OH}^{-}\right]=3.12 \mathrm{M},[\mathrm{Cr}]=0.00095 \mathrm{M}$.

The dissolved chromium concentration (that is, $0.00095 \mathrm{M}$ in $3.12 \mathrm{M} \mathrm{NaOH}$ ) is similar to that predicted by the work of Felmy et al. (1994) (approximately $0.0006 \mathrm{M}$ chromium). However, the dissolved chromium concentration is low compared with the concentration available in tank 101-SY tank waste (approximately $0.13 \mathrm{M}$, nearly all in the solid phase) (Herting et al. 1992). To dissolve this solid phase chromium by ESW, approximately $0.13 / 0.00095=140$ waste volumes of $3.1 \mathrm{M} \mathrm{NaOH}$ leachant would be required.

The dissolution behaviors of the radioactive components under ESW and C/D are shown in Figure 4-5. The behavior of uranium, shown in Figure 4-4 as a bulk component, is similar for both techniques: approximately 90 percent dissolution by $\mathrm{C} / \mathrm{D}$ and 73 percent dissolution by ESW. However, the concentration of uranium in tank 101-SY waste is relatively low. The fraction dissolved may reflect only a solubility limit imposed, for example, by a sodium diuranate solid phase. Almost complete dissolution of ${ }^{137} \mathrm{Cs}$ (exceeding 99 percent) is shown

Figure 4-5. Dissolution of Radioactive Components in ESW and C/D Processing of Tank 101-SY Waste.

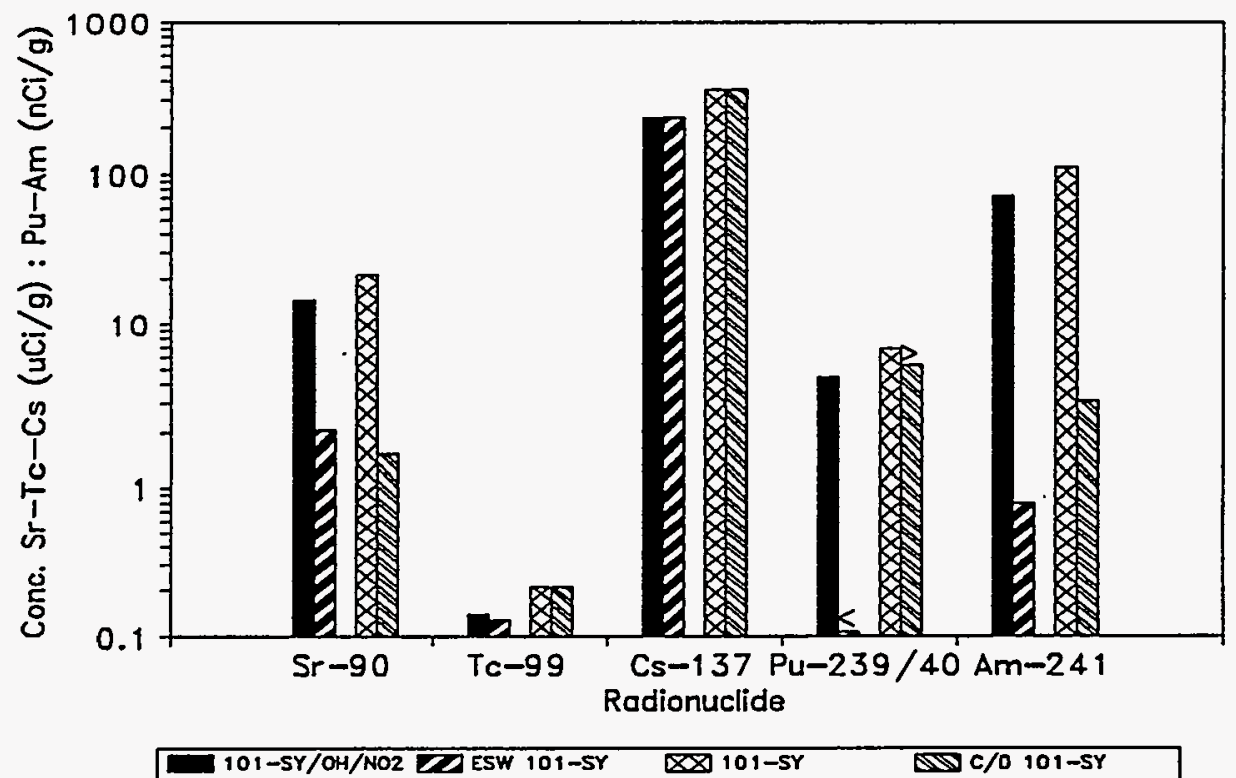


by both techniques. Technetium-99 dissolution also is complete for $\mathrm{C} / \mathrm{D}$ and approximately 93 percent by ESW. As expected, dissolutions of ${ }^{90} \mathrm{Sr}$ and ${ }^{241} \mathrm{Am}$ were low by $\mathrm{C} / \mathrm{D}$ and ESW. Approximately 7 percent of the ${ }^{90} \mathrm{Sr}$ dissolved by $\mathrm{C} / \mathrm{D}$ versus approximately 14 percent by ESW; the analogous figures for ${ }^{241} \mathrm{Am}$ were 3 percent and 1 percent.

The behavior of ${ }^{239,240} \mathrm{Pu}$ in $\mathrm{C} / \mathrm{D}$ again was consistent with the oxidative dissolution postulated for plutonium. Over 78 percent of the plutonium dissolved by $C / D$ versus less than 3 percent dissolved by ESW. Because of low concentrations, neptunium behavior could not be determined reliably.

4.1.6.2 Comparison of ESW and ESW/Peroxide for Tank 101-SY Waste. The effects of adding peroxide on the reference ESW flowsheet were determined by comparing the leaching results for bulk chemical (chromium and aluminum) and radionuclide (uranium and ${ }^{239.240} \mathrm{Pu}$ ) components in ESW and ESW/peroxide tests with tank 101-SY waste.

Although markedly enhanced solubilization of chromium (caused by oxidative dissolution to chromate) was shown in the alkaline peroxide leaching tests with the simulant tank 101-SY waste, little increase in chromium dissolution was shown in the comparative tests with genuine tank 101-SY waste. For ESW, approximately 5.2 percent chromium dissolution was obtained; with ESW/peroxide, the chromium dissolution increased to 8.2 percent. Aluminum dissolution decreased from 98.8 percent by ESW to 93 percent by ESW/peroxide.

Uranium dissolution increased to greater than 94 percent by ESW/peroxide versus 73 percent dissolved by ESW. Plutonium dissolution also increased from 2.4 percent by ESW to 4.2 percent by ESW/peroxide. In summary, the ESW/peroxide treatment showed marginal differences from the reference ESW treatment for tank 101-SY waste.

\subsubsection{Results of C/D, ESW, and ESW/Peroxide Testing for Tank 102-SY Waste}

ESW and C/D test results for tank 102-SY waste can be compared based on bulk chemical components and trace radionuclides dissolved by the respective processing techniques. The effects of the alkaline peroxide ESW then can be compared with those obtained by ESW. Experimental data are given in Appendix D.

4.1.7.1 Comparison of C/D and ESW for Tank 102-SY Waste. Comparisons of the dissolutions of bulk chemical components by ESW and C/D processes are shown in Figure 4-6. Taken together, the sodium, aluminum, and silicon dissolution behaviors for the ESW tests give evidence for the possible formation of a limited amount of sodium aluminosilicate. Nevertheless, sodium dissolutions for ESW and C/D were almost complete. Silicon, the limiting reagent in tank 102-SY waste for the formation of sodium aluminosilicates, was approximately 20 percent dissolved in ESW and approximately 50 percent dissolved in $\mathrm{C} / \mathrm{D}$. 
Figure 4-6. Dissolution of Bulk Waste Constituents in ESW and C/D Processing of Tank 102-SY Waste.

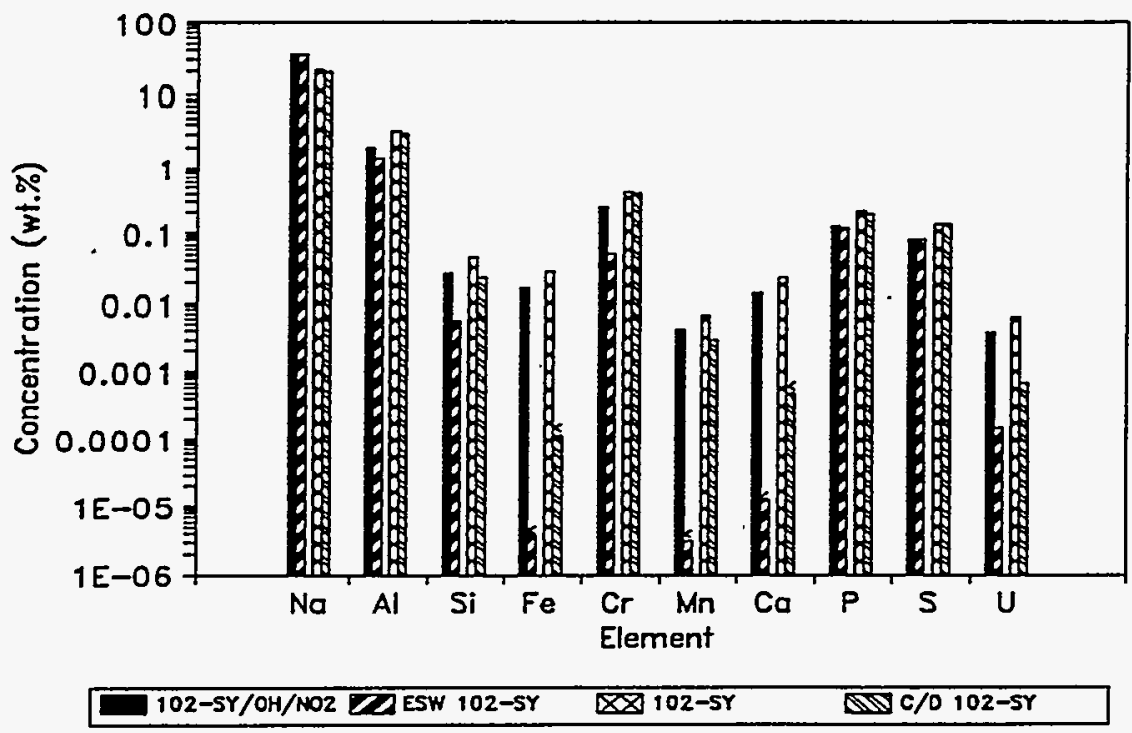

Aluminum dissolution was approximately 70 percent by ESW versus approximately 95 percent dissolved by $\mathrm{C} / \mathrm{D}$. The aluminum solution concentration achieved in the ESW alkaline leach step $(0.143 \mathrm{M}$ at $2.65 \mathrm{M} \mathrm{NaOH})$ is a little lower than that expected in the solubility limit for gibbsite (approximately $0.2 \mathrm{M}$ [Bamey 1976]); it may reflect the formation of sodium aluminosilicates.

As with tests with tank 101-SY waste, chromium dissolution behaviors were different for ESW (approximately 21 percent dissolved) and C/D (over 99 percent dissolved). In C/D tests, the chromium dissolved by the oxidative dissolution imposed by the separate calcination and water dissolution steps. For the ESW test, most of the chromium reporting to the solution was chromate in the initial dilute alkali wash steps. The solution concentration of chromium found in the $2.65 \mathrm{M} \mathrm{NaOH}$ ESW leach step was approximately $0.002 \mathrm{M}$. According to the work of Felmy et al. (1994), the solubility limit of $\mathrm{Cr}(\mathrm{OH})_{3}$ at $2.65 \mathrm{M}$ $\mathrm{NaOH}$ should be approximately $0.0005 \mathrm{M}$. The pale yellow color observed in the leach solution indicates that "excess" dissolved chromium may be caused by chromate that is not completely removed in the initial wash. The concentration of chromium remaining in tank 102-SY waste after a dilute alkali wash is approximately $0.26 \mathrm{M}$ (based on the original waste volume). To dissolve this chromium by alkaline hydrolysis would require $0.26 / 0.0006$ or approximately 430 waste volumes of $3 \mathrm{M} \mathrm{NaOH}$. 
Iron dissolution was less than 1 percent by ESW and C/D. Manganese dissolutions were different. Less than 1 percent of the manganese dissolved by ESW. Approximately 42 percent of the manganese dissolved by $C / D$ processing. Oxidative dissolution of manganese was evident by the observation of the intensely green manganate $\left(\mathrm{MnO}_{4}^{2-}\right)$ solution species.

The dissolution behaviors of radioactive components in tank 102-SY waste by ESW and C/D processing are compared in Figure 4-7. The dissolution of uranium, a bulk waste component that is also radioactive, is shown in Figure 4-6. Uranium dissolution was approximately 4 percent in the ESW tests and about 10 percent by the $C / D$ processing. Dissolutions of ${ }^{137} \mathrm{Cs}$ were high for ESW (95 percent) and C/D (over 99 percent) while the dissolutions of ${ }^{90} \mathrm{Sr}$ were low (0.3 percent and 7 percent, respectively). Technetium-99 dissolutions were complete for C/D but less than 1 percent by ESW. This is an unexpected result (most ${ }^{99} \mathrm{Tc}$ should be dissolved). Further experimental testing for technetium behavior in sludge processing is required. ${ }^{241} \mathrm{Am}$ dissolutions were low (less than 3 percent) for $E S W$ and $C / D$.

The parallel behaviors of manganese and plutonium in C/D processing were shown again. While ESW dissolved less than 1 percent of the manganese and plutonium, $C / D$ dissolved approximately 42 percent of the manganese and approximately 77 percent of the ${ }^{239,240} \mathrm{Pu}$. Oxidative dissolution of manganese and plutonium is at work. Further tests to determine the joint and separate behaviors of manganese and plutonium in $C / D$ processing are described in later sections.

Figure 4-7. Dissolution of Radioactive Components in ESW and C/D Processing of Tank 102-SY Waste.

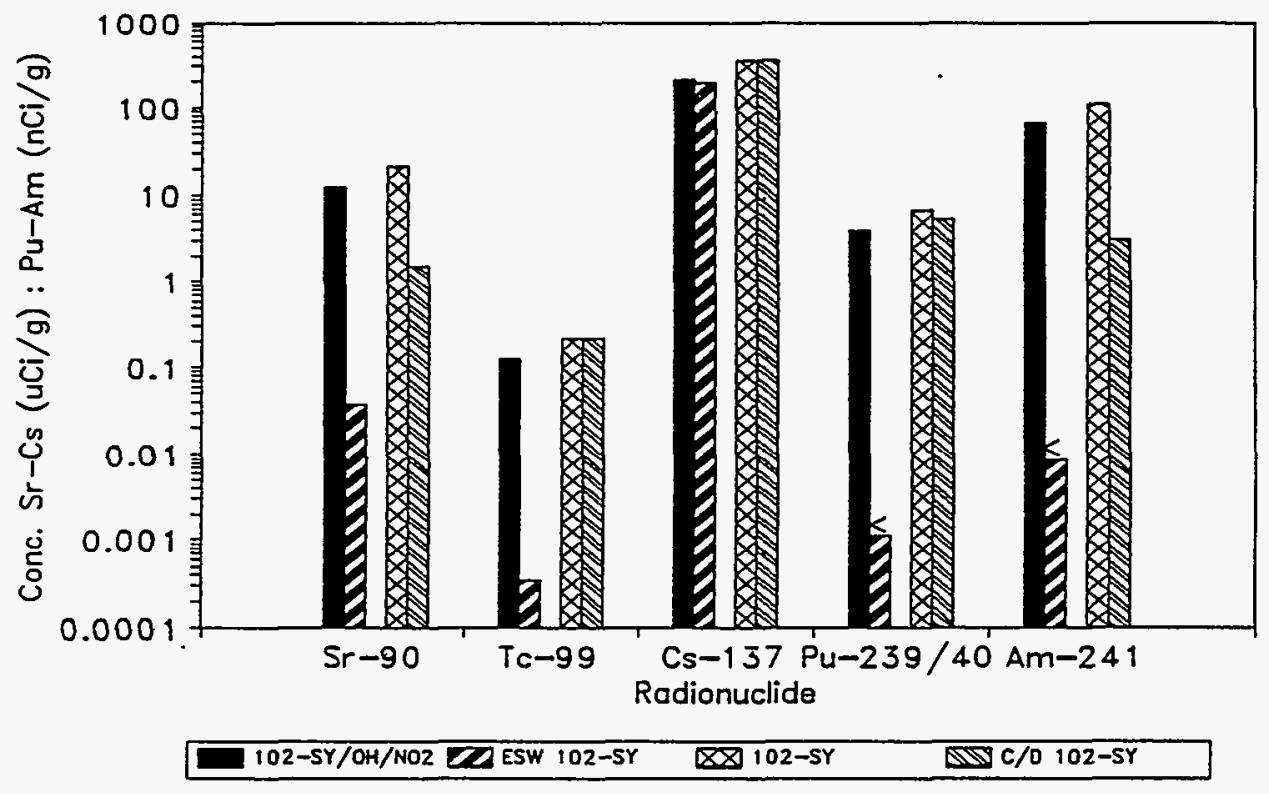


4.1.7.2 Comparison of ESW and ESW/Peroxide for Tank 102-SY Waste. Leaching results were compared for ESW and ESW/peroxide tests on waste from tank 102-SY. Enhanced solubilization of chromium was the goal of adding peroxide to the ESW alkaline leach step. For tank 102-SY waste, the amount of chromium dissolved decreased from the 21 percent found by ESW to approximately 16 percent by the combined ESW/peroxide treatment. Aluminum dissolution also decreased: 71 percent dissolved by ESW and 66 percent dissolved by the ESW/peroxide treatment. Uranium dissolutions were equivalent ( 3 to 4 percent) by both and ESW/peroxide. Plutonium dissolutions also were similar and were less than 1 percent for both techniques.

The ESW/peroxide results from wastes of tanks 101-SY and 102-SY indicate no benefit is gained by adding peroxide. The solubilization of chromium(II) hydroxide by the reference ESW flowsheet remains limited by its low solubility compared with the concentrations available in many wastes (including wastes from tanks 101-SY and 102-SY). Oxidative dissolution remains the only viable way of achieving reasonable $\operatorname{Cr}(\mathrm{OH})_{3}$ solubilization. Further tests of other possible $\mathrm{Cr}(\mathrm{OH})_{3}$ oxidants (such as hypochlorite) are proposed for future investigations.

\subsection{PLUTONIUM REMOVAL FROM C/D PRODUCT SOLUTIONS}

Previous discussions of C/D results for wastes in tanks 104-S, 101-SY, and 102-SY and discussions in earlier reports on $\mathrm{C} / \mathrm{D}$ testing have shown that manganese and plutonium dissolution behaviors are similar in $\mathrm{C} / \mathrm{D}$ processing. Similar behaviors are thought to be caused by oxidation forming soluble anions [manganate, $\mathrm{MnO}_{4}^{2-}$, and plutonium(VI) or (V) species, $\mathrm{PuO}_{2}(\mathrm{OH})_{4}^{2-}$ or $\mathrm{PuO}_{2}(\mathrm{OH})_{4}^{3-}$, respectively]. The dissolution of plutonium, and its reporting to the LIW solution phase in pretreatment processing, is not desired. If plutonium reports to the dissolved LLW stream, a secondary step must be used to remove plutonium from solution.

Reduction of manganate to form insoluble manganese dioxide $\left(\mathrm{MnO}_{2}\right)$, the corollary reduction of the solubilized plutonate $[\mathrm{Pu}(\mathrm{VI})$ or $\mathrm{Pu}(\mathrm{V})]$ to form plutonium dioxide $\left(\mathrm{PuO}_{2}\right)$, and coprecipitation of the product oxides offer a promising approach to remove the solubilized plutonium from the LLW stream. Experiments were conducted to test reduction/coprecipitation with C/D product solutions originating from genuine tank 102-SY waste and plutonium- and neptunium-spiked Hanford Site tank composite simulant waste. The reductants tested, hydroxylamine hydrochloride $\left(\mathrm{NH}_{2} \mathrm{OH} \cdot \mathrm{HCl}\right)$ and hydrogen peroxide $\left(\mathrm{H}_{2} \mathrm{O}_{2}\right)$, are volatile at glass forming temperatures and have the advantage of not adding bulk to the vitrified waste form. Experimental data are summarized in Appendix E. 


\section{WHC-EP-0882}

\subsubsection{Coprecipitation Tests with Tank 102-SY Waste C/D Solution}

Reduction and coprecipitation experiments were conducted with three separate product solutions from C/D testing of tank 102-SY waste. Although the solutions had been stored in the laboratory for up to 100 days following the C/D experiments, the continuing presence of dissolved manganese was evident by the intense green solution coloration caused by manganate $\left(\mathrm{MnO}_{4}^{2-}\right)$ for two solutions and maroon caused by permanganate $\left(\mathrm{MnO}_{4}^{-}\right)$for the remaining solution.

Each of the three stored solutions were centrifuged, and the supernatant solutions were withdrawn. Aliquots of solutions were analyzed to determine bulk metal concentrations and concentrations of dissolved radionuclides. One molar solutions of the hydroxylamine and peroxide reductants were prepared from reagent chemicals and $Q$ water.

Five $\mathrm{mL}$ aliquots of the clarified solutions were drawn. In separate tests, reductants were added by drop (approximately $0.05 \mathrm{~mL}$ per drop) to the $5 \mathrm{~mL}$ test aliquots, then the solutions were agitated, and the solution's appearances were noted.

In all cases, reactions were rapid and vivid. Introduction of one drop of reductant was sufficient in all cases to cause solution color to change instantly from dark green (caused by manganate) or maroon (caused by permanganate in the solution having lower hydroxide concentration), to brown, then to bright yellow. After a few seconds, as the brown color was supplanted by the yellow, small dark brown solid particles formed. These observations are consistent with the precipitation of brown manganese(IV) dioxide reduced from soluble manganate or permanganate. The residual yellow solution color was caused by chromate $\left(\mathrm{CrO}_{4}^{2-}\right)$.

Adding peroxide resulted in some bubbling in the solution; hydroxylamine addition gave a small amount of white precipitate at the point of introduction. The precipitate [probably $\mathrm{Al}(\mathrm{OH})_{3}$ precipitated by the acidic hydrochloride salt] dissolved rapidly with mixing.

The suspensions were centrifuged and the supernatant solutions were analyzed for bulk metal and radionuclide concentrations. The results of the analyses for one manganate test solution are shown in Figures 4-8 and 4-9. Similar results were obtained for the other two test solutions.

Test data indicate that hydroxylamine and peroxide removed manganese (see Figure 4-8) and plutonium (see Figure 4-9) from solution. Concentration reductions for both metals with each reagent were approximately a factor of three hundred. Significantly, chromium solution concentrations did not decrease by reduction of chromate to the poorly soluble $\mathrm{Cr}(\mathrm{OH})_{3}$. Thus, the beneficial effect of chromium solubilization by $C / D$ was not negated by the plutonium/manganese reductive coprecipitation. Some coprecipitation of ${ }^{90} \mathrm{Sr}$ also occurred. Concentrations of other metals or radionuclides were not affected by using the reductants. 
Figure 4-8. Concentration of Bulk Waste Constituents in Tank 102-SY C/D Solution Before and After Treatment with Peroxide and Hydroxylamine.

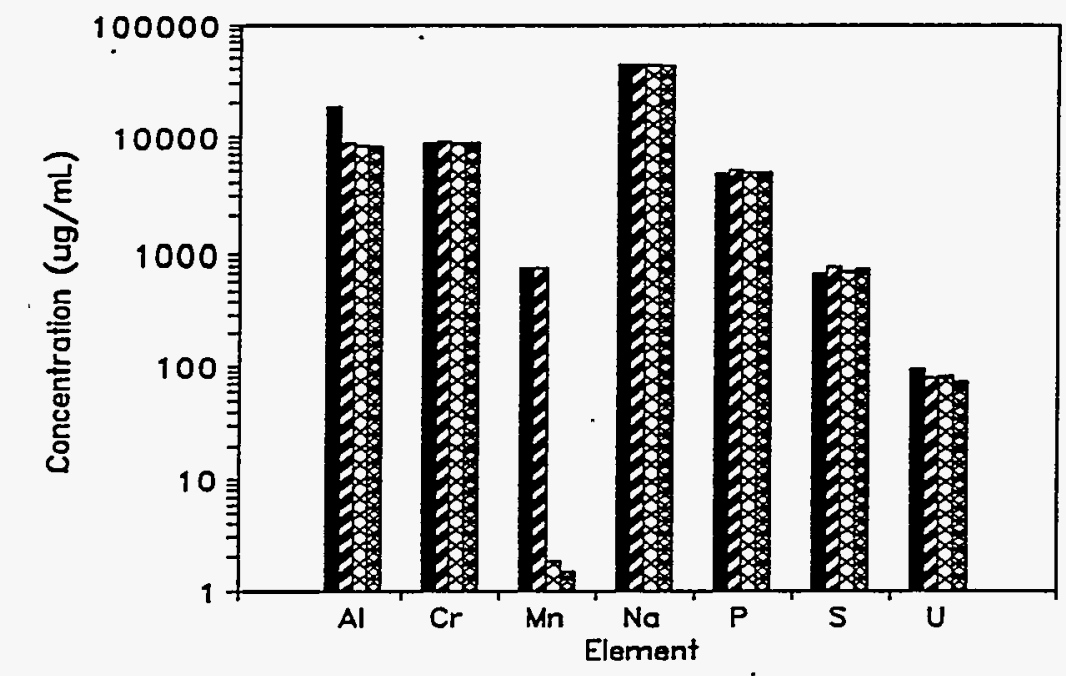

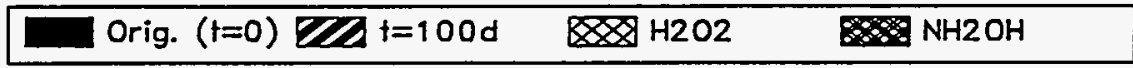

Figure 4-9. Concentrations of Radionuclides in Tank 102-SY C/D Solution Before and After Treatments with Peroxide and Hydroxylamine.

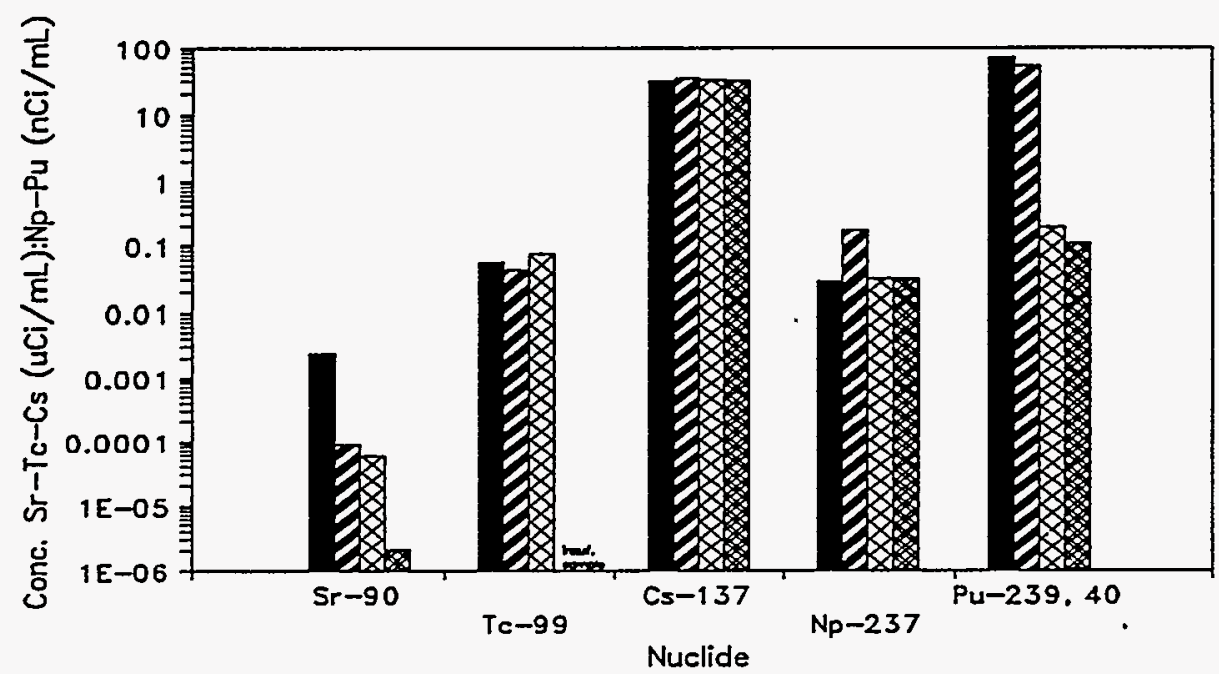

Orig. $(t=0) \mathbb{Z O H} \mathrm{t=100 \textrm {d }} \quad \mathrm{NH} 2 \mathrm{OH}$


Results from initial scoping tests for coprecipitation indicate that plutonium solubilized by $\mathrm{C} / \mathrm{D}$ may be rapidly and efficiently removed from solution. However, analytical results for neptunium were near the analytical detection limit and were difficult to interpret. Further tests using neptunium-spiked simulant waste were performed to clarify the behavior of neptunium.

\subsubsection{Coprecipitation Tests with Neptunium- and Plutonium-Spiked Simulant}

The behavior of neptunium in C/D processing has been difficult to determine because of its low concentration in tested Hanford Site tank wastes. Some solubilization of neptunium by $\mathrm{C} / \mathrm{D}$ is expected based on the similarity of its chemistry to that of plutonium. Neptunium is easier to oxidize in alkaline solution than plutonium (Peretrukhin et al. 1995); therefore, it would be more susceptible to oxidative dissolution by C/D processing.

The composition of a comprehensive Hanford Site tank waste simulant containing the most prevalent 27 chemical components of the tank waste (over 99.99 mole percent) has been described (Delegard et al. 1994a). Nitric acid solutions of plutonium(IV) and neptunium(V) spike were added to an aliquot of the comprehensive simulant and the spiked simulant processed by $\mathrm{C} / \mathrm{D}$.

The C/D product solution was separated for analysis, and a $5 \mathrm{~mL}$ aliquot of the clarified solution was treated with $3 \mathrm{M}$ hydroxylamine hydrochloride. Upon adding a drop of the hydroxylamine, the color changed immediately from blue-green to yellow. No precipitate appeared even after 30 minutes. The treated solution was allowed to stand about 80 hours after which a fine brown precipitate appeared. The original C/D product and the hydroxylamine-treated supernatant solutions were analyzed.

Equal concentrations (approximately $0.004 \mathrm{~g} / \mathrm{L}$ or $1.8 \times 10^{-5} \mathrm{M}$ ) of plutonium and neptunium were found in the C/D product solution. The equal concentrations give evidence for similar solubility-limiting phases for these two neighboring actinides.

The results of the solution analyses before and after hydroxylamine treatment show manganese and plutonium solution concentrations dropped approximately a factor of thirty by treatment with hydroxylamine; neptunium concentrations dropped approximately a factor of three (see Figure 4-10). Chromium solution concentrations also decreased approximately 20 percent and lead decreased approximately 30 percent. The slowness of the precipitation reaction may be caused by the low initial concentration of the dissolved manganese or by complexation by excess hydroxylamine. Further tests must be conducted to determine the cause of slowness of the precipitation reaction, whether heating improves the rate of reduction/coprecipitation and to confirm whether hydroxylamine causes the undesired precipitation of chromium. 
Figure 4-10. Concentrations of Bulk Constituents and Radionuclides in Simulant C/D Solution Before and After Treatment with Hydroxylamine.

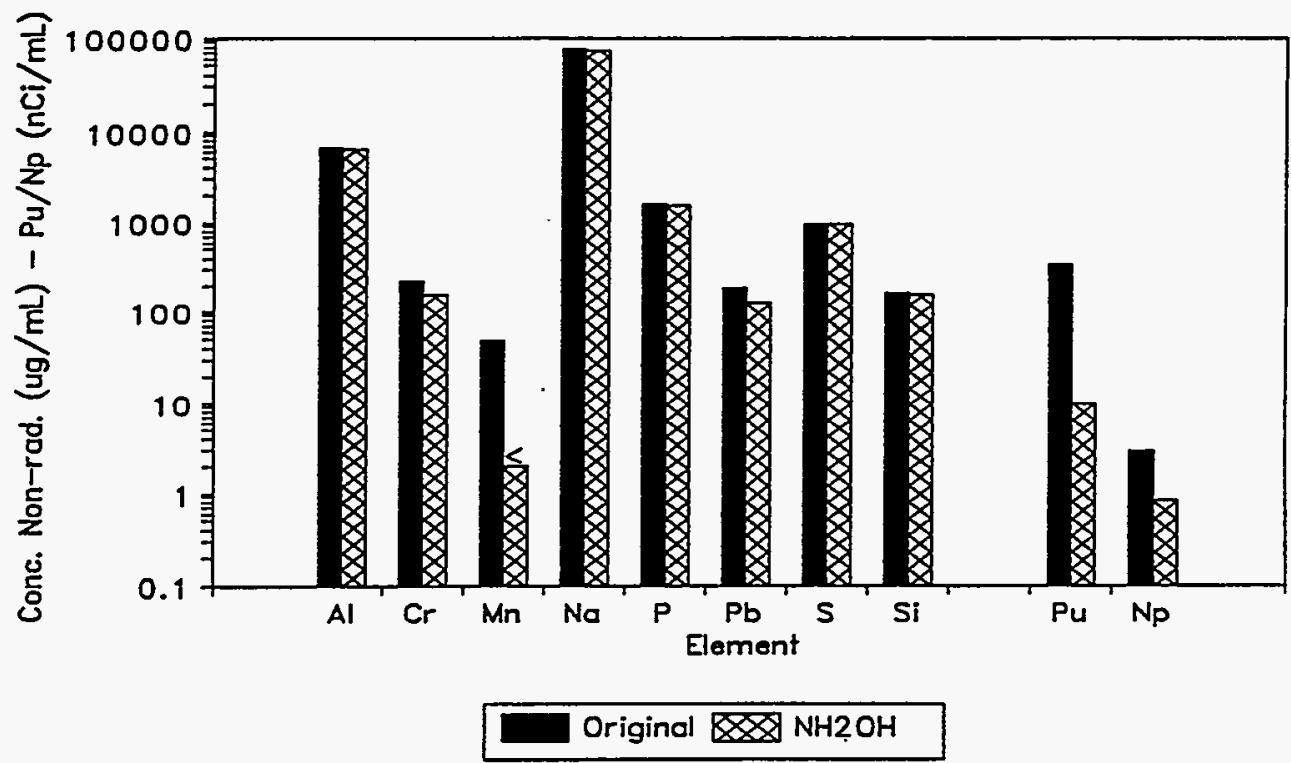

\subsection{DETERMINATION OF PLUTONIUM AND NEPTUNIUM SOLUTION SPECIES}

The solubilization of plutonium occurring in the $C / D$ processing of genuine tank waste has been attributed to the formation of soluble anionic oxidized species. Similar solubilities of plutonium and neptunium, found in the C/D processing of spiked simulant wastes, imply that similar chemistries exist for these two neighboring actinides. On this basis, tests were performed to identify plutonium and neptunium solution species created in the C/D of simulant waste materials.

Because spectrophotometric techniques are noninvasive and do not disturb the solution chemistry, they are ideally suited to identify dissolved species. Separate plutonium- and neptunium-spiked simulant wastes were prepared, subjected to C/D processing, and the product solution was analyzed spectrophotometrically (using a spectrophotometer with a lower detection limit of approximately 0.0001 absorbance units for a 1-cm cell).

To facilitate observation of suspected actinide species, which have low concentrations and low molar absorptivities, simulant wastes with no strongly absorbing chromophores were prepared. A Hanford Site tank waste composite sludge was created according to the published recipe (Delegard et al. 1994a) but from which iron, chromium, nickel, manganese, and bismuth had been omitted. A surrogate waste simulating the composition of tank 102-SY waste and including added $\mathrm{NaNO}_{3}$ (but with iron, chromium, and manganese omitted) also was created. The compositions of the two simulant waste types are given in Table 4-3. 


\section{WHC-EP-0882}

Table 4-3. Compositions of Waste Simulants Used in Speciation Tests.

\begin{tabular}{|c|c|c|}
\hline \multirow{2}{*}{ I: } & \multicolumn{2}{|c|}{ 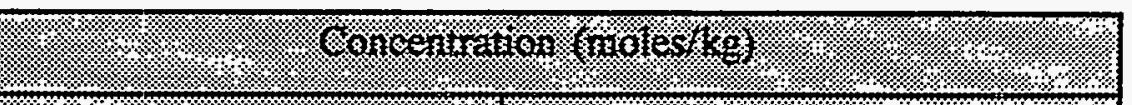 } \\
\hline & Q Q & 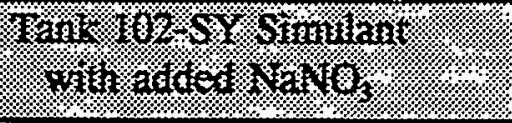 \\
\hline $\mathrm{Al}$ & 0.52 & 0.58 \\
\hline $\bar{B}$ & 0.00074 & - \\
\hline $\mathrm{Ca}$ & 0.011 & 0.023 \\
\hline $\mathrm{Ce}$ & 0.0053 & -- \\
\hline $\bar{K}$ & 0.073 & 0.038 \\
\hline $\mathrm{Mg}$ & 0.00069 & - \\
\hline $\mathrm{Na}$ & 8.91 & 5.66 \\
\hline $\mathrm{Pb}$ & 0.0067 & -- \\
\hline $\mathrm{Si}$ & 0.056 & 0.026 \\
\hline Sr & 0.0013 & - \\
\hline $\mathrm{Cl}^{-}$ & 0.038 & 0.037 \\
\hline $\mathrm{F}$ & 0.18 & 0.018 \\
\hline $\mathrm{NO}_{2}^{-}$ & 0.65 & 0.38 \\
\hline $\mathrm{NO}_{3}^{-}$ & 5.34 & 3.69 \\
\hline $\mathrm{PO}_{4}^{3-}$ & 0.29 & 0.085 \\
\hline $\mathrm{SO}_{4}^{2-}$ & 0.065 & 0.21 \\
\hline $\mathrm{CO}_{3}^{2-}$ & 0.14 & 0.28 \\
\hline $\mathrm{OH}^{-}$ & 1.4 & 0.55 \\
\hline $\mathrm{TOC}^{*}$ & 0.20 & 0.36 \\
\hline $\mathrm{H}_{2} \mathrm{O}$ & 10.9 & 26.2 \\
\hline
\end{tabular}

Note:

- Added as acetate.

The absorption spectra of the C/D product solutions were gathered for both simulant waste types. The neptunium-spiked tank waste composite sludge had a dissolved neptunium concentration of $0.034 \mathrm{~g} / \mathrm{L}$ (equivalent to $1.4 \times 10^{-4} \mathrm{M}$ or approximately $20 \mathrm{nCi} / \mathrm{g}$ ) and 
showed a spectrum matching a published spectrum of $\mathrm{Np}(\mathrm{V})$ (Cohen and Fried 1969). The corresponding plutonium-spiked material had a dissolved plutonium concentration of approximately $0.028 \mathrm{~g} / \mathrm{L}\left(1.2 \times 10^{-4} \mathrm{M}\right.$ or approximately $\left.1600 \mathrm{nCi} / \mathrm{g}\right)$. The spectrum was less distinct but resembled a published spectrum of Pu(V) (Bourges 1972).

A non-spiked sample of the tank $102-\mathrm{SY} / \mathrm{NaNO}_{3}$ simulant also underwent $\mathrm{C} / \mathrm{D}$ processing. Colorless bubbles were observed in the product solution. The neptunium-spiked tank 102-SY/NaNO ${ }_{3} \mathrm{C} / \mathrm{D}$ product solution had approximately $0.26 \mathrm{~g} / \mathrm{L}$ dissolved neptunium. The solution was tea colored and had an intense absorption in the spectrum below approximately $700 \mathrm{~nm}$ wavelength. Over several days, the solution color faded and the characteristic absorption caused by $\mathrm{Np}(\mathrm{V})$ emerged. A quantity of white precipitate also appeared in the sample vial.

Based on the bubbling observed in the non-spiked C/D solution and the intense absorption in the lower wave lengths of the neptunium-spiked $C / D$ solution, peroxide complexes of neptunium were suspected. To confirm this, a drop of $1 \mathrm{M} \mathrm{H}_{2} \mathrm{O}_{2}$ was added directly into the spectrophotometric cuvette containing approximately $3 \mathrm{~mL}$ of the clarified $\mathrm{Np}(\mathrm{V})$ solution. The solution immediately changed to the original tea color with a spectrum matching the original spectrum, except for intensity. Adding $100 \mu \mathrm{L}$ of $1 \mathrm{M} \mathrm{H}_{2} \mathrm{O}_{2}$ to the $10 \mathrm{~mL}$ sample containing the neptunium C/D product almost instantly produced the original dark tea color, dissolved the previously observed white precipitate, and gave the original spectrum. The assignment of the tea-colored neptunium spectrum to a $\mathrm{Np}(\mathrm{V})$ peroxide complex was corroborated by spectra and other experimental results found in a published report (Musikas 1976).

The plutonium-spiked tank 102-SY/NaNO ${ }_{3}$ simulant gave a dissolved plutonium concentration of $0.009 \mathrm{~g} / \mathrm{L}$. No readily identifiable spectrum was observed. The work of Musikas (1976) indicates that plutonium(VI) and (V) in alkaline solution form peroxide complexes of only fleeting existence and are rapidly reduced to form $\mathrm{Pu}(\mathrm{IV})$ precipitates.

The speciation coprecipitation test data reported in Section 4:2.2 substantiate the use of chemical reductants, such as peroxide or hydroxylamine, to effect reduction and (co)precipitation of plutonium. The coprecipitation of neptunium is more difficult and complicated by the formation of relatively stable peroxide complexes. In analogy with the well-known reactions of peroxide with actinides in acid media, the plutonium and neptunium peroxide complexes may be destroyed readily by heating.

\subsection{CARBONATE COMPLEXES OF PLUTONIUM IN ALKALINE SOLUTION}

Quantitative evidence of the formation of carbonate complexes of Pu(IV) in alkaline solution has recently been presented in the technical literature (Yamaguchi et al. 1994). The evidence consists of enhanced solution concentration of plutonium as carbonate or bicarbonate concentrations increase. 
In the experiments of Yamaguchi et al. (1994), plutonium valence was controlled to the (IV) state by use of $\mathrm{NaNO}_{2}$. Tests showed the solid phase contained no carbonate; on this basis, the solid phase $\mathrm{PuO}_{2} \cdot \mathrm{xH}_{2} \mathrm{O}$ was inferred though no spectrophotometry was performed to identify the valence of the dissolved plutonium species, plutonium in the clarified (filtered, at $450 \mathrm{~nm}$ and $3 \mathrm{~nm}$ pore size) solutions was identified as being in the (IV) state by TTA (thenoyltrifluoroacetone) extraction.

The plutonium solution concentration increased in the presence of carbonate and bicarbonate, and the plutonium concentration was proportional to the square of the carbonate or bicarbonate concentration. Two regimes of increasing plutonium concentration were identified: in the range $\mathrm{pH} 9.4$ to 10.1 (where bicarbonate, $\mathrm{HCO}_{3}^{-}$, is predominant) and in the range $\mathrm{pH} 12$ to 13 (where carbonate, $\mathrm{CO}_{3}^{2-}$, is predominant).

On the basis of the $\mathrm{pH}$ dependencies and the observed dependencies of the plutonium solution concentration on (bi)carbonate concentration, two reactions were proposed:

$$
\mathrm{PuO}_{2} \cdot \mathrm{xH}_{2} \mathrm{O}+2 \mathrm{HCO}_{3}^{-} \rightleftharpoons \mathrm{Pu}(\mathrm{OH})_{2}\left(\mathrm{CO}_{3}\right)_{2}^{2-}+\mathrm{x} \mathrm{H}_{2} \mathrm{O}
$$

in bicarbonate ( $\mathrm{pH} 9.4$ to 10.1$), \log \mathrm{K}=-2.7 \pm 0.5$; and

$$
\mathrm{PuO}_{2} \cdot \mathrm{xH}_{2} \mathrm{O}+2 \mathrm{CO}_{3}^{2-} \rightleftarrows \mathrm{Pu}(\mathrm{OH})_{4}\left(\mathrm{CO}_{3}\right)_{2}^{4-}+(\mathrm{x}-2) \mathrm{H}_{2} \mathrm{O}
$$

in carbonate ( $\mathrm{pH} 12$ to 13$), \log \mathrm{K}=-4.98 \pm 0.31$.

Thus, the solubility of the plutonium solid phase $\left(\mathrm{PuO}_{2} \cdot \mathrm{xH}_{2} \mathrm{O}\right)$ was found to increase in proportion to the square of the bicarbonate or carbonate concentrations.

The solubility of $\mathrm{PuO}_{2} \cdot \mathrm{xH}_{2} \mathrm{O}$ in the system $\mathrm{NaOH} / \mathrm{Na}_{2} \mathrm{CO}_{3}$ has been reported previously (Delegard 1985). In this study, $\mathrm{Pu}(\mathrm{V})$ species had been observed in concentrated $\mathrm{NaOH}$ solutions having no added carbonate; therefore, the solubilities observed in mixed $\mathrm{NaOH} / \mathrm{Na}_{2} \mathrm{CO}_{3}$ solutions were modeled on the net reaction (3) involving $\mathrm{Pu}(\mathrm{V})$ :

$$
\mathrm{PuO}_{2} \cdot \mathrm{xH}_{2} \mathrm{O}+4 \mathrm{OH}^{-}+2 \mathrm{CO}_{3}^{2-} \rightleftarrows \mathrm{PuO}_{2}(\mathrm{OH})_{4}\left(\mathrm{CO}_{3}\right)_{2}^{7-}+\mathrm{x} \mathrm{H}_{2} \mathrm{O}+\mathrm{e}^{-}
$$

where reaction (3) is a combination of reactions (4)

$$
\mathrm{PuO}_{2} \cdot \mathrm{xH}_{2} \mathrm{O}+4 \mathrm{OH}^{-} \rightleftarrows \mathrm{PuO}_{2}(\mathrm{OH})_{4}^{3-}+\mathrm{xH}_{2} \mathrm{O}+\mathrm{e}^{-}
$$

$\log \mathrm{K}=-8.93 \pm 0.16 ;$ and $(5)$

$$
\mathrm{PuO}_{2}(\mathrm{OH})_{4}^{3-}+2 \mathrm{CO}_{3}^{2-} \rightleftarrows \mathrm{PuO}_{2}(\mathrm{OH})_{4}\left(\mathrm{CO}_{3}\right)_{2}^{7-}
$$

$\log K=1.13 \pm 0.20$ 
Reaction (4) was observed in pure concentrated ( 1 to $15 \mathrm{M}$ ) NaOH aqueous systems. The solid phase (poorly crystalline $\mathrm{PuO}_{2}$ ) was idenitified by $\mathrm{X}$-ray diffraction; and the solution species was identified as $\mathrm{Pu}(\mathrm{V})$ by spectrophotometric techniques. Reaction (5) was suggested by the enhanced solubility shown when large concentrations of $\mathrm{Na}_{2} \mathrm{CO}_{3}(0.25$ to $1.06 \mathrm{M}$ ) were included in 2.90 to $4.94 \mathrm{M} \mathrm{NaOH}$ solutions. No spectrophotometric or other check of the valence of the dissolved plutonium species was performed for the carbonate experiments. On the basis of the experiments in the "pure" $\mathrm{NaOH}$ solution, $\mathrm{Pu}(\mathrm{V})$ species were assumed in the $\mathrm{NaOH} / \mathrm{Na}_{2} \mathrm{CO}_{3}$ solutions.

Because of the large negative charge $(-7)$ on the $\mathrm{PuO}_{2}^{+}$central species and because $\mathrm{PuO}_{2}^{+}$has the lowest tendency towards complexation in aqueous media of any plutonium valence, the existence of the proposed mixed hydroxide/carbonate complex described in reactions (3) and (5) is unlikely. Spectrophotometric studies of $\mathrm{Pu}(\mathrm{V})$ in concentrated (1 to $2 \mathrm{M}^{2} \mathrm{Na}_{2} \mathrm{CO}_{3}$ (Varlashkin et al. 1984) show that as $\mathrm{NaOH}$ concentration increases stepwise from 0.04 to 1.04 to 1.75 to $2.29 \mathrm{M}$, the Pu(V) spectra change to resemble closely but not identically the spectra observed in $4 \mathrm{M} \mathrm{NaOH}$ (Bourges 1972) and $15 \mathrm{M} \mathrm{NaOH}$ (Delegard 1985) having no added carbonate. Therefore, the observations of Varlashkin et al. (1984) also give evidence for the decreasing stability of possible $\mathrm{Pu}(\mathrm{V})$ carbonate complexes as $\mathrm{NaOH}$ concentrations increase.

Based on the research of Yamaguchi et al. (1994), the original experimental data of Delegard (1985) were re-examined. The enhanced solubility of plutonium observed in the presence of carbonate was calculated to be the difference between the total measured plutonium solution concentration and the concentration expected solely by hydrolysis reaction (4).

Solubility was observed to change as a function of time (Delegard 1985); therefore, the solubility caused by reaction (4) in the pure $\mathrm{NaOH}$ system was calculated based on the data taken at 153 days' equilibration. This equilibration time closely matched the 156-day equilibration time allowed for the $\mathrm{NaOH} / \mathrm{Na}_{2} \mathrm{CO}_{3}$ system. Using data taken from Table A-1 of Delegard (1985), the plutonium solution concentration caused by the $\mathrm{Pu}(\mathrm{V})$ hydroxide complex was calculated. The calculated solubility caused by reaction (4) can be described accurately $\left(R^{2}=0.996\right)$ by the function:

$$
\log [\mathrm{Pu}]=1.997 \log (\mathrm{NaOH})-7.543
$$

where [ ] indicates molal concentrations and () indicates chemical activities.

The data in Table 4-4 are derived from Table A-6 of Delegard (1985). The contribution of the $\mathrm{Pu}(\mathrm{V})$ hydroxide complex concentration (designated $[\mathrm{PuOH}]$ in Table 4-4) to the total solution concentration (designated [Pu]) was determined by equation (6). The amount of plutonium solution concentration attributed to the carbonate complex (that is, $\left[\mathrm{PuCO}_{3}\right]$ ) was 
calculated as the difference between the total concentration and the concentration due to the hydroxide complex:

$$
\left[\mathrm{PuCO}_{3}\right]=[\mathrm{Pu}]_{\mathrm{t}}-[\mathrm{PuOH}]
$$

The calculated plutonium carbonate complex concentration can be plotted versus the carbonate chemical activity $\left(\mathrm{a}_{\mathrm{N}_{22} \mathrm{CO} 3}\right)$; the slope of the plot should be proportional to the ligand:metal $\left(\mathrm{CO}_{3}^{2-}: \mathrm{Pu}\right)$ ratio. Such a plot for the data derived from Delegard (1985) is shown in Figure 4-11. Figure 4-11 also gives data obtained by Yamaguchi et al. (1994). In the case of the Yamaguchi et al. (1994) data, where total ionic strength was limited to 0.1 molal (m), the molar (M) concentrations of plutonium were assumed to be equal to their molal concentrations and the carbonate molar concentrations were assumed to be equal to their activities.

Figure 4-11. Effect of Carbonate on Plutonium Compound Solubility.

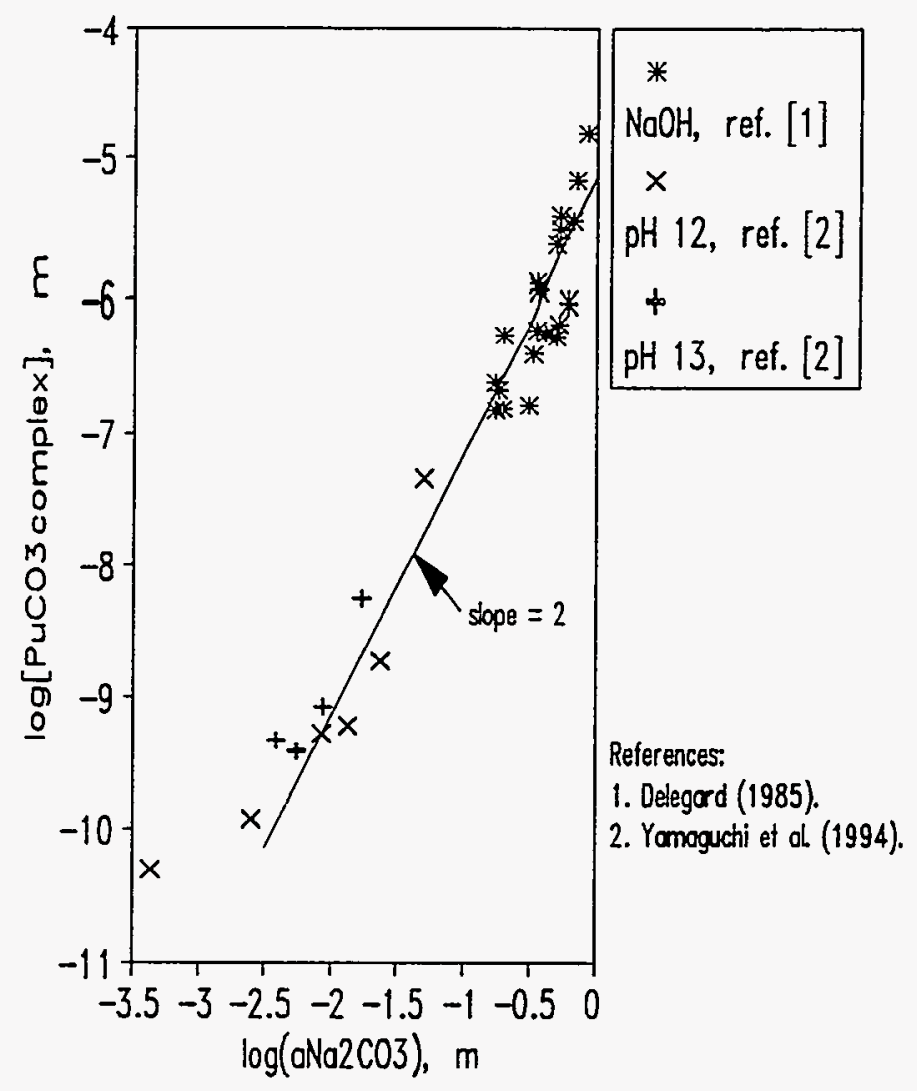




\section{WHC-EP-0882}

Table 4-4. Experimental and Derived Data for Plutonium Compound Solubility in the $\mathrm{NaOH} / \mathrm{Na}_{2} \mathrm{CO}_{3}$ Aqueous System.

\begin{tabular}{|c|c|c|c|c|c|c|c|}
\hline $4=$ & $4^{2}=0$ & 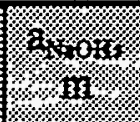 & 9 & togen?in: & 9ogrion & IggI & 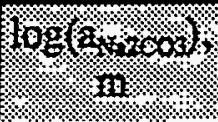 \\
\hline 2.90 & 0.701 & 2.39 & 0.416 & -6.124 & -6.788 & -6.230 & -0.381 \\
\hline 2.95 & 0.512 & 2.38 & 0.310 & -6.488 & -6.791 & -6.787 & -0.509 \\
\hline 2.95 & 0.912 & 2.45 & 0.522 & -6.058 & -6.766 & -6.153 & -0.282 \\
\hline 2.95 & 1.050 & 2.58 & 0.610 & -5.940 & -6.721 & -6.019 & -0.215 \\
\hline 2.96 & 0.261 & 2.46 & 0.172 & -6.377 & -6.763 & -6.607 & -0.764 \\
\hline 3.24 & 0.255 & 2.81 & 0.172 & -6.424 & -6.647 & -6.820 & -0.764 \\
\hline 3.47 & 0.515 & 3.18 & 0.335 & -6.157 & -6.540 & -6.389 & -0.475 \\
\hline 3.47 & 0.783 & 3.32 & 0.496 & -6.061 & -6.503 & -6.256 & -0.305 \\
\hline 3.94 & 0.515 & 3.92 & 0.347 & -5.975 & -6.359 & -6.207 & -0.460 \\
\hline 3.94 & 0.771 & 4.02 & 0.500 & -5.567 & -6.337 & -5.648 & -0.301 \\
\hline 3.99 & 1.060 & 4.29 & 0.673 & -5.421 & -6.280 & -5.486 & -0.172 \\
\hline 4.00 & 0.260 & 3.88 & 0.185 & -6.192 & -6.367 & -6.670 & -0.733 \\
\hline 4.43 & 0.513 & 4.85 & 0.362 & -5.745 & -6.174 & -5:947 & -0.441 \\
\hline 4.52 & 0.766 & 5.29 & 0.531 & -5.358 & -6.099 & -5.445 & -0.275 \\
\hline 4.69 & 1.060 & 5.76 & 0.712 & -5.118 & -6.025 & -5.175 & -0.148 \\
\hline 4.75 & 0.765 & 5.57 & 0.527 & -5.421 & -6.054 & -5.536 & -0.278 \\
\hline 4.80 & 0.484 & 5.61 & 0.354 & -5.674 & -6.048 & -5.913 & -0.451 \\
\hline 4.85 & 0.250 & 5.57 & 0.194 & -5.983 & -6.054 & -6.805 & -0.712 \\
\hline 4.89 & 1.050 & 6.72 & 0.852 & -4.779 & -5.891 & -4.814 & -0.070 \\
\hline 4.94 & 0.257 & 5.78 & 0.201 & -5.816 & -6.022 & -6.239 & -0.697 \\
\hline
\end{tabular}

The effect of carbonate on the plutonium solubility observed in the data derived from Delegard (1985) is consistent with the effect carbonate has on plutonium solubility on the pH 12 and 13 data of Yamaguchi et al. (1994) (see Figure 4-11). The data also are 
consistent with a $2: 1$ ratio in the postulated $\mathrm{CO}_{3}^{2-}: \mathrm{Pu}(\mathrm{IV})$ complex. The coincidence of these results and the carbonate complexation reactions proposed by Yamaguchi et al. (1994) suggest that a similar mechanism and complex operates in the $\mathrm{NaOH} / \mathrm{Na}_{2} \mathrm{CO}_{3}$ system.

Further confirmation tests were attempted, based on spectrophotometric verification of $\mathrm{Pu}(\mathrm{IV})$ in aqueous $\mathrm{NaOH} / \mathrm{Na}_{2} \mathrm{CO}_{3}$ solutions. To ensure initial formation of a $\mathrm{Pu}$ (IV) carbonate complex, $\mathrm{Pu}(\mathrm{IV})$-spiked $1.0 \mathrm{M} \mathrm{NaHCO}_{3}$ solutions were prepared to give approximately $1.7 \times 10^{-4} \mathrm{M} \mathrm{Pu}$ final concentration. All the plutonium spike dissolved. The resulting solution spectrum matched spectra of $\mathrm{Pu}(\mathrm{IV})$ in $1 \mathrm{M} \mathrm{NaHCO}_{3}$ previously published (Wester and Sullivan 1983 and Varlashkin et al. 1984). The molar absorptivity of the prominent $487 \mathrm{~nm}$ peak was approximately $70 \mathrm{~L} / \mathrm{cm}$-mol (versus approximately $90 \mathrm{~L} / \mathrm{cm}-\mathrm{mol}$ found by Wester and Sullivan [1983] and Varlashkin et al. [1984]).

Sufficient 50 percent $\mathrm{NaOH}$ solution was added to this solution to make the resulting solution $4.1 \mathrm{M} \mathrm{NaOH}$ and $0.80 \mathrm{M} \mathrm{Na}_{2} \mathrm{CO}_{3}$. Grass green plutonium solids formed immediately. After mixing and centrifuging for clarification, absorption spectra were gathered. Spectra also were obtained for solutions of $4.7 \mathrm{M} \mathrm{NaOH}$ and $1.2 \mathrm{M} \mathrm{Na}_{2} \mathrm{CO}_{3}$ to which $\mathrm{Pu}$ (IV) spike was added. Green plutonium solids precipitated immediately on introduction of the Pu(IV) spike. Finally, spectra were obtained for $\mathrm{Pu}(\mathrm{IV})$-spiked solutions of $4.7 \mathrm{M} \mathrm{NaOH}$ and $1.2 \mathrm{M} \mathrm{Na}_{2} \mathrm{CO}_{3}$ which were made approximately $0.1 \mathrm{M}$ in hydroxylamine $\left(\mathrm{NH}_{2} \mathrm{OH}\right)$ as a reductant.

The plutonium spectra obtained in all highly alkaline solutions were weak. Assignment of peaks was complicated by the possible existence of several dissolved plutonium species (for example, the Pu(V)-hydroxide complex, possible Pu(V)-carbonate complexes, as well as the $\mathrm{Pu}(\mathrm{IV})$-carbonate complex being sought). Summaries of the spectral observations are given in Table 4-5.

Table 4-5. Spectral Features for $\mathrm{Pu}$ in $\mathrm{NaOH} / \mathrm{Na}_{2} \mathrm{CO}_{3}$ Solutions.

\begin{tabular}{|c|c|c|c|c|c|c|}
\hline \multirow{2}{*}{ 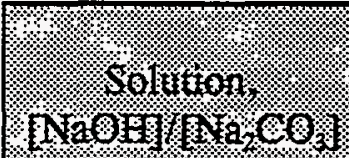 } & \multirow{2}{*}{ 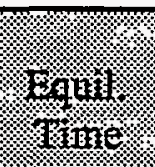 } & \multicolumn{5}{|c|}{ 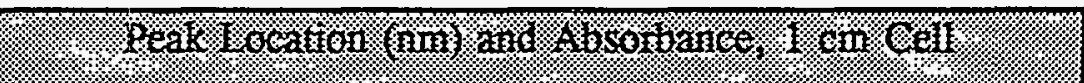 } \\
\hline & & 460.170 & & 9 & $609 \div 20$ & 400,50 \\
\hline $4.1 / 0.8$ & $10 \mathrm{~min}$. & 0.003 & 0.0015 & 0.0008 & 0.003 & 0.001 \\
\hline $4.1 / 0.8$ & $10 \mathrm{~min}$. & 0.005 & 0.001 & 0.0005 & 0.004 & 0.0008 \\
\hline $4.7 / 1.2$ & 82 days & 0.0005 & 0.0001 & ND & ND & ND \\
\hline $4.7 / 1.2-\mathrm{NH}_{2} \mathrm{OH}$ & $10 \mathrm{~min}$. & 0.006 & 0.0015 & 0.0008 & ND & ND \\
\hline $4.7 / 1.2-\mathrm{NH}_{2} \mathrm{OH}$ & $30 \mathrm{~min}$. & 0.007 & 0.002 & 0.001 & ND & ND \\
\hline $4.7 / 1.2-\mathrm{NH}_{2} \mathrm{OH}$ & 2 hours & 0.005 & 0.0015 & 0.001 & ND & ND \\
\hline
\end{tabular}

Note:

ND: not detectible; $<0.0001$ absorbance unit. 
The most prominent peak, observed in all spectra, occurred around $1170 \mathrm{~nm}$. This peak generally was accompanied by a doublet, observed in the near infrared region and centered around 980 and $950 \mathrm{~nm}$. Broad absorbance peaks were found in the visible region (at 490 to $550 \mathrm{~nm}$ and 600 to $700 \mathrm{~nm}$ ) for the tests in $4.0 \mathrm{M} \mathrm{NaOH}$ and $0.8 \mathrm{M} \mathrm{Na}_{2} \mathrm{CO}_{3}$. The peaks observed around 600 to $700 \mathrm{~nm}$ were approximately as intense as the peak at $1170 \mathrm{~nm}$.

For the sample aged 82 days and for all the samples to which hydroxylamine reductant had been added, no spectral features were observed in the visible region (below $800 \mathrm{~nm}$ ). Because Pu(V) solution species should not exist in the presence of hydroxylamine and the peaks appearing in the visible region disappeared when hydroxylamine was added, the peaks observed in the visible region were probably caused by $\mathrm{Pu}(\mathrm{V})$. The absence of peaks in the visible region for the aged sample implies that $\mathrm{Pu}(\mathrm{V})$ dissolved species do not contribute significantly to the plutonium solution concentration. According to the solubility data in Table 4-4, the expected concentration of the Pu(V)-hydroxide complex would be approximately 10 percent as much as the plutonium carbonate complex.

In summary, these limited experiments give evidence for the existence, in aged strongly alkaline solution, of $\mathrm{Pu}(\mathrm{IV})$-carbonate complexes but not of $\mathrm{Pu}(\mathrm{V})$-carbonate complexes. Further experiments are required to determine more confidently the existence and behavior of possible $\mathrm{Pu}(\mathrm{IV})$-carbonate complexes in highly alkaline solution. One such experiment would be the determination of $\mathrm{Pu}^{(\mathrm{IV})} \mathrm{O}_{2} \cdot \mathrm{xH}_{2} \mathrm{O}$ solubility in mixed $\mathrm{NaOH} / \mathrm{Na}_{2} \mathrm{CO}_{3}$ solutions in the presence of reductants.

\subsection{WORK WITH THE UNIVERSITY OF IDAHO PLASMA LABORATORY}

Engineering lab scale calcination studies of simulated Hanford Site tank wastes were conducted at the University of Idaho under the direction of Professor Patrick Taylor. Mr. R. S. Goheen of the Pacific National Laboratory coordinated the work. Results of the studies have been reported (Goheen et al. 1995).

In the University of Idaho tests, the kinetics of fundamental calcination chemical reactions; nitrate/nitrite decomposition, conversion of $\mathrm{Al}(\mathrm{OH})_{3}$ to $\mathrm{NaAlO}_{2}$, oxidation of $\mathrm{Cr}(\mathrm{OH})_{3}$ to form $\mathrm{CrO}_{4}^{2-}$, and organic carbon destruction; were investigated as functions of calciner power and residence time. A 50-kilowatt nontransferred plasma torch was used to provide the rapid heating required for the tests. The nontransferred torch means the plasma arc does not pass through the material to be heated. Instead, gas heated by the plasma arc is used to transfer heat to the waste. This heat transfer method is identical to that used in earlier pilot-scale calcination tests of tank 101-SY simulant waste conducted in November 1992 and November 1993 at the Westinghouse Science and Technology Center in Waltz Mill, Pennsylvania (Delegard et al. 1994b).

The principal investigator provided information to the researchers at the University of Idaho on compositions of candidate Hanford Site waste simulants, analytical methods, and goals of $\mathrm{C} / \mathrm{D}$ processing. He also visited the laboratory at the Idaho campus for discussions with 
Professor Taylor and his staff, reviewed the interim and final reports, and arranged a technical seminar by the investigator (on C/D chemistry) and Professor Taylor (on the plasma reactor results) at the Hanford Site for Tank Waste Remediation System program managers and engineers. Tank Waste Remediation System funding of the plasma calciner tests was terminated on 31 January 1995 with the publication of the test results (Goheen et al. 1995).

\subsection{TECHNICAL PAPERS}

An external release document on laboratory studies of $C / D$ processing of genuine Hanford Site tank wastes from tanks 104-T and 111-T (from the bismuth phosphate process) and tank 102-SY (from the Plutonium Finishing Plant) was prepared and issued in January 1995 (Delegard 1995b). The document also compared the new results with results from earlier studies of the C/D of tank 101-SY (a complexant concentrate), tank 104-S (a REDOX process sludge), and tank 107-BX (another bismuth phosphate process waste).

Contributions were made to a paper on plutonium compound solubility in alkaline solution prepared for the 19th Annual Actinide Separations Conference in June 1995 (Rao et al. 1995).

A paper summarizing the laboratory studies of $C / D$ over the past several years has been accepted for presentation at the Tank Waste Chemistry symposium of the Industrial and Engineering Chemistry Division of the 211th national meeting of the American Chemical Society in March 1996 (Delegard 1995a). 
WHC-EP-0882

\subsection{ACKNOWLEDGEMENTS}

The author would like to thank Judy Watts, Jeff Chenault, Jerry Kunkel, and especially

Wayne Edmonson for able assistance in the laboratory. 
WHC-EP-0882

This page intentionally left blank. 


\subsection{REFERENCES}

Bamey, G. S., 1976, Vapor-Liquid-Solid Phase Equilibria of Radioactive Sodium Salt Wastes at Hanford, ARH-ST-133, Atlantic Richfield Hanford Company, Richland, Washington.

Bourges, J., 1972, "Preparation et Identification du Plutonium a l'Etat d'Oxydation-V en Mileau Basique," Radiochemical Radioanalytical Letters 12, pp. 111-116.

Bratsch, S. G., 1989, "Standard Electrode Potentials and Temperature Coefficients in Water at 298.15 K," Journal of Physical and Chemical Reference Data 18(1), pp. 1-21.

Chernyaev, I. I., 1966, Complex Compounds of Uranium, translation of Kompleksnye Soedineniya Urana, by Israel Program for Scientific Translations Ltd., Jerusalem, Israel, pp. 38-54.

Cohen, D., and S. Fried, 1969, "Some Observations on the Chemistry of Neptunium in Basic Solution," Inorganic Nuclear Chemistry Letters 5, pp. 653-663.

Delegard, C. H., 1985, Solubility of $\mathrm{PuO}_{2} \cdot \mathrm{xH}_{2} \mathrm{O}$ in Alkaline Hanford High-Level Waste Solution, RHO-RE-SA-75 P, Rockwell Hanford Operations, Richland, Washington.

Delegard, C. H., A. M. Stubbs, and S. D. Bolling, 1993, Laboratory Testing of Ozone Oxidation of Hanford Site Waste from Tank 241-SY-101, WHC-EP-0701, Westinghouse Hanford Company, Richland, Washington.

Delegard, C. H., T. D. Elcan, and B. E. Hey, 1994a, Chemistry of Application of Calcination/Dissolution to the Hanford Tank Waste Inventory, WHC-EP-0766, Westinghouse Hanford Company, Richland, Washington.

Delegard, C. H., R. F. Creed, and D. W: Hendrickson (Westinghouse Hanford Company) and D. F. McLaughlin (Westinghouse Science and Technology Center) 1994b, Calcination/Dissolution Process Development 1994, WHC-SP-1093, Rev. 0, Westinghouse Hanford Company, Richland, Washington.

Delegard, C. H., 1995a, Calcination/Dissolution Treatment of Hanford Site Tank Waste, WHC-SA-2911-A, Westinghouse Hanford Company, Richland, Washington.

Delegard, C. H., 1995b, Chemistry of Proposed Calcination/Dissolution Processing of Hanford Site Tank Wastes, WHC-EP-0832, Westinghouse Hanford Company, Richland, Washington. 
Delegard, C. H., 1995c, Liaison Activities with the Institute of Physical Chemistry, Russian Academy of Science: FY 1995, WHC-SP-1166, Westinghouse Hanford Company, Richland, Washington.

Felmy, A. R., D. Rai, and R. W. Fulton, 1994, The Solubility of $\mathrm{Cr}(\mathrm{OH})_{3}(\mathrm{am})$ in Concentrated $\mathrm{NaOH}$ and $\mathrm{NaOH}-\mathrm{NaNO}_{3}$ Solutions, PNL-SA-24027, Pacific Northwest Laboratory, Richland, Washington.

Goheen, R. S. (Battelle Pacific Northwest Laboratories), P. R. Taylor, S. A. Pirzada, and M. Manrique (College of Mines, University of Idaho), 1995, Thermal Reconstitution of a Hanford Tank Waste Simulant via Plasma Calcination, TWRSPP-95-003, Battelle Pacific Northwest Laboratory, Richland, Washington.

Herting, D. L., D. B. Bechtold, B. E. Hey, B. D. Keele, L. Jensen, and T. L. Welsh, 1992, Laboratory Characterization of Samples Taken in December 1991 (Window E) from Hanford Waste Tank 241-SY-101, WHC-SD-DTR-026, Rev. 0, Westinghouse Hanford Company, Richland, Washington.

Hudson, L. K., 1987, "Alumina Production," in Production of Aluminum and Alumina, A. R. Burkin, (ed.), Critical Reports on Applied Chemistry, Vol. 20, John Wiley \& Sons, Inc., Chichester, UK.

Kirk-Othmer, 1981, Kirk-Othmer Encyclopedia of Chemical Technology, $3^{\text {rd }}$ Edition, Vol. 6, "Chromium Compounds," John Wiley \& Sons, Inc., New York, New York, pp. 88-89.

Kirk-Othmer, 1993, Kirk-Othmer Encyclopedia of Chemical Technology, $4^{\text {th }}$ Edition, Vol. 6, "Chromium Compounds," John Wiley \& Sons, Inc., New York, New York, p. 283.

Musikas, C., 1976, "Contribution to the Study of U(V) Ions and Pentavalent Transuranics in Aqueous Solution," in Proceedings of the Moscow Symposium on the Chemistry of the Transuranium Elements, V. I. Spitsyn and J. J. Katz, eds., Supplement to the Journal of Inorganic and Nuclear Chemistry, pp. 171-177, Pergamon Press, Oxford, UK.

Oelschläger, W., 1955, "Bestimmung kleinster Chromgehalte aus salzsaurer Lösung," $Z$. anal. Chem. 145, pp. 81-88.

Peretrukhin, V. F., V. P. Shilov, and A. K. Pikaev, 1995, Alkaline Chemistry of Transuranium Elements and Technetium and the Treatment of Alkaline Radioactive Wastes, WHC-EP-0817, Westinghouse Hanford Company, Richland, Washington.

Rao, L., A. R. Felmy, D. Rai, C. H. Delegard, 1995, Thermodynamic Modelling of the Solubility of $\mathrm{PuO}_{2} \cdot \mathrm{xH}_{2} \mathrm{O}$ (am) in Alkaline Hanford Waste Solutions, PNL-SA-26055, Battelle Pacific Northwest Laboratories, Richland, Washington. 
Sandell, E. B., 1959, Colorimetric Determination of Trace Metals, $3^{\text {rd }}$ Edition, Interscience Publishers, Inc., New York, New York, pp. 388-397.

Varlashkin, P. G., G. M. Begun, and J. R. Peterson, 1984, "Electrochemical and Spectroscopic Studies of Plutonium in Concentrated Aqueous Carbonate and Carbonate-Hydroxide Solutions," Radiochimica Acta 35, pp. 211-218.

Wester, D. W., and J. C. Sullivan, 1983, "The Absorption Spectra of Pu(VI), -(V) and -(IV) Produced Electrochemically in Carbonate-Bicarbonate Media," Radiochemical and Radioanalytical Letters 57(1), pp. 35-42.

Wulfsberg, G., 1991, Principles of Descriptive Inorganic Chemistry, University Science Books, Mill Valley, California, p. 143.

Yamaguchi, T., Y. Sakamoto, and T. Ohnuki, 1994, "Effect of the Complexation on Solubility of Pu(IV) in Aqueous Carbonate System," Radiochimica Acta 66/67, pp. 9-14. 
WHC-EP-0882

This page intentionally left blank. 
WHC-EP-0882

APPENDIX A

RESULTS OF ESW AND C/D TESTS

OF WASTES FROM TANK 104-S

A-1 
WHC-EP-0882

This page intentionally left blank. 
C/D of lors wth NaNO3

ESW of 1045

\begin{tabular}{|c|c|c|c|c|c|c|c|c|c|c|c|c|}
\hline 104-S ESW & $\begin{array}{c}\text { Semple } \\
\text { DES104W/J2340 } \\
\text { DES104L/J2454 } \\
\text { DES104P/J231 }\end{array}$ & $\begin{array}{l}\text { Tmo } \\
\text { Wash } \\
\text { Loench } \\
\text { Pinas }\end{array}$ & $\begin{array}{c}\text { WherueB4 } \\
14.137\end{array}$ & $\begin{array}{c}\text { Whansyn } \\
10.136\end{array}$ & VW/NO3 & Wirizec & WhBSOC & $\begin{array}{r}\text { WTub0 } \\
13.070 \\
14.300 \\
14.054\end{array}$ & $\begin{array}{l}\text { Whibol } \\
62.264 \\
47.160 \\
45.010\end{array}$ & WhoncAft & CrusWtL & Cralloss \\
\hline 104-s/co & $\begin{array}{l}1045 C O N J 2350 \\
104 S C D B / J 2351\end{array}$ & $\mathbf{2 0}$ & 03727 & 73.738 & 80.888 & 75.273 & 72620 & $\begin{array}{l}14.081 \\
14.061 \\
14.061\end{array}$ & $\begin{array}{l}48.978 \\
35.026 \\
25.032\end{array}$ & 02722 & 0.006 & 0.000 \\
\hline
\end{tabular}

104S/ESW

DES10aw/J23 DES1OA4J2454

DES104PJ234

$104-8 / C 0$

$104900 N J 2350$ 1048CDB/J2351

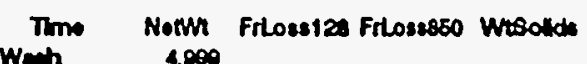

Wiah 4.009

Louch

4.000

4.000
4.000

$20 \quad 10.0110$

10.0110
10.0110

$0.3272 \quad 0.4870 \quad 0.7000$$$
\text { NO2 }
$$

NO2 NOS

NOS OH

104-8/ESW DESIOAW/J234 OES1OAN2AS4 DES1OARJIES

$104-6 / C 0$

$1045 C D N J 2350$ 104SCDB/J2351

Trmo
Womh
losch
Pinses
(ughim) (uglmu) (ughthl)

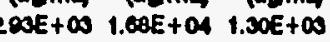

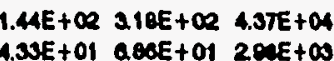

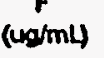

1.

1.

$207.67 E+04$ a.60E+04 $2.00 E+\infty$

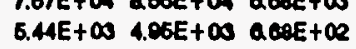

$265+01$

Whoth won

30.285
3270

30.056

Onytub Whorysa

0.468

32364 20.000

14.54

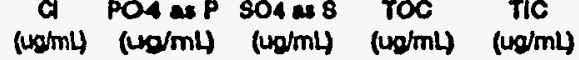
$267 E+\infty \quad 1.10 E+\infty \quad 331 E+\infty 2 \quad 242 E+\infty$ $\begin{array}{llll}1.12 E+01 & 0.62 E+01 & 1.42 E+\infty\end{array}$ $3.60 E+01$ 2.30E+01

$\begin{array}{lll}\text { A.1EE+01 } & 0.70 E+01 & 2.00 E+\infty \\ 4.70 E+01\end{array}$

\section{8mpoto}

$104-8$

Enh.siWathe

NaNOS

1048/EBW

1048/NaNOS
1048/E8W

Thro

mLool'n.

de $g$ samplo

4.451045

.246897

2504602

4.000 gSha chotgNLOHANO2

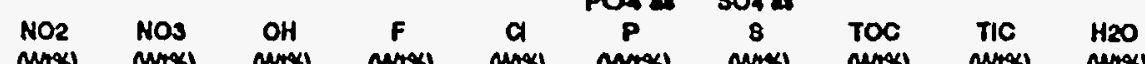

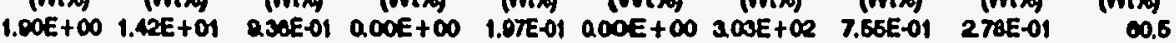

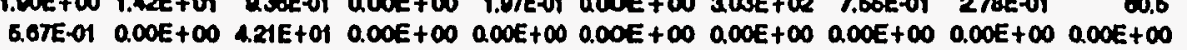

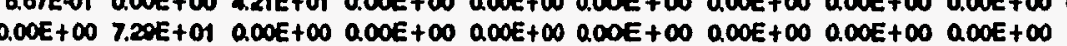

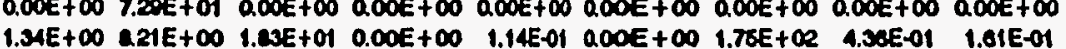

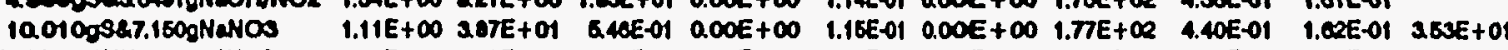

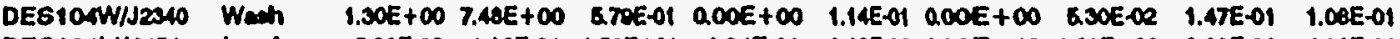

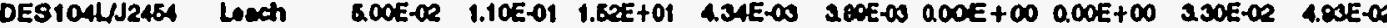

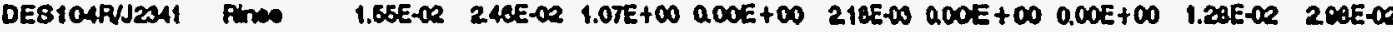

Bum EnhsiWeah

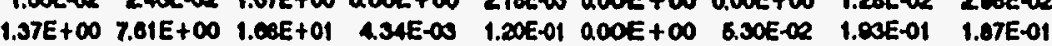

104-8KD TOLSCONJ2360

$1045 C D B / J 2351$

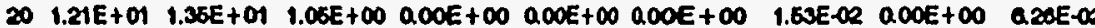

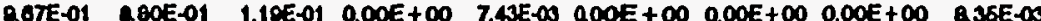

$1.30 E+01 \quad 1.43 E+01 \quad 1.17 E+\infty \quad 0.00 E+\infty \quad 7.43 E-\infty 00000+\infty \quad 1.53 E-\infty 80.00 E+\infty \quad 7.10 E-\infty$

Sum C/D 1048

$1.02 E+\infty$ Q.28E-01 Q1TE-01

ERA $1.005+\infty$

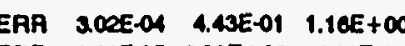

Frect Diws. - ESW
Frect Dias. - C/D

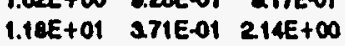

ERP Q $40 E D$

ERA $\triangle 03 E-05 \quad 0.00 E+\infty \quad 4.30 E-01$ 


\section{WHC-EP-0882}

This page intentionally left blank. 


\begin{tabular}{|c|c|c|c|c|c|c|c|c|c|c|c|c|c|}
\hline 104S/EBW & $\begin{array}{l}\text { Smplo } \\
\text { DEs104W/J2340 } \\
\text { DES1044/J2464 } \\
\text { DE8104P/J2341 }\end{array}$ & $\begin{array}{l}\text { Timo } \\
\text { Wmh } \\
\text { Losech } \\
\text { Pines }\end{array}$ & $\begin{array}{c}N E \\
(u g / m L) \\
0.76 E+\infty 3 \\
0.03 E+04 \\
4.23 E+\infty 0\end{array}$ & $\begin{array}{c}N \\
(u g / m L) \\
5.20 E+\infty \\
2.15 E+\infty \\
3.05 E+\infty\end{array}$ & $\begin{array}{c}81 \\
(40 / m 4) \\
1.41 E+01 \\
7.64 E+01 \\
2.60 E+\infty\end{array}$ & $\begin{array}{l}\text { loss thens } \\
\text { Fo } \\
\text { (ug/mL) } \\
200 E-01 \\
200 E-01 \\
200 E-01\end{array}$ & $\begin{array}{c}c r \\
(u g / m 4) \\
200 E+\infty \\
203 E+\infty \\
264 E-01\end{array}$ & $\begin{array}{c}\text { ESW } \\
\text { hosthens } \\
\text { Mn } \\
(u g / m L) \\
200 E-01 \\
200 E-01 \\
200 E-01\end{array}$ & $\begin{array}{c}\text { lessthens } \\
\text { NI } \\
\text { (ug/mL) } \\
4.00 E-01 \\
4.00 E-01 \\
4.00 E-01\end{array}$ & $\begin{array}{c}S \\
(u g / m 4) \\
3.63 E+01 \\
1.20 E+\infty\end{array}$ & $\begin{array}{l}\text { lose thens } \\
\text { Ca } \\
\text { (ug/mL) } \\
200 E-01 \\
200 E-01 \\
200 E-01\end{array}$ & $\begin{array}{c}U \\
(u 0 / m L) \\
<.000037 \\
4.48 E-01 \\
3.30 E-\infty 2\end{array}$ & $\begin{array}{c}K \\
(u g / m l) \\
201 E+01\end{array}$ \\
\hline 104S/CD & $\begin{array}{l}\text { 104SCDNJ2350 } \\
\text { 104SCDB/J2351 }\end{array}$ & 20 & $\begin{array}{l}2.72 E+04 \\
5.65 E+\infty\end{array}$ & $\begin{array}{l}217 E+04 \\
1.72 E+\infty\end{array}$ & $\begin{array}{l}3.68 E+02 \\
1.30 E+01\end{array}$ & $\begin{array}{l}200 E-01 \\
200 E-01\end{array}$ & $\begin{array}{l}5.43 E+\infty 2 \\
3.63 E+01\end{array}$ & $\begin{array}{l}2.34 E+01 \\
2.52 E+\infty\end{array}$ & $\begin{array}{l}4.00 E-01 \\
4.00 E-01\end{array}$ & $\begin{array}{l}9.83 E+01 \\
6.72 E+\infty 0\end{array}$ & $\begin{array}{l}200 E-01 \\
200 E-01\end{array}$ & $\begin{array}{l}0.51 E+01 \\
7.52 E+\infty\end{array}$ & $3.97 E+\infty$ \\
\hline $\begin{array}{l}\text { 1048 } \\
\text { Enh.SLWaghes } \\
\text { NaNOS } \\
\text { 104S/ESW } \\
\text { 104S/NaNOS } \\
\text { 1048/ESW }\end{array}$ & 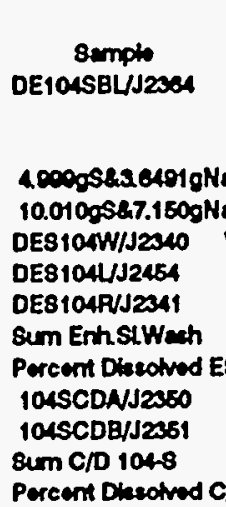 & 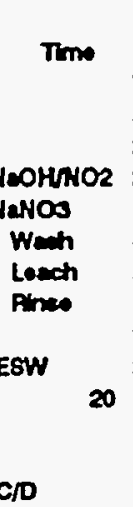 & $\begin{array}{c}N E \\
(W h(x) \\
7.00 E++\infty \\
6.73 E+01 \\
271 E+01 \\
282 E+01 \\
1.54 E+01 \\
4.34 E+\infty \\
200 E+01 \\
1.62 E+\infty \\
268 E+01 \\
270 E+01 \\
1.37 E+01 \\
1.00 E+\infty \\
1.47 E+01 \\
1.62 E+01\end{array}$ & $\begin{array}{c}N \\
(W 1 X) \\
2.78 E+\infty \\
0.00 E+\infty \\
0.00 E+\infty \\
3.22 E+\infty \\
3206+\infty \\
236 E-01 \\
213 E+\infty \\
1.42 E-01 \\
251 E+\infty \\
1.24 E+\infty \\
241 E+\infty \\
306 E-01 \\
2.72 E+\infty \\
100 E+\infty\end{array}$ & 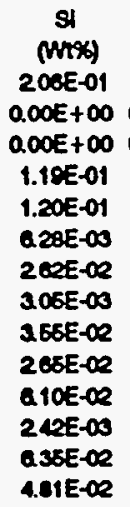 & 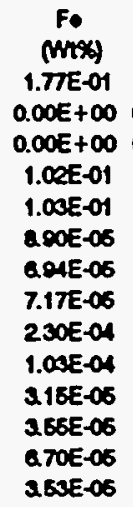 & 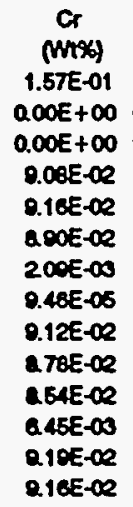 & $\begin{array}{c}\text { Mn } \\
(M n \times) \\
7.06 E-02 \\
0.00 E+\infty \\
0.00 E+\infty \\
4.00 E-02 \\
1.64 E-02 \\
6.00 E-06 \\
6.04 E-06 \\
7.17 E-06 \\
230 E-04 \\
1.26 E-04 \\
1.31 E-02 \\
2.26 E-04 \\
1.37 E-02 \\
2.15 E-00\end{array}$ & 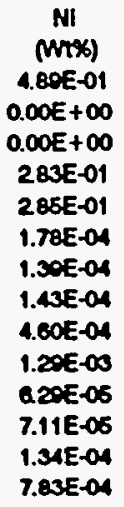 & 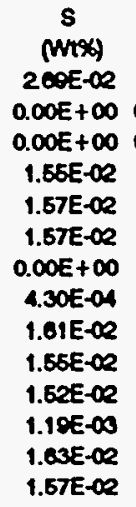 & 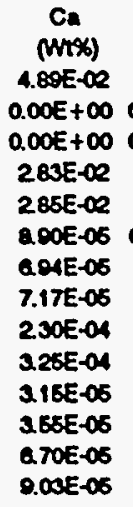 & $\begin{array}{c}U \\
m(x) \\
246 E-01 \\
0.00 E+\infty \\
0.00 E+\infty 0 \\
1.42 E-01 \\
1.44 E-01 \\
0.00 E+\infty \\
1.66 E-04 \\
1.18 E-\infty 5 \\
1.07 E-04 \\
7.76 E-\infty 5 \\
1.60 E-\infty \\
1.34 E-\infty \\
1.03 E-\infty 2 \\
1.27 E-\infty\end{array}$ & $\begin{array}{r}0.00 E+\infty \\
0.00 E+\infty \\
0.00 E+\infty \\
0.00 E+\infty \\
1.30 E-\infty \\
0.00 E+\infty \\
0.00 E+\infty \\
1.30 E-\infty 2 \\
0.00 E+\infty \\
0.00 E+\infty \\
T .06 E-04 \\
7.06 E-04 \\
0.00 E+\infty\end{array}$ \\
\hline & $\begin{array}{l}\text { Frect Dke. - ESW } \\
\text { Fract Dles. - C/D }\end{array}$ & $\begin{array}{l}\text { Wanh } \\
\text { Leach } \\
\text { Pinen }\end{array}$ & $\begin{array}{l}\text { O.40E-01 } \\
\text { O.50E-01 } \\
\text { Na } \\
16.0 \\
7.1 \\
5.6\end{array}$ & $\begin{array}{l}\text { Q.41E-01 } \\
0.41 E-01 \\
\begin{array}{r}\text { N } \\
4.4 \\
10.0 \\
27\end{array}\end{array}$ & $\begin{array}{r}200 E-01 \\
\text { L.26E-01 } \\
81 \\
30 \\
164 \\
1.0\end{array}$ & $\begin{array}{c}2.25 E-03 \\
6.40 E-0.4 \\
F 0 \\
0.0 \\
0.0 \\
0.0\end{array}$ & $\begin{array}{c}1.01 E+\infty \\
1.00 E+\infty 0 \\
C r \\
04.4 \\
22 \\
0.1\end{array}$ & $\begin{array}{c}\text { 5.01E-03 } \\
\text { 200E-01 } \\
\text { Mn } \\
0.1 \\
0.1 \\
0.1\end{array}$ & $\begin{array}{c}1.03 E-\infty \\
4.70 E-0.4 \\
N I \\
0.2 \\
0.1 \\
0.1\end{array}$ & $\begin{array}{c}1.04 E+\infty \\
1.04 E+\infty \\
5 \\
97.3 \\
0.0 \\
27\end{array}$ & $\begin{array}{l}\text { C. } \\
0.4 \\
0.3 \\
0.4\end{array}$ & $\begin{array}{l}u \\
0.0 \\
0.1 \\
0.0\end{array}$ & $\begin{array}{l}\text { EAR } \\
\text { ERA }\end{array}$ \\
\hline $\begin{array}{l}\text { Aorldens } \\
\text { 104-6/ESW } \\
\text { 104-S/CD }\end{array}$ & $\begin{array}{c}\text { 8mple } \\
\text { DESWB1/J2344 } \\
\text { DE104CD1/J2345 }\end{array}$ & $\begin{array}{r}0 \\
20\end{array}$ & $\begin{array}{c}N a \\
(\mu a / g) \\
3.81 E+04 \\
\text { Q.33E+O4 }\end{array}$ & $\begin{array}{c}A \\
(U 9 / 0) \\
310 E+\infty 5 \\
1.47 E+\infty 5\end{array}$ & $\begin{array}{c}S i \\
(u g / g) \\
1.36 E+04 \\
281 E+04\end{array}$ & $\begin{array}{c}F \bullet \\
(19 / 0) \\
251 E+04 \\
7.85 E+04\end{array}$ & $\begin{array}{c}\text { bes then } \\
C r \\
(40 / 9) \\
240 E+\infty \\
1.10 E-01\end{array}$ & $\begin{array}{c}M n \\
(u g / 9) \\
0.17 E+\infty \\
268 E+\infty\end{array}$ & $\begin{array}{c}N I \\
(u g / \theta) \\
1.10 E+04 \\
1.06 E+04\end{array}$ & $\begin{array}{c}s \\
(u g / g) \\
0.00 E+\infty \\
0.00 E+\infty\end{array}$ & $\begin{array}{c}C \\
(\cup 9 / 0) \\
217 E+\infty \\
246 E+\infty\end{array}$ & $\begin{array}{c}U \\
(u g / 0) \\
3.35 E+04 \\
1.54 E+04\end{array}$ & $\begin{array}{c}K \\
(\omega / Q / \alpha)\end{array}$ \\
\hline $\begin{array}{l}\text { 104-B/ESW } \\
\text { 104B/CD }\end{array}$ & 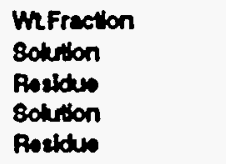 & 20 & $\begin{array}{c}N a \\
268 E-01 \\
3.48 E-\infty \\
1.47 E-01 \\
1.68 E-\infty\end{array}$ & $\begin{array}{c}N \\
251 E-\infty 2 \\
283 E-\infty 2 \\
3.72 E-\infty \\
367 E-\infty\end{array}$ & $\begin{array}{c}84 \\
2.56 E-04 \\
1.24 E-03 \\
0.36 E-04 \\
251 E-04\end{array}$ & $\begin{array}{c}F \bullet \\
230 E-06 \\
230 E-00 \\
270 E-07 \\
1.00 E-00\end{array}$ & $\begin{array}{c}C \\
2.12 E-04 \\
2.10 E-\infty 6 \\
2.19 E-04 \\
275 E-\infty\end{array}$ & $\begin{array}{c}\text { Mn } \\
230 E-06 \\
236 E-04 \\
1.37 E-04 \\
2.4 E-04\end{array}$ & $\begin{array}{c}N I \\
1.00 E-06 \\
1.00 E-\infty 6 \\
1.34 E-06 \\
4.87 E-04\end{array}$ & $\begin{array}{c}S \\
1.61 E-04 \\
0.00 E+\infty \\
1.63 E-04 \\
0.00 E+\infty\end{array}$ & $\begin{array}{c}\text { C. } \\
230 E-\infty 6 \\
1.06 E-01 \\
270 E-07 \\
211 E-01\end{array}$ & $\begin{array}{c}U \\
1.07 E-\infty 8 \\
200 E-\infty \\
1.00 E-\infty 4 \\
3.85 E-\infty 4\end{array}$ & $\begin{array}{c}K \\
1.30 E-04 \\
0.00 E+\alpha \\
7.00 E-\infty \\
0.00 E+\alpha\end{array}$ \\
\hline & $\begin{array}{l}\text { Frect Diss. ESW } \\
\text { FreetDins.C/D }\end{array}$ & & $\begin{array}{c}\text { Na } \\
\text { Q.87E-01 } \\
9.00 E-01\end{array}$ & $\begin{array}{c}N \\
\text { ATOE-08 } \\
\text { Q.10E-Ot }\end{array}$ & $\begin{array}{c}S 1 \\
222 E-01 \\
4.00 E-01\end{array}$ & $\begin{array}{c}F 0 \\
.00 E-\infty 0 \\
342 E-04\end{array}$ & $\begin{array}{c}C r \\
9.67 E-01 \\
1.00 E+\infty 0\end{array}$ & $\begin{array}{c}M n \\
274 E-\infty \\
1.70 E-01\end{array}$ & $\begin{array}{c}N ! \\
4.67 E-\infty \\
274 E-\infty\end{array}$ & $\begin{array}{c}S \\
1.00 E+\infty \\
1.00 E+\infty\end{array}$ & $\begin{array}{c}\text { Ca } \\
1.16 E-\infty \\
317 E-\infty\end{array}$ & $\begin{array}{c}\text { U } \\
\text { 5.4TE-04 } \\
200 E-01\end{array}$ & $\begin{array}{c}K \\
1.00 E+\alpha \\
1.00 E+\infty\end{array}$ \\
\hline
\end{tabular}




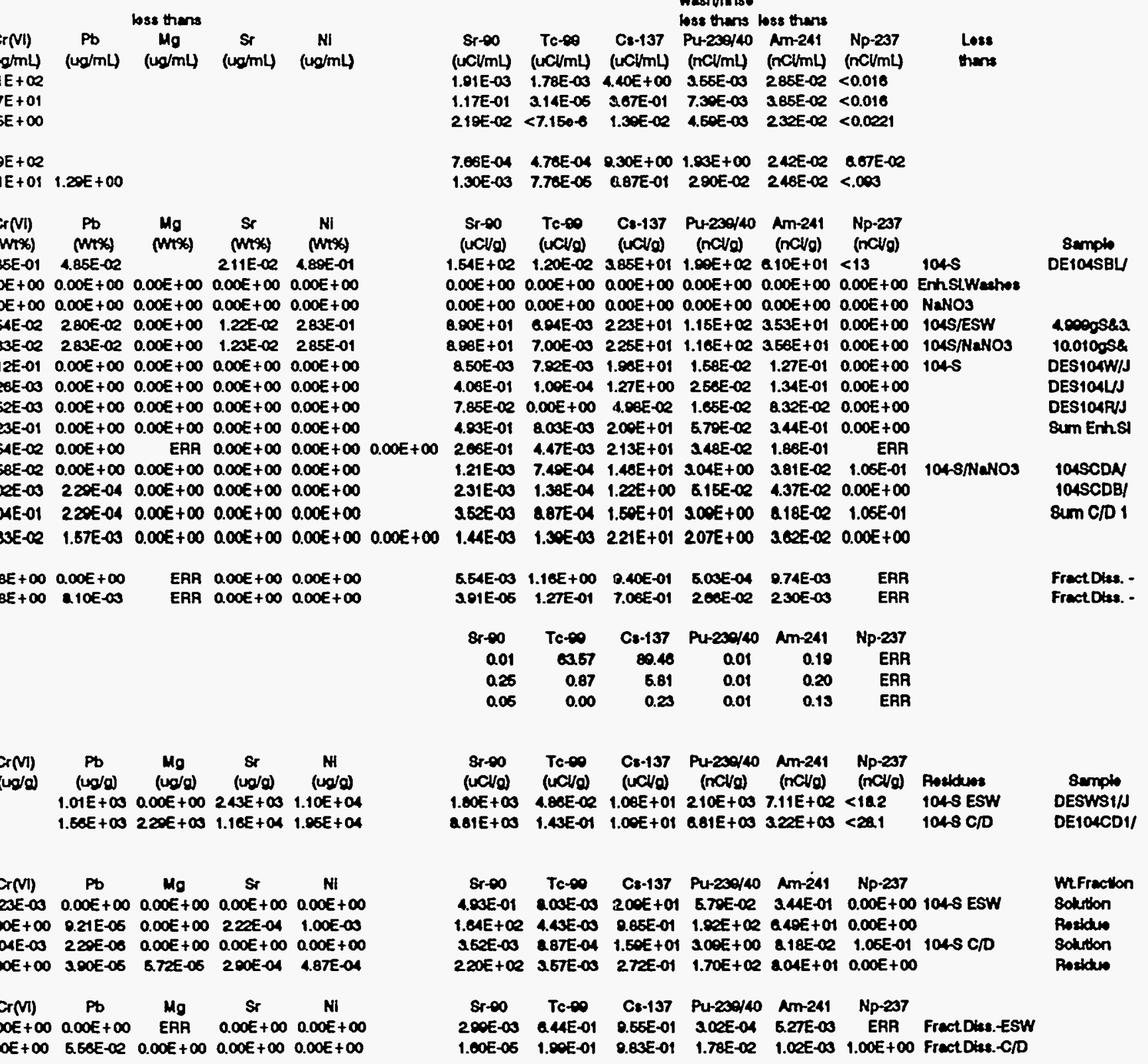


WHC-EP-0882

APPENDIX B

RESULTS OF ESW/PEROXIDE TESTS OF SIMULANT TANK 101-SY WASTE 
WHC-EP-0882

This page intentionally left blank. 
Chromium Hydroxide Dissolution from Sim. 101-SY: Cr(NI) Solution Measurements Notebook WHC-N-656 1; pp. 121-122

Standard calibration curve for Beer-Lambert relationship for chromate in $0.5 \mathrm{M} \mathrm{NaOH}$ @ $372 \mathrm{~nm}$.

\begin{tabular}{rrrr} 
Conc. (mM) & Absorbance & \multicolumn{1}{c}{ Fit } & Res.(Abs-Fit) \\
$9.99 E-01$ & & 4.999 & \\
$7.50 E-01$ & 3.755 & 3.751 & $4.31 E-03$ \\
$5.00 E-01$ & 2.490 & 2.499 & $-9.28 E-03$ \\
$2.50 E-01$ & 1.258 & 1.248 & $1.01 E-02$ \\
$1.50 E-01$ & 0.742 & 0.747 & $-5.32 E-03$ \\
$1.00 E-01$ & 0.492 & 0.497 & $-5.04 E-03$ \\
$7.50 E-02$ & 0.372 & 0.372 & $9.85 E-05$ \\
$5.00 E-02$ & 0.250 & 0.247 & $3.24 E-03$ \\
$3.00 E-02$ & 0.145 & 0.147 & $-1.65 E-03$ \\
$7.03 E-04$ & & 0.000 & \\
$0.00 E+00$ & 0.000 & & \\
& & &
\end{tabular}

\begin{tabular}{lr}
\multicolumn{2}{c}{$\quad$ Regression Output: } \\
in $0.5 \mathrm{M} \mathrm{NaOH} @ 372 \mathrm{~nm}$. \\
Constant & 0.000703 \\
Std Err of Y Est & 0.001278 \\
R Squared & 0.999978 \\
No. of Observations & 9 \\
Degrees of Freedom & 7
\end{tabular}

Leach tests from tank 101-SY simulant; results

\begin{tabular}{|c|c|c|c|c|c|c|c|c|c|}
\hline & Series A & Series B & Series C & Series D & & & & & \\
\hline Wt. sample & 17.065 & 17.129 & 17.192 & 17.116 & & & & & \\
\hline Total Cr (g) & 6.997E-02 & 7.023E-02 & 7.049E-02 & 7.018E-02 & & & & & \\
\hline Tot $\mathrm{Cr}(\mathrm{mol})$ & $1.346 \mathrm{E}-03$ & $1.351 E-03$ & 1.356E-03 & $1.350 \mathrm{E}-03$ & & & & & \\
\hline [Cr]diss.(M) & $1.324 \mathrm{E}-01$ & 1.322E-01 & 1.303E-01 & $1.261 \mathrm{E}-01$ & & & & & \\
\hline$[\mathrm{Cr}]$ cuvet(mM) & $1.104 \mathrm{E}-03$ & 1.101E-03 & $1.086 \mathrm{E}-03$ & $1.051 E-03$ & & & & & \\
\hline H2O2add(uL) & 60 & 120 & 300 & 600 & & & & & \\
\hline \multicolumn{2}{|c|}{ Leach solution measurements } & \multicolumn{4}{|c|}{ ABSORBANCE } & \multicolumn{4}{|c|}{ CONCENTRATION (mM) } \\
\hline & Time (h) & Series A & Series B & Series C & Series D & Series A & Series B & Series C & Series D \\
\hline \multirow[t]{7}{*}{ First Contact } & 0.5 & 0.207 & 0.230 & 0.359 & 0.503 & 4.21E-02 & 4.67E-02 & 7.24E-02 & 1.01E-01 \\
\hline & 1 & 0.257 & 0.342 & 0.572 & 0.842 & $5.20 \mathrm{E}-02$ & 6.90E-02 & 1.15E-01 & 1.69E-01 \\
\hline & 3 & 0.423 & 0.578 & 1.088 & 1.474 & 8.52E-02 & 1.16E-01 & 2.18E-01 & 2.95E-01 \\
\hline & 25.75 & 0.735 & 1.054 & 1.748 & 2.180 & 1.48E-01 & 2.11E-01 & 3.50E-01 & 4.36E-01 \\
\hline & 139.25 & 0.845 & 1.204 & 1.786 & 2.245 & 1.70E-01 & 2.41E-01 & 3.58E-01 & 4.49E-01 \\
\hline & 307.75 & 0.836 & 1.209 & 1.795 & 2.293 & 1.68E-01 & 2.42E-01 & 3.59E-01 & 4.59E-01 \\
\hline & 361 & 0.863 & 1.229 & 1.862 & 2.366 & 1.73E-01 & $2.46 \mathrm{E}-01$ & 3.73E-01 & 4.73E-01 \\
\hline \multirow[t]{2}{*}{ 2nd Contact } & 431 & 1.526 & 2.095 & 2.798 & 3.126 & $3.06 \mathrm{E}-01$ & 4.19E-01 & 5.60E-01 & $6.25 \mathrm{E}-01$ \\
\hline & 70 & 0.663 & 0.866 & 0.936 & 0.760 & 1.33E-01 & $1.74 \mathrm{E}-01$ & 1.88E-01 & $1.53 \mathrm{E}-01$ \\
\hline
\end{tabular}


WHC-EP-0882

This page intentionally left blank. 
WHC-EP-0882

APPENDIX C

RESULTS OF ESW AND C/D TESTS OF

WASTES FROM TANK 101-SY

C-1 
WHC-EP-0882

This page intentionally left blank. 
ESW of 101-SY

ESW/PER of 101-SY

101.SYESW

DEIOISWW/J

DE101SYLJJ2458 Leach

DE101SYPJJ2457 Rinso

101-SY ESW/PE 1SYPERW/JZ637 Wash ISYPERL1/J2641 LOsch ISYPERLIJZ2645 Loach ISYPERANJZG47 Rinso

101-SY ESW

$$
\text { Samplo }
$$

DE101SWW/J2450 Wash DEIOISYUJ2458 Loach DE101SYRJJ2457 Rins:

101-SY ESW/PE 1SYPERW/J2637 Wash ISYPERLI/JZ6A1 Loach 1 ISYPERLI/JZEA5 Loach 2 1SYPERRYJ2647 Rinso

$$
\text { Sampto }
$$

Samplo Tmo DE101STW/J2456 Wash1 DE101SYHJ2458 Wash Avat 182 $101 S Y L C H / J 2480$ Loach DE101SYRJJ2457 Finso

101-SY ESWIPE 1SYPERW/J2637 Wash 1SYPERLI/JZ6A1 Looch I
ISYPERL/JJ2645 LOach 2 ISYPERLL/J2645 Loach 2
ISYPERRUJZ647 Finso
WhCrucB4 WtCruSym WLW/NO3 WH128C Wh250C 13.09518 .078

$14.195 \quad 19.000$

Nothn filossize frloss850 WhSords

5.083

5.003

5.003

4805

4.805

4.805

$\mathrm{NO2} \mathrm{NO}^{\mathrm{OH}} \mathrm{OH}$

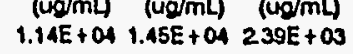

$1.15 E+041.41 E+$ a4 $5.26 E+03$

$1.15 E+041.43 E+04383 E+03$

$5.31 E+04$

$507 E+\infty 06.94 E+03$

$1.97 E+041.81 E+04213 E+03$

$4.50 E+04$

$4.85 E+04$

$7.53 E+02$
WhTube WrTubel WtCrucAt Cruckil CrAlloss

13.63861 .278

$14.028 \quad 12448$

1400

18.821

$14.039 \quad 57.580$

$\begin{array}{ll}14.372 & 32150 \\ 13.990 & 30.234\end{array}$

$13.707 \quad 42886$

mLsol'n.

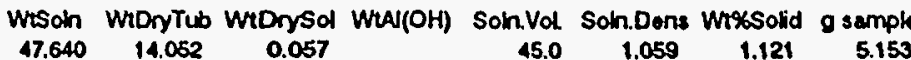

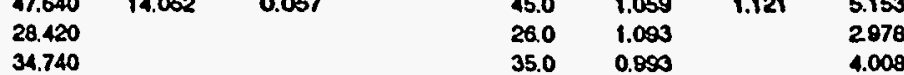

$\begin{array}{llllllll}43.541 & 15.336 & 1.14 t & 46.0 & 0.968 & 23.746 & 5.323\end{array}$

$\begin{array}{llll}15.0 & 1.185 & 1.774\end{array}$

29.178

101-SY

NO2

C POA asP SOA as S TOC TIC

(ug/mL) (ug/mL) (ug/mL) (ug/mL) (ug/mL)

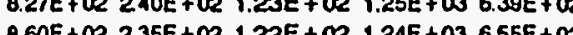

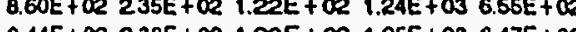
(..24E+01 $0.47 E+\infty$ 6.44E+01

$9.95 E+023.36 E+02 \quad 1.66 E+02 \quad 1.68 E+031.10 E+03$ $0.25 E+019.05 E+01$ $6.00 E+011.26 E+02$ $0.00 E+005.90 E+01$

Erh.SI.Washos WINDOW Th Trmo Corroctod IOS RHZO

101-SY/ESW

$6.083858 .36491 \mathrm{ON} \mathrm{OH} / \mathrm{NO}$

101.SY ESW

IOISYLCH/J248B Loach DE101SYRY245? Pinse Sum Enh SIWosh

Sum Erh.SI. Wash

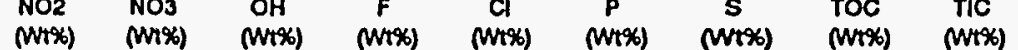
$\begin{array}{llllllllll}1.05 E+01 & 1.17 E+01 & 247 E+\infty & 300 E-02 & 7.00 E-01 & 209 E-01 & 1.33 E-01 & 1.53 E+\infty & 6.30 E-01 & \text { (WTX) }\end{array}$

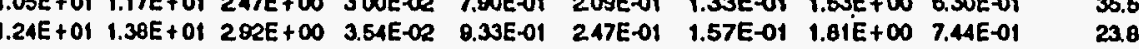
$\begin{array}{llllllllll}6.67 E-01 & 0.00 E+\infty & 4.21 E+01 & 0.00 E+\infty & 0.00 E+\infty & 0.00 E+\infty & 0.00 E+\infty & 0.00 E+\infty & 0.00 E+\infty & 0.00 E+\infty\end{array}$

$6.90 E+\infty 07.37 E+\infty 01.97 E+\infty \quad 0.00 E+\infty \quad 4.35 E-01 \quad 1.22 E-01 \quad 6.31 E-02 \quad 6.42 E-01 \quad 3.33 E-01$ $0.00 E+\infty \quad 0.00 E+\infty 0 \quad 1.58 E+01 \quad 0.00 E+\infty 0.00 E+\infty 00.00 E+\infty \quad 0.00 E+\infty \quad 1.92 E-02 \quad 0.00 E+\infty$

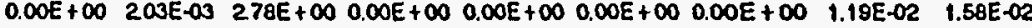

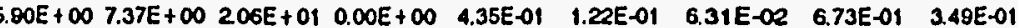

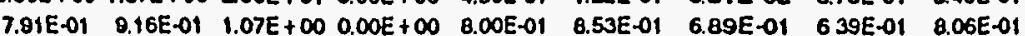

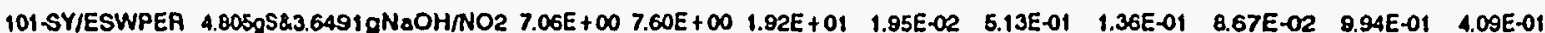

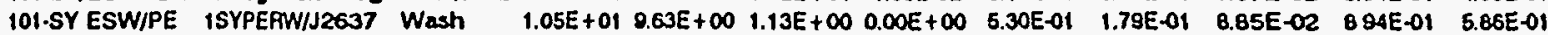

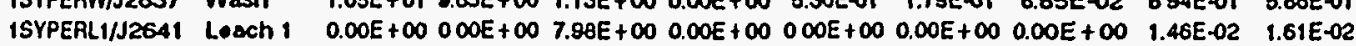

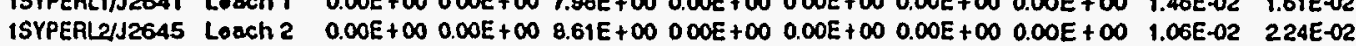

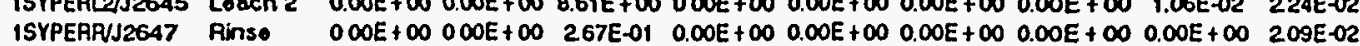

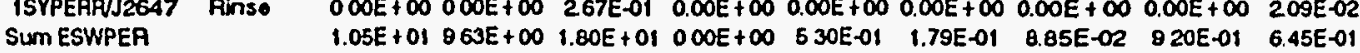

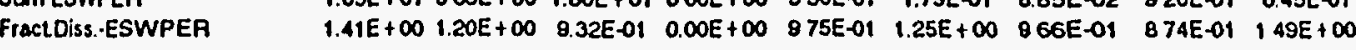


This page intentionally left blank. 


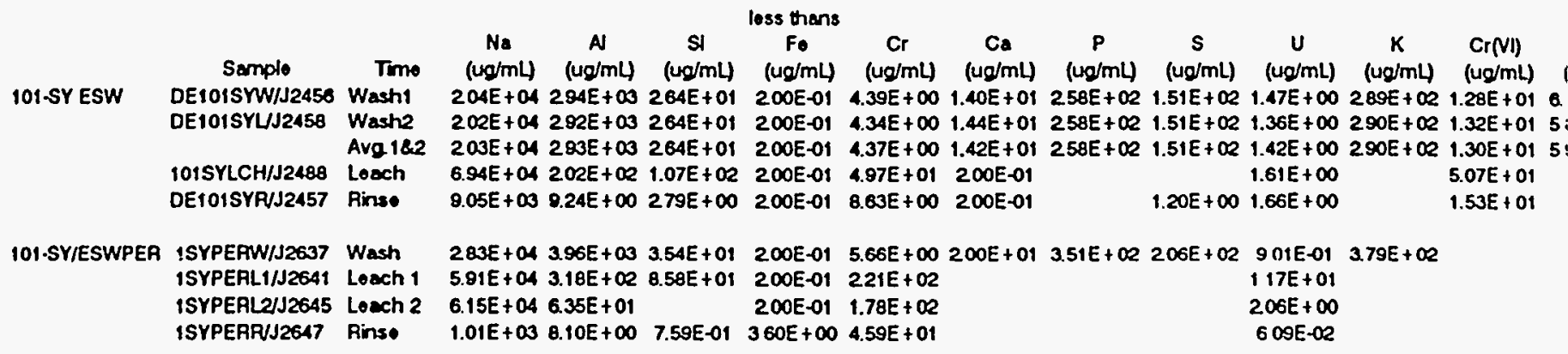

\begin{tabular}{|c|c|c|c|c|c|c|c|c|c|c|c|c|c|}
\hline & & Timo & $\begin{array}{c}\mathrm{Na} \\
(W+x)\end{array}$ & $\underset{(W+x)}{A}$ & $\begin{array}{c}\text { Si } \\
(m+x)\end{array}$ & $\begin{array}{c}F_{0} \\
(W+\%)\end{array}$ & $\begin{array}{c}C r \\
(W+x)\end{array}$ & 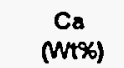 & $\begin{array}{c}P \\
(m+\%)\end{array}$ & $\begin{array}{c}S \\
M+(x)\end{array}$ & $\underset{\left(W+x_{0}\right)}{U}$ & $\begin{array}{c}K \\
\left(W^{\prime}\left(x_{0}\right)\right.\end{array}$ & $\begin{array}{l}\mathrm{Cr}(\mathrm{VI}) \\
\left.(\mathrm{N} \times)_{1}\right)\end{array}$ \\
\hline SY & AEPORT & & $207 E+01$ & $320 E+\infty$ & $4.58 E-02$ & 280E-02 & 4.10E-01 & $230 E-02$ & $209 \mathrm{E}-01$ & $133 E-01$ & $630 E-03$ & $326 E-01$ & OE-03 \\
\hline h. SIWashes & & & $\begin{array}{l}244 E+01 \\
573 E+01\end{array}$ & $\begin{array}{l}3.78 E+\infty \\
0.00 E+\infty\end{array}$ & $\begin{array}{r}4.58 E-02 \\
0.00 E+\infty 0\end{array}$ & $\begin{array}{r}3.31 E-02 \\
0.00 E+\infty 0\end{array}$ & $\begin{array}{c}4.84 E-01 \\
000 E+\infty\end{array}$ & $\begin{array}{r}272 E-02 \\
0.00 E+\infty\end{array}$ & $\begin{array}{c}247 E-01 \\
000 E+00\end{array}$ & $\begin{array}{c}1.57 E-01 \\
000 E+\infty\end{array}$ & $\begin{array}{r}7.44 E-03 \\
000 E+\infty\end{array}$ & $\begin{array}{c}3.85 E-01 \\
000 E+\infty\end{array}$ & $\begin{array}{r}236 E-03 \\
0.00 E+\infty\end{array}$ \\
\hline
\end{tabular}

101.SY/ESW $5003 g S Y \& 3.6491$ gNAOH/NO $382 E+01 \quad 220 E+\infty \quad 267 E-02 \quad 1.93 E-02 \quad 262 E-01 \quad 1.58 E-02 \quad 1.44 E-01 \quad 9.17 E-02 \quad 433 E-03 \quad 224 E-01 \quad 138 E-03 \quad 2$

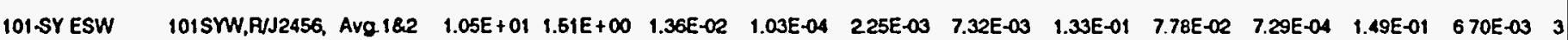

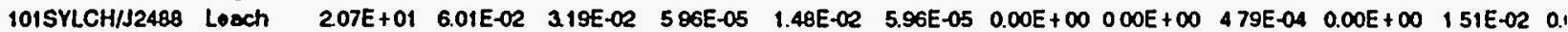

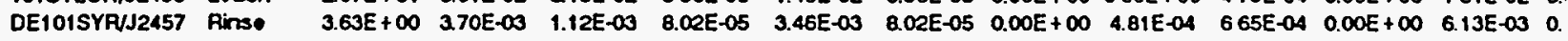
$\begin{array}{lllllllllllll}\text { Sum Enh.SI.Wash } & 3.48 E+01 & 1.57 E+00 & 4.66 E-02 & 243 E-04 & 205 E-02 & 7.46 E-03 & 1.33 E-01 & 7.83 E-02 & 187 E-03 & 1.49 E-01 & 279 E-02 & 3\end{array}$

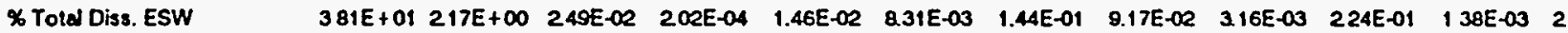

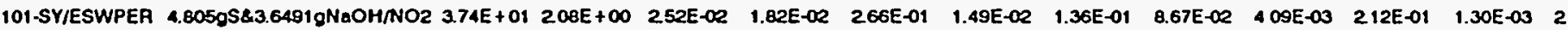

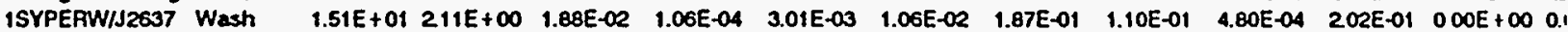

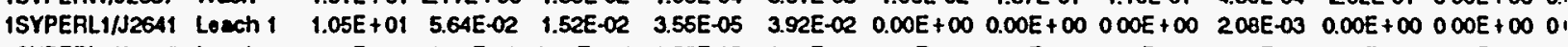

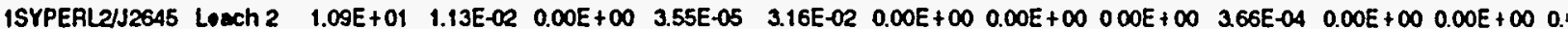

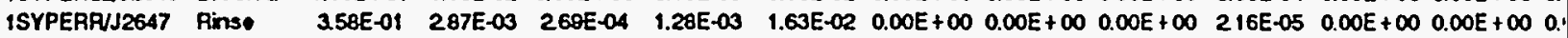
$3.68 E+01218 E+\infty \quad 3.43 E-02 \quad 1.45 E-03 \quad 9.01 E-02 \quad 1.06 E-02 \quad 1.87 E-01 \quad 110 E-01 \quad 294 E-03 \quad 202 E-01 \quad 000 E+\infty \quad 01$

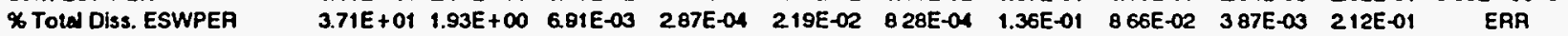

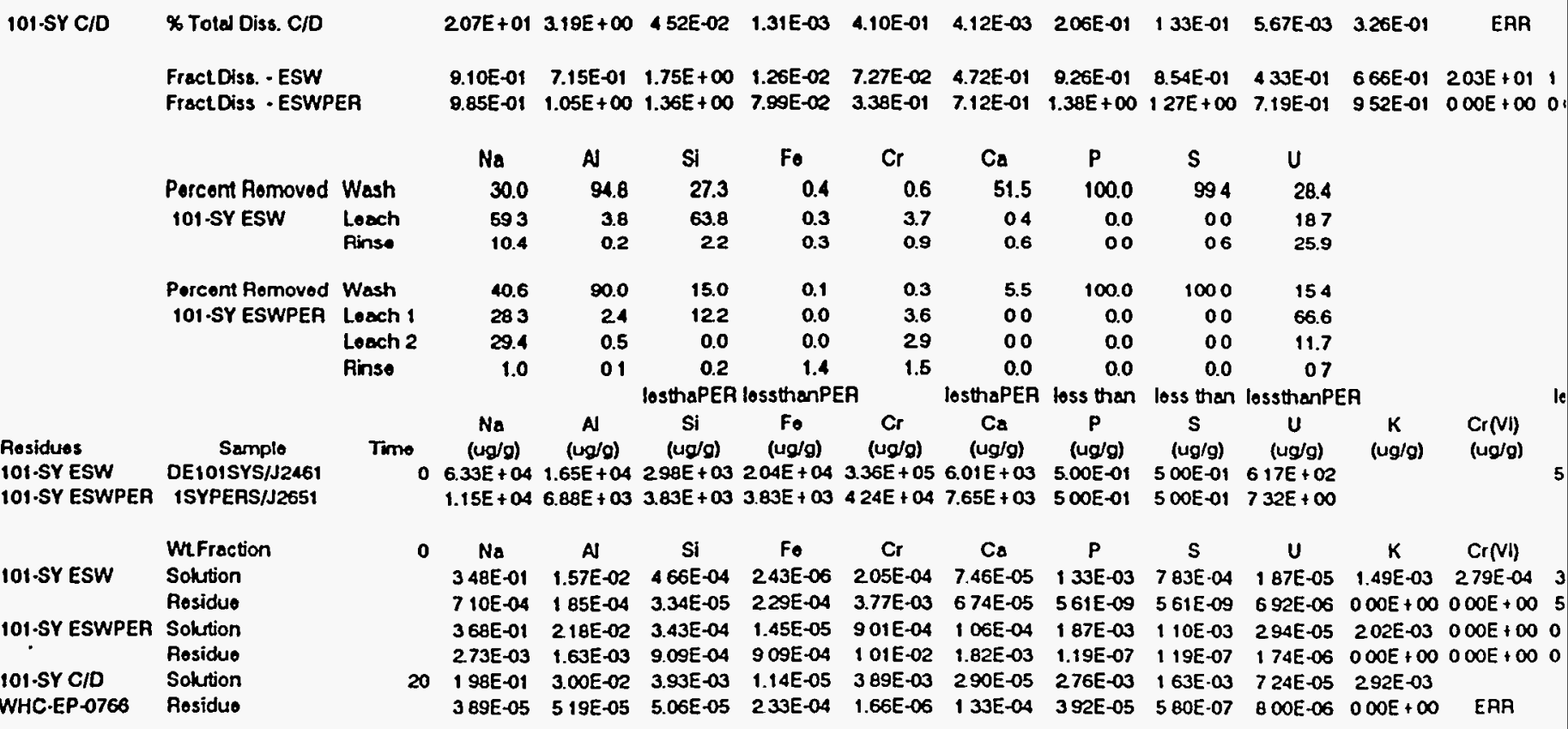

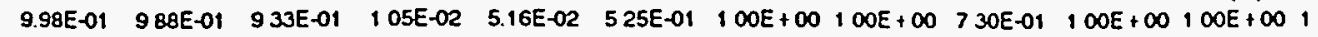
Fract Diss -ESWPER $\begin{array}{lllllllllll}9.93 E-01 & 9.30 E-01 & 274 E-01 & 157 E-02 & 821 E-02 & 5.54 E-02 & 1.00 E+\infty & 100 E+\infty & 944 E-01 & 100 E+\infty & \text { ERA }\end{array}$ $100 E+\infty 0998 E-01 \quad 9.87 E-01 \quad 466 E-02 \quad 100 E+\infty \quad 179 E-01 \quad 986 E-01 \quad 100 E+\infty \quad 900 E-01 \quad 100 E+\infty \quad$ ERA 
WHC-EP-0882

\begin{tabular}{|c|c|c|}
\hline \multicolumn{3}{|c|}{ lossthans } \\
\hline $\begin{array}{c}\mathrm{Sr} \\
(\mathrm{ug} / \mathrm{mL})\end{array}$ & $\begin{array}{c}\mathrm{Mn} \\
(u g / m l)\end{array}$ & $\begin{array}{c}\mathrm{Ni} \\
(\mathrm{ug} / \mathrm{mL})\end{array}$ \\
\hline & $200 E-01$ & $1.38 E+01$ \\
\hline & 200E-01 & $1.30 E+01$ \\
\hline & 200E-01 & $1.34 E+09$ \\
\hline & $200 E-01$ & $400 E-01$ \\
\hline & $200 E-01$ & $400 E-01$ \\
\hline & $200 E-01$ & $1.87 E+01$ \\
\hline & 200E-01 & \\
\hline & $200 E-01$ & \\
\hline & $957 E-01$ & $3.08 E-01$ \\
\hline
\end{tabular}

\begin{tabular}{|c|c|c|}
\hline $\begin{array}{c}\mathrm{Sr} \\
(W+X)\end{array}$ & $\underset{(W+x)}{M n}$ & $\begin{array}{c}\mathrm{Ni} \\
\left(\mathrm{N}+\mathbf{s}^{2}\right)\end{array}$ \\
\hline $169 E-04$ & $682 E-03$ & $1.50 E-02$ \\
\hline $169 E-04$ & $6.82 E-03$ & $1.77 E-02$ \\
\hline $000 E+\infty$ & $0 \infty E+\infty$ & $0 O 0 E+\infty$ \\
\hline 9 B4E-05 & 3 97E-03 & $1.03 E-02$ \\
\hline $000 E+\infty$ & $103 E-04$ & $691 E-03$ \\
\hline $000 E+\infty$ & $596 E-05$ & $119 E-04$ \\
\hline $000 E+\infty$ & B.02E-05 & $160 E-04$ \\
\hline $0.00 E+\infty$ & $243 E-04$ & $718 E-03$ \\
\hline ERR & I 41E-04 & $351 E-03$ \\
\hline $930 E-05$ & $375 E-03$ & 9.75E-03 \\
\hline $0.00 E+\infty 0$ & $106 E-04$ & $995 E-03$ \\
\hline $000 E+00$ & $355 E-05$ & $0.00 E+\infty$ \\
\hline $0.00 E+\infty$ & $355 E-05$ & $0.00 E+\infty$ \\
\hline $000 E+\infty 0$ & $340 \mathrm{E}-04$ & $1.00 E-04$ \\
\hline $000 E+\infty$ & $517 E-04$ & $101 E-02$ \\
\hline ERR & B OAE-05 & $186 E-04$ \\
\hline
\end{tabular}

RR 235E-05 $000 E+\infty 0 \quad$ ERR

$00 \quad 000 E+\infty \quad 612 E-02 \quad 697 E-01$ $00000+\infty 0138 E-01 \quad 103 E+\infty 0$

Wash

Loach

Rinse

\begin{tabular}{|c|c|c|c|c|c|c|}
\hline & & & less thans & & Joss thens & \\
\hline Sr-90 & TC- 99 & Cs.137 & Pu-233/40 & Am-241 & Np.237 & Loss \\
\hline (uCl/ml) & (uCVmL) & (uCl/mu) & (nCiml) & (nCi/mL) & (nCi/ml) & thans \\
\hline $455 E-01$ & B. $00 E-03$ & $3.01 E+01$ & $5.82 E-\infty 3$ & $326 E-02$ & $216 E-02$ & \\
\hline 4.33E-01 & 6. $40 E-\infty 0$ & $290 E+01$ & $4.08 E-03$ & $3.31 E-02$ & 252E-02 & \\
\hline 4.44E-01 & 8.20E-03 & $3.00 E+01$ & 4.95E-03 & $3.29 E-02$ & 234E- 02 & \\
\hline 224E-03 & 9.47E-04 & $270 E-01$ & 8.86E-02 & 263E-01 & $3.04 E-\infty 2$ & Np \\
\hline $1.48 E-02$ & $3.30 E-02$ & 8.87E-03 & 4.72E-03 & $\begin{array}{l}3.09 E-\infty 2 \\
\text { loss than }\end{array}$ & $202 E-02$ & \\
\hline $647 E-01$ & $1.53 E .02$ & $390 E+01$ & $5.00 E-\infty$ & 7.77E-01 & 206E-02 & loss than Pu,Am, Np \\
\hline $8.77 E-03$ & $7.02 E-04$ & 6.55E-01 & $7.18 E-03$ & $5.02 E-02$ & $252 E-\infty 2$ & loss than Pu,Am \\
\hline 9.41E-03 & 3.48E-04 & 277E-02 & 277E-01 & 9.97E-01 & 1. A7E-02 & \\
\hline $1.76 \mathrm{E}-0 \mathrm{r}$ & 1.88E-05 & & 1.31E-01 & $1.47 E+\infty 0$ & $290 E-02$ & loss than Np \\
\hline
\end{tabular}

\begin{tabular}{|c|c|c|c|c|c|c|c|}
\hline $\begin{array}{c}\text { Sr-90 } \\
(u \subset \mathrm{C} v g)\end{array}$ & $\begin{array}{c}\text { Tc.99 } \\
\text { (uCi/g) }\end{array}$ & $\begin{array}{l}\text { Cs- } 137 \\
(\mathrm{uCl} / 9)\end{array}$ & $\begin{array}{c}\mathrm{Pu}-239 / 40 \\
\text { (nCi/g) }\end{array}$ & $\begin{array}{l}\text { Am-241 } \\
\text { (nCi/g) }\end{array}$ & $\begin{array}{l}\mathrm{Np} \cdot 237 \\
(\mathrm{nCi} / \mathrm{g})\end{array}$ & & Sampto \\
\hline $210 E+01$ & 210E-01 & $3.50 E+02$ & $670 E+\infty 0$ & $1.10 E+02$ & $280 E-02$ & $101-S Y$ & WINDOW E REPO \\
\hline $248 E+01$ & 238E-01 & $3.96 E+02$ & $7.59 E+00$ & $1.25 E+02$ & $3.17 E-02$ & & Corrected for $\mathrm{XH}_{2}$ \\
\hline $000 E+\infty$ & $0.00 E+\infty$ & $0.00 E+\infty$ & $000 E+00$ & $0.00 E+00$ & $000 E+\infty$ & Enh SI.Washes & \\
\hline $1.44 E+01$ & 1.38E-01 & $231 E+02$ & $4.42 E+00$ & $725 E+01$ & $185 E-02$ & 101SY/ESW & $5.0039 S Y 8.36491$ \\
\hline $229 E+00$ & 4.23E-02 & $1.54 E+\infty 2$ & 255E-02 & $1.69 E-01$ & $121 E-01$ & 101-SY ESW & 101SWW,AJJ2456, \\
\hline $6.67 \mathrm{E}-03$ & 282E-03 & B 04E-01 & $264 E-01$ & $7.83 E-01$ & $905 E-02$ & & 101SYLCH/J24BB \\
\hline $5.93 E-02$ & 1.32E-01 & $3.56 E-02$ & $1.69 E-02$ & $1.24 E-01$ & 8.10E-02 & & DE101SYAJJ2457 \\
\hline $2.35 E+00$ & 1.77E-01 & $1.55 E+02$ & $3.08 E-01$ & $1.08 E+00$ & 292E-01 & & Sum Erhs Sl.Wash \\
\hline $208 E+00$ & $1.28 E-01$ & $231 E+02$ & $1.06 E-01$ & $8.03 E-01$ & $1.54 E-03$ & & \% Total Diss. ESW \\
\hline
\end{tabular}

$1.36 E+01 \quad 1.31 E-01 \quad 218 E+02 \quad 4.17 E+006.85 E+01 \quad 1.74 E-02$ $3.44 E+00$ 8.14E-02 208E +02 266E-01 4.14E +00 1.10E-01 1.56E-02 1.25E-03 1.16E+00 1.27E-02 B.91E-02 4.47E-02 1.67E-02 6.17E-04 4.91E-02 4.91E-01 \$.77E+00 332E-02 6.25E-01 6.67E-05 $0.00 E+00 \quad 4.65 E-01 \quad 5.22 E+00 \quad 1.03 E-01$ $4.10 E+\infty 0$ 8.34E- 02 209E $+02124 E+\infty 01.12 E+01 \quad 290 E-01$

$1.53 E+\infty \quad 210 E-01 \quad 3.49 E+02 \quad 5.19 E+00312 E+00 \quad 263 E-02$

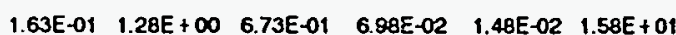
$300 E-01 \quad 637 E-01 \quad 9.58 E-01$ 296E-01 1.64E-01 $1.66 E+01$

$\begin{array}{rrrrrr}\text { Sr-90 } & \text { Tc-99 } & \text { Cs-137 } & \text { Pu-239/40 } & \text { Am-241 } & \text { Np-237 } \\ 14.0 & 221 & 99.4 & 02 & 02 & 3.4 \\ 00 & 1.5 & 0.5 & 21 & 08 & 26 \\ 04 & 692 & 0.0 & 0.1 & 01 & 23\end{array}$

FractDiss. - ESW

\begin{tabular}{|c|c|c|c|c|c|c|c|}
\hline & & & & & less than & & \\
\hline $\begin{array}{c}\text { Sr-90 } \\
\text { (uCi/g) }\end{array}$ & $\begin{array}{c}\text { Tc-99 } \\
\text { (uCi/g) }\end{array}$ & $\begin{array}{l}\text { Cs-137 } \\
\text { (uCivg) }\end{array}$ & $\begin{array}{l}\text { Pu-239/40 } \\
\text { (nCi/g) }\end{array}$ & $\begin{array}{l}\text { Am-241 } \\
(n C / g)\end{array}$ & $\begin{array}{c}\text { Np-237 } \\
\text { (nCi/g) }\end{array}$ & Rosidues & Sampl \\
\hline $125 E+03$ & $1.22 \mathrm{E}+\infty 0$ & $1.00 E+01$ & $1.12 E+03$ & $857 E+03$ & $286 E+02$ & & \\
\hline $200 E+02$ & $249 E-01$ & 213E-01 & $1.20 E+02$ & $1.64 E+03$ & $370 E+01$ & & \\
\hline Sr-90 & Tc.99 & Cs.137 & Pu-239/40 & Am-241 & Np-237 & & Wh Fraction \\
\hline $2.35 E+\infty$ & $1.77 E-01$ & $1.55 E+02$ & $3.08 E-01$ & $1.0 \mathrm{EE}+00$ & 292E-01 & & Solution \\
\hline $140 E+01$ & $1.37 E-02$ & $1.12 E-01$ & $126 E+01$ & $961 E+01$ & $3.21 E+\infty$ & & Residue \\
\hline $410 E+00$ & $834 E-02$ & $209 E+02$ & $124 E+00$ & $112 E+01$ & $290 E-01$ & & \\
\hline $475 E+01$ & $591 E-02$ & $506 \mathrm{E}-02$ & $285 E+01$ & $389 E+02$ & $000 E+\infty$ & & \\
\hline $1.45 E+\infty 0$ & $365 E-01$ & $344 E+02$ & $803 E+00$ & $224 E+\infty$ & $441 E-02$ & 104.S C/D & Solution \\
\hline $185 E+01$ & $222 E-05$ & B 97E-01 & $233 E+\infty 0$ & $768 E+01$ & $277 E-03$ & & Residue \\
\hline Sr-90 & Tc-99 & Cs-137 & Pu-239/40 & An-241 & Np.237 & & \\
\hline $144 E-01$ & 9 28E-01 & 9 99E-01 & $240 E-02$ & $1.11 E-02$ & $835 E .02$ & Fract Diss.-ESW & \\
\hline 7 95E-02 & $5.85 E-01$ & $1.00 E+\infty$ & $4.15 E-02$ & $280 E-02$ & $100 E+\infty$ & & \\
\hline $727 E-02$ & $100 E+\infty$ & $997 E-01$ & $7.75 E-01$ & $283 E-02$ & $941 E-01$ & Fract Diss $-C / D$ & \\
\hline
\end{tabular}


APPENDIX D

RESULTS OF ESW AND C/D TESTS

OF WASTES FROM TANK 102-SY

D-1 


\section{WHC-EP-0882}

This page intentionally left blank.

\section{D-2}


ESW of $102-S Y$
ESW/PER of $102-S Y$

From WHC-N-650 1; PP. 120 and 124

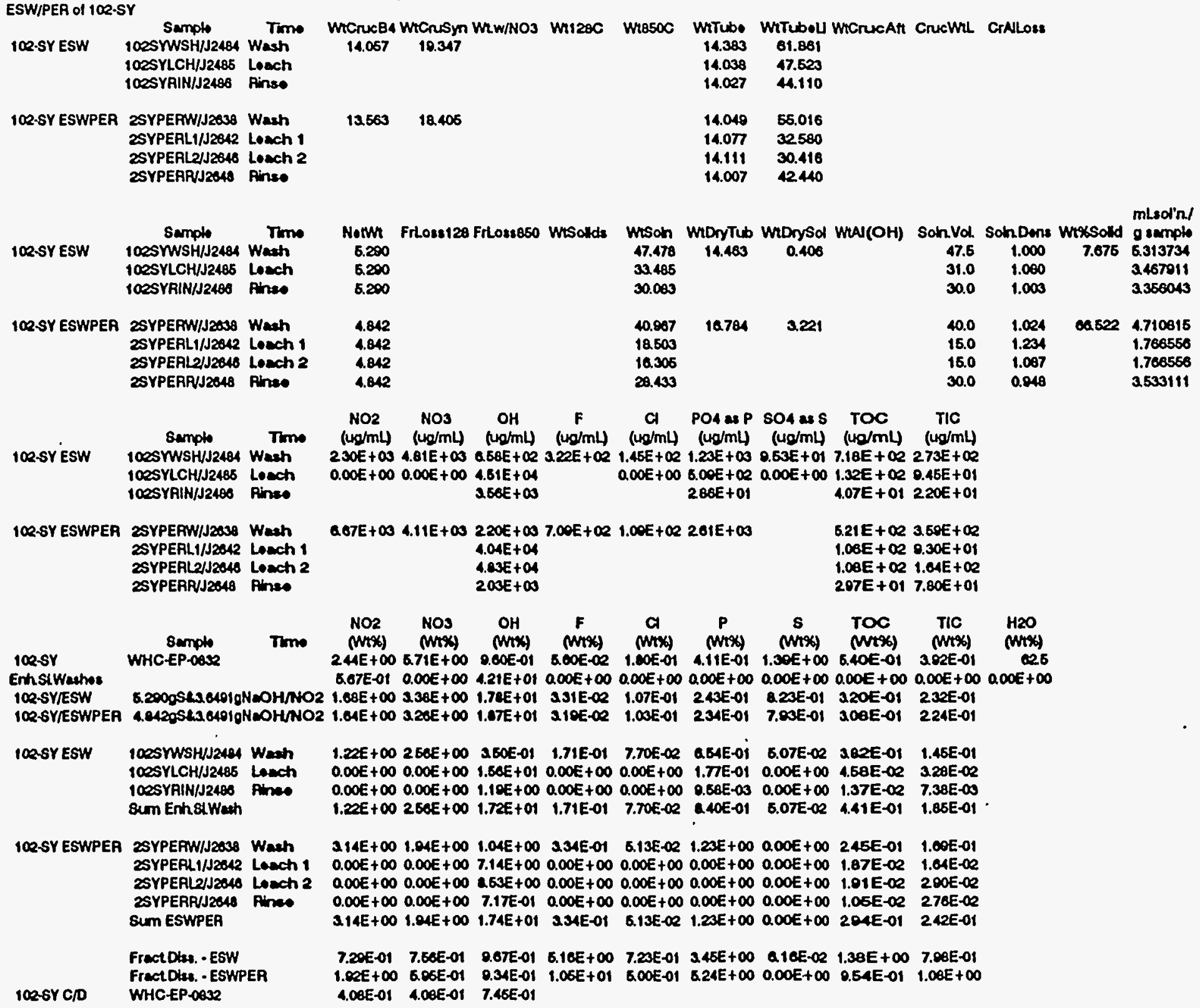


WHC-EP-0882

This page intentionally left blank. 


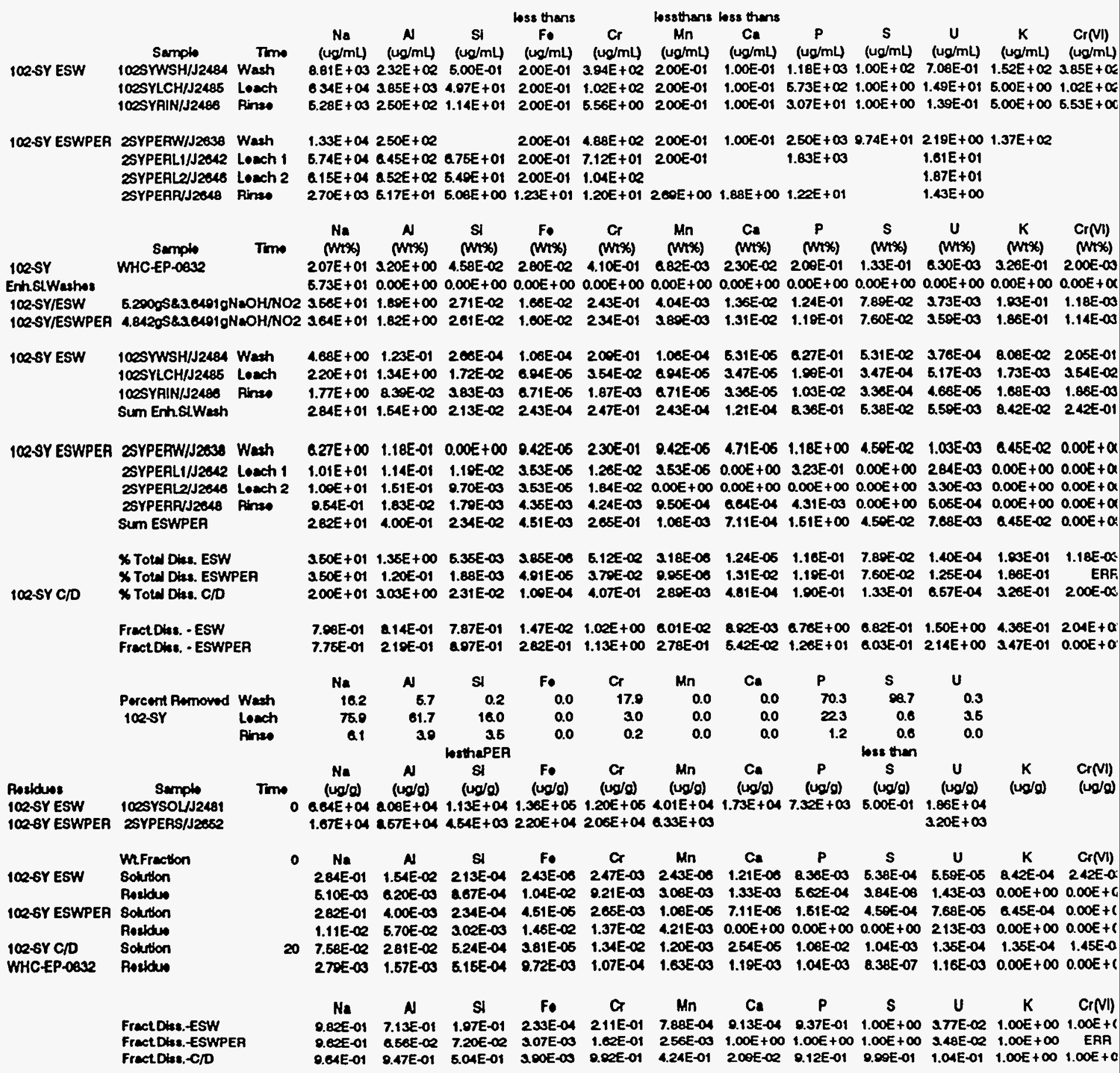


APPENDIX E

\section{RESULTS OF TESTS TO REMOVE PLUTONIUM} FROM C/D SOLUTIONS 
WHC-EP-0882

This page intentionally left blank.

E-2 
Testing of Reductants for Plutonium and Manganese in C/D Products Nolobook WHC-N-656 1; p. 79

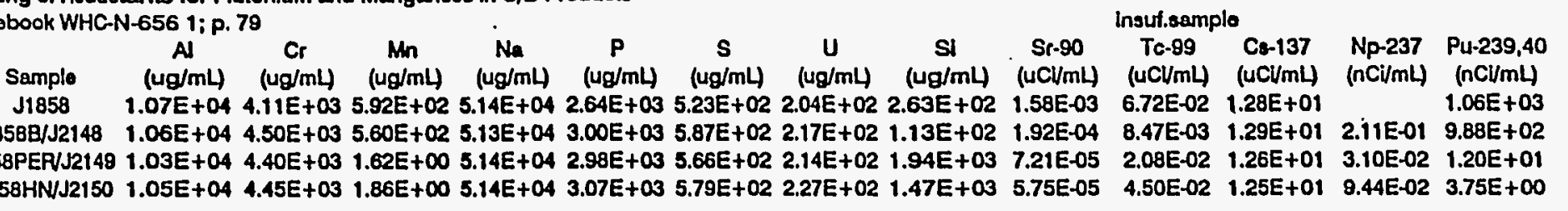

$J 2121 \quad 1.83 E+04 \quad 8.64 E+03 \quad 7.72 E+024.36 E+04 \quad 4.72 E+03 \quad 6.93 E+02 \quad 9.66 E+01 \quad 3.64 E+02 \quad 2.41 E-03 \quad 5.66 E-02 \quad 3.03 E+01 \quad 2.81 E-02 \quad 6.90 E+01$ $21218 / J 2151 \quad 8.66 E+03$ 9.20E+03 7.61E+02 4.41E+04 5.01E+03 7.77E+02 7.97E+01 2.22E+02 8.72E-05 4.32E-02 3.26E+01 1.73E-01 5.15E+01 2121PERJ2152 B.33E+03 8.59E+03 $1.83 E+\infty 00$ 4.32E+04 4.60E+03 7.26E+02 8.47E+01 1.68E+03 5.77E-05 $7.64 E-02 \quad 3.14 E+01 \quad 3.19 E-02 \quad 1.90 E-01$ $2121 \mathrm{HN} / \mathrm{J} 2154$ 8.22E+03 $8.72 E+03 \quad 1.51 E+\infty 004.20 E+04$ 4.82E+03 7.48E+02 7.37E+01 1.95E+02 2.07E-06 $3.03 E+01 \quad 3.13 E-02 \quad 1.04 E-01$

J2122 4.12E+03 2.06E+03 1.88E+02 1.66E+04 3.78E+03 1.35E+02 1.13E+01 5.50E+01 2.43E-03 $2122 \mathrm{~B} / \mathrm{J} 2155 \quad 3.18 \mathrm{E}+03 \quad 1.78 \mathrm{E}+03 \quad 1.27 \mathrm{E}+02 \quad 1.33 \mathrm{E}+04 \quad 3.20 \mathrm{E}+03 \quad 1.16 \mathrm{E}+02 \quad 1.10 \mathrm{E}+01$ 3.95E+01 $1.44 \mathrm{E}-04$ 2122PERJJ2156 3.92E+03 2.17E+03 $1.00 E+001.07 E+04$ 4.04E+03 $1.45 E+021.10 E+01$ 4.09E+01 $2.81 E-06$

$1.33 E-02 \quad 7.01 E+\infty \quad 7.93 E-02 \quad 4.04 E+01$ $7.48 E+\infty$ 2.81E-02 $4.42 E+01$ 2122HNJ 2157 3.89E+03 2.10E+03 1.00E+00 1.66E+04 3.87E+03 1.43E+02 1.10E+01 3.87E+01 1.88E-05

$7.18 E+\infty \quad 2.74 E-02 \quad 1.21 E-01$

PUPPTRES/CDelogard

C/D of Np and Pu Spiked Simulated HLW Composito; Solution Analyeo: Boforo and Aftor Addition of Hydroxylamine

$\mathrm{nCl} / \mathrm{mL}$

Notobook WHCN-658 1 ip 118

$\begin{array}{lcccccccc}\text { Sample * } & \text { A } & \mathrm{Cr} & \mathrm{Mn} & \mathrm{Na} & \mathrm{P} & \mathrm{Pb} & \mathrm{S} & \mathrm{Si} \\ \text { OEHLW1/J2347 } & 6.59 E+03 & 2.23 E+02 & 4.84 E+01 & 7.50 E+04 & 1.60 E+03 & 1.85 E+02 & 9.47 E+02 & 1.59 E+02\end{array}$

$\begin{array}{llllllllll}\text { mitted } & \mathrm{DEHLW} / \mathrm{J} 2397 & 6.59 E+03 & 2.23 E+02 & 4.04 E+01 & 7.50 E+04 & 1.00 E+03 & 1.05 E+02 & 0.47 E+02 & 1.59 E+02\end{array}$

$\mathrm{Np}$

$3.43 E+02 \quad 2.92 E+\infty$

$9.60 E+\infty \quad 8.42 E-01$

PUNPCOPT/CDologard 
WHC-EP-0882

This page intentionally left blank. 


\section{DISTRIBUTION}

Number of Copies

\section{QFFSITE}

1

United States Department of Energy

12800 Middlebrook Road

Trevion II Building

Germantown, MD 20874

T. Fryberger

1 Oak Ridge National Laboratory

P. O. Box 2008

Oak Ridge, TN 37831-6178

J. S. Watson

QNSITE

1

MACTEC

D. J. Swanberg

K8-50

5

Pacific Northwest Laboratory
A. R. Felmy
K9-77
W. L. Kuhn (2)
K2-21
G. J. Lumetta
P7-25
L. Rao
K9-77

4

U.S. Department of Energy

Richland Field Office

R. F. Christensen

K8-50

P. E. LaMont

S7-53

B. A. Mauss

K8-50

S. N. Runyon

K8-50 


\section{DISTRIBUTION (Continued)}

21

Westinghouse Hanford Company

H. Babad

S7-15

R. A. Bechtold

L0-18

J. D. Berger

A. L. Boldt

LO-18

K. D. Boomer

H5-49

C. H. Delegard (5)

H5-49

D. W. Hendrickson

T6-09

J. R. Jewett

L5-31

S. L. Lambert

T6-09

G. T. MacLean

H5-27

C. T. Narquis

H5-49

R. M. Orme

T6-16

J. P. Sloughter

H5-27

D. J. Washenfelder

R2-54

OSTI (2)

H5-27

Central Files

L8-07

L8-04 